\title{
LBL --23175
}

DE87 009278

Earth Sciences Division Lawrence Berkeley Laboratory

University of California Berkeley, California 94720

\author{
Prepared for \\ The U.S. Geological Survey \\ Western Region \\ Menlo Park, Californiá
}

USGS Authorization Number 3-9900-5143

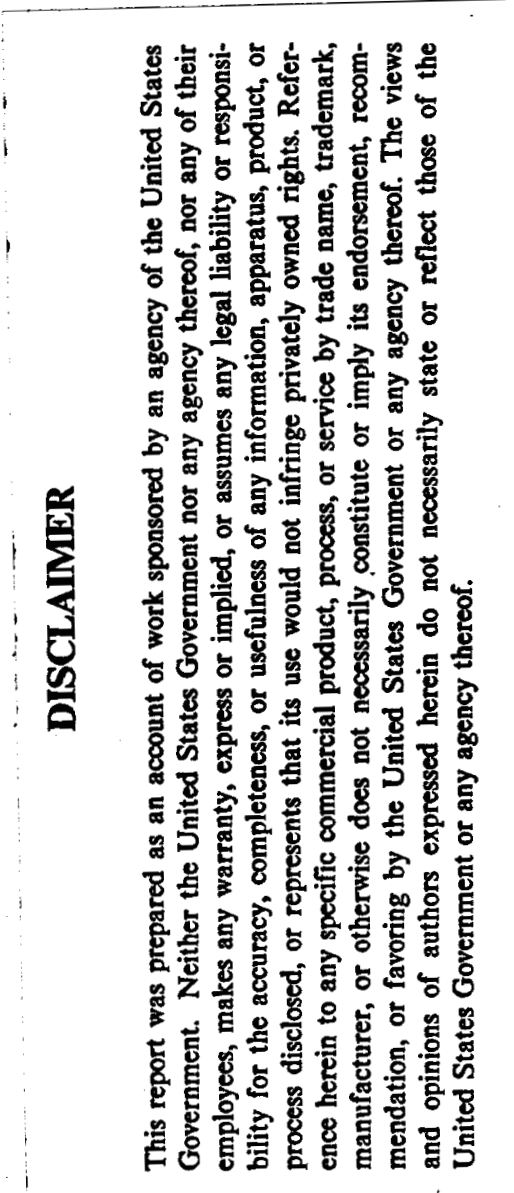

This work was supported under the U.S. Department of Energy Contract No. DE-AC03-76SF00098. 


\section{DISCLAIMER}

This report was prepared as an account of work sponsored by an agency of the United States Government. Neither the United States Government nor any agency Thereof, nor any of their employees, makes any warranty, express or implied, or assumes any legal liability or responsibility for the accuracy, completeness, or usefulness of any information, apparatus, product, or process disclosed, or represents that its use would not infringe privately owned rights. Reference herein to any specific commercial product, process, or service by trade name, trademark, manufacturer, or otherwise does not necessarily constitute or imply its endorsement, recommendation, or favoring by the United States Government or any agency thereof. The views and opinions of authors expressed herein do not necessarily state or reflect those of the United States Government or any agency thereof. 


\section{DISCLAIMER}

Portions of this document may be illegible in electronic image products. Images are produced from the best available original document. 


\section{Table of Contents}

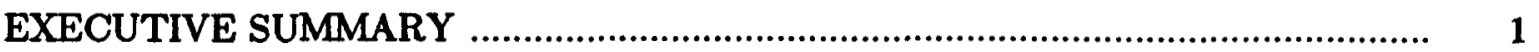

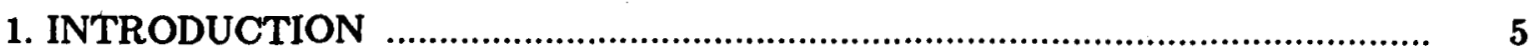

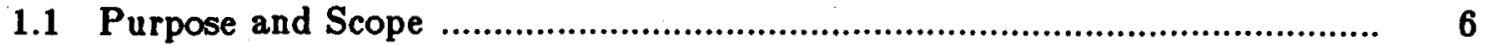

2. THEORETICAL CONSIDERATIONS …....................................................... 8

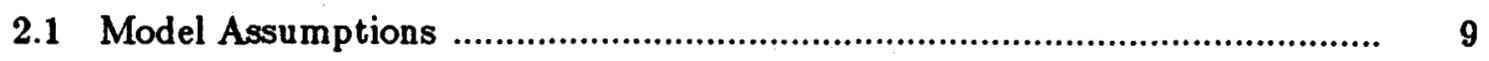

2.1.1 The Fluid Flow Problem ............................................................ 9

2.1.2 Criteria For Fracture Propagation .............................................. 12

3. THE NUMERICAL ALGORITHM …....................................................... 16

3.1 The Discrete Equations ................................................................... 16

3.2 Fracture Propagation .................................................................... 17

3.2.1 The First Fracture Segment ................................................... 19

3.2.2 Subsequent Fracture Segments ..................................................... 20

3.2.3 The Process Of Fracture Extension ............................................. 21

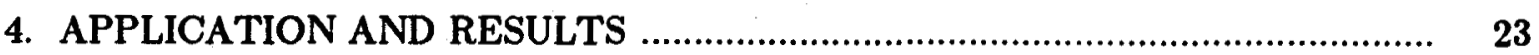

4.1 Verification of the Algorithm ........................................................... 23

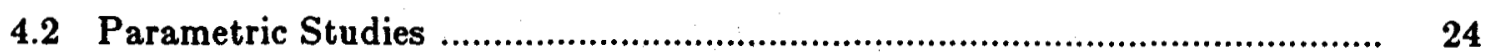

4.2.1 Constant Rate Injection .............................................................. 25

4.2.2 Constant Pressure Injection ........................................................ 29

4.2.3 Punctuated Injection ................................................................ 31

4.2.4 Step-Rate Injection ................................................................. $\quad 34$

4.2.5 Threshold Injection Rate …...................................................... $\quad 35$

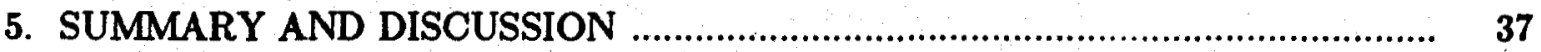

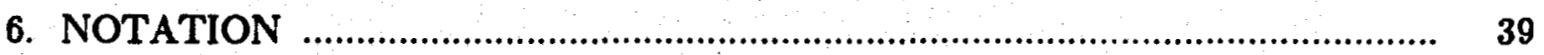

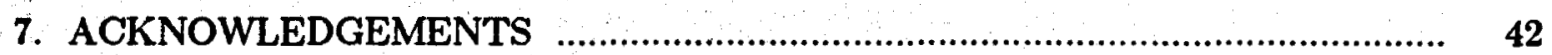

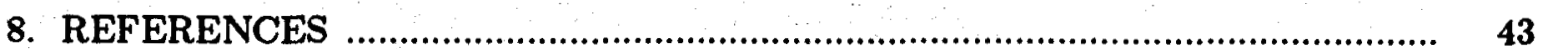




\section{LIST OF FIGURES}

Figure 1: Schematic representation of a vertical fracture.

Figure 2: The IFD mesh used in the simulation studies.

Figure 3: Flow to a well with a single vertical fracture of fixed geometry. Comparison of analytical and numerical results.

Figure 4A: Case I-1: Constant flow rate of 2 lps. Well bore pressure head as a function of time.

Figure 4B: Case I-1: Constant flow rate of 2 lps. Pressure head in fracture $0.5 \mathrm{~m}$ away from well.

Figure 4C: Case I-1: Constant flow rate of 2 lps. Fracture length as a function of time.

Figure 5: Typical occurrence rate of seismic activity during the salt block experiment. Notice the banded nature of the activity.

Figure 6: Case I-2: Constant flow rate of 8lps. Well bore pressure head as a function of time.

Figure 7: Constant flow rate. Effect of injection rate on fracture propagation.

Figure 8: Sensitivity of fracture propagation to efficiency, $r_{c}, k_{\text {rock }}$ and well bore capacity.

Figure 9A: Constant pressure head injection Case II-1. Injection rate versus time.

Figure 9B: Constant pressure head injection Case II-1. Well bore pressure head versus time.

Figure 9C: Constant pressure head injection Case II-1. Pressure head in the fracture element 100 versus time.

Figure 9D: Constant pressure head injection Case II-1. Fracture propagation versus time.

Figure 10A: Constant pressure head injection Case II-2. Injection rate versus time.

Figure 10B: Constant pressure head injection Case II-2. Well bore pressure head versus time. 
Figure 10C: Constant pressure head injection Case II-2. Fracture pressure head $0.5 \mathrm{~m}$ from well.

Figure 10D: Constant pressure head injection Case II-2. Fracture length versus time.

Figure 11: An example tluid injection history for an experiment involving 4 cycles of injection separated by 3 cycles of shut in and bleed off.

Figure 12A: Sensitivity to initial fracture aperture and compressibility: Case III-1 $a_{v, f}=3 \times 10^{-11} \mathrm{~Pa}^{-1} ; w_{f, o}=20$ microns.

Figure 12B: Sensitivity to initial fracture aperture and compressibility: Case III-2B, $a_{v, f}=1 \times 10^{-11} \mathrm{~Pa}^{-1} ; w_{f, o}=10$ microns.

Figure 12C: Sensitivity to initial fracture aperture and compressibility: Case III-2 $a_{\mathrm{v}, \mathrm{f}}=1 \times 10^{-11} \mathrm{~Pa}^{-1} ; \mathrm{w}_{\mathrm{f}, \mathrm{o}}=20$ microns.

Figure 13A: Pressure within the fracture, $0.5 \mathrm{~m}$ from well bore; Case III-1.

Figure 13B: Pressure within the fracture, $0.5 \mathrm{~m}$ from well bore; Case III-2B.

Figure 13C: Pressure within the fracture, $0.5 \mathrm{~m}$ from well bore; Case III-2.

Figure 14: Capacity of the fracture element closest to the well bore as a function of time.

Figure 15: Aperture of the first fracture element as a function of time.

Figure 16A: Effect of injection rate on well bore pressure transient: Case III-2, 0.2 lps.

Figure 16B: Effect of injection rate on well bore pressure transient: Case III-3, $0.4 \mathrm{lps}$.

Figure 16C: Effect of injection rate on well bore pressure transient: Case III-4, 1 lps.

Figure 17A: Third injection cycle well bore pressure transients: Case III-1.

Figure 17B: Third injection cycle well bore pressure transients: Case III-2.

Figure 17C: Third injection cycle well bore pressure transien ts: Case III-4.

Figure 18A: Stepwise injection. Case IV-2A.

Figure 18B: Stepwise injection. Case IV-2. 
Figure 19A: Stepwise injection: Pressure transients for Case IV-2A.

Figure 19B: Step wise injection: Pressure transients for Case IV-2.

Figure 20A: Threshold injection : Pressure transients for Case IV-4A

Figure 20B: Threshold injection: Pressure Transients for Case IV-5

\section{LIST OF TABLES}

Table 1: $\quad$ Paramaters used in the Simulations 


\title{
HYDRODYNAMICS OF A VERTICAL HYDRAULIC FRACTURE
}

\author{
T.N. Narasimhan \\ Earth Sciences Division \\ Lawrence Berkeley Laboratory \\ University of California \\ Berkeley, California 94720
}

\section{EXECUTIVE SUMMARY}

This research aims at improving our current ability to estimate in situ rock stresses through pressure transient analysis of hydraulic fracturing experiments. A numerical approach is used in which attention is focussed on the fluid flow process, using assumptions based on elasticity theory to take into account rock deformation.

A vertical fracture of constant height and rectangular shape in a homogeneous rock is considered. This fracture is created and propagated as energy is supplied at the injection pump and is transmitted to the fracture by the fracturing fluid, water. The process of fracture initiation and propagation is considered with respect a fracture that has an elliptical cross section in mid section to a distance equal to fracture height, beyond which it has a parallel plate configuration. A energy criterion based on Griffith's theory is used to model rock rupture. The Griffith's criterion is transformed to an equivalent criterion of fracture over pressure for purposes of modeling. Fracture propagation is a discrete process in time, accompanied by sudden releases of energy from a capacitor. In the present case, the capacitor is mainly the well bore, with the fracture itself playing a subordinate role. As the energy is released, it is expended in many ways as work. The energy release is accompanied by a sudden drop in fluid pressure in the fracture and a small increase in the fracture aperture. Work is done by displacing the fracture walls against the least principal stress in situ, and work is done by creating a new fracture surface by overcoming rock cohesion. Energy is also consumed by way of seismic, acoustic and other radiations. An important inference is that only a small portion of the energy supplied at the pump is actually expended in creating the new fracture surface. 
Based on the Integral Finite Difference Approach, a numerical model, HUBBERT, has been developed. Using the criteria discussed above, this model simulates the initiation and propagation of a vertical hydraulic fracture of constant height. In addition to the usual information required for modeling fiuid flow, in rocks, the present model requires such additional data as depth to the fracture, breakdown pressure, fracture height, intitial fracture aperture, well bore dimensions, Youngs modulus, Crack extension force and so on. Injection history can be arbitrary and cyclic. Time steps are automatically controlled and account for sharp changes in the forcing function (injection history) and abrupt fracture extension.

The credibility of the model is partly verified against a known semi-analytic solution from the petroleum literature for a finite conductivity vertical fracture of fixed length.

A series of parameteric studies conducted with the model, HUBBERT, has indicated the following:

1. Using paramaters relevant on a field scale, the model simulations yield results on fracture length, pressure magnitudes and time scales that are compatible with field experience.

2. The pressure transient pattern in the well bore is characterized by instantaneous spikes accompanying sudden releases of energy. This pattern as well as its time scale appear to be compatible with acoustic emission data from experimental hydraulic fractures.

3. As the fracture grows, more energy is needed to pressurize it and it also stores more energy. As a consequence, the interval between successive fracture events become longer as the fracture grows and the magnitude of incremental fracture extension also increases. This phenomenon is consistent with the knowledge that on seismic faults, the longer the seismic gap the larger the seismic event.

4. The pattern of fracture evolution is quite sensitive to several factors such as Efficiency (energy actually spent in extending the fracture as a ratio of the available energy in the water), rock permeability, the capacity of the well bore, aperture and 
stiffness of the incipient fracture, and the pattern of fluid injection.

5. All but two of the cases studied dealt with controlled injection rates. In the two cases in which the injection pressure was maintained constant, fracture propagation tended to become unstable with fracture growth. There is reason to suspect that this pattern is relevant to the analysis of Massive Hydraulic Fracturing, a topic that is beyond the scope of the present study.

6. Current techniques of pressure transient analysis with reference to in situ stress measurement rely on identifying changes in slope on the pressure transient curve to interpret for least principal stress. The present study shows that that approach can be successful provided that the aperture and stiffness of the nascent fracture are relatively large. The pressure transients may show spikes and mask the identity of the least principal stress if the the newly created fracture is stiff and has a small aperture. All the analyses in the present study were carried out using simple arithmetic plots. No need was felt nor any special advantage perceived to resort to logaithmic time scale. Indeed, in some situations a logaithmic time scale may actually suppress slope contrasts that are essential to identify least principal stress.

7. Step-rate injection tests could be useful in identifying least principal stress. However, some caution is in order. The use of step-rate tests stems from simple reasoning based on steady or quasi steady flow behavior. However, the problem on hand is intrinsically a transient one. It appears that the best chance of identifying the least principal stress is likely when injection is carried out at low rates over a long period of time. The break in slope of the time transient manifests itself most markedly. under low flow rates.

8. Two outstanding issues in the area of present research relate to a) the identification of maximum stress in the horizontal plane and b) the identification of the fracture opening pressure. Both these issues require for their resolution a detailed handling of the stress field within few well bore diameter. In the context of elastic theory such a stress field can be effectively incorporated into the present model if the need arises. 
9. The present model has shown that the features of pressure transient curves of bydraulic fracturing experiments can be simulated in terms of physically realistic processes. The next step is to apply the model to the wealth of data that is already available in the literature. Such an application should be motivated by a two-fold iterative purpose: How best to get the most out of available field data? How best to minimise the gap between the mathematical model and the physical system it seeks to portray? 


\section{INTRODUCTION}

The technique of hydraulic fracturing is currently being used widely to estimate in situ rock stresses in the earth's crust. The method consists of injecting an appropriate fluid (usually water) at measured rates into a packed-of interval of a well-bore to create a small vertical fracture. Simultaneously, the fluid pressure transients in the well-bore itself or at the land surface are measured. The pressure - time behavior before and after the creation of the fracture is then analyzed to draw inferences about the in situ rock stresses, mainly the least principal stress, in the horizontal plane. In these miniature fracture experiments we consider fractures which extend but a few meters from the bore hole. Invariably, field experiments on minifractures involve a cyclic manipulation of the fluid injection activity in which periods of injection are punctuated by periods of shut-in, bleed-off or even pumpage.

Because the fluid pressure is the only variable other than flow rate that can be reliably measured during a hydraulic fracture experiment, an ability to critically analyse the pressure transient history is imperative in order to draw inferences about the in situ rock stresses as well as the mechanics of hydraulic fracture propagation. In particular, it is now widely recognized by the practitioners of hydraulic fracturing experiments (see, for example, several papers in Zoback and Haimson, 1982) that the least principal stress in situ is best recognized from inflections and breaks in the slopes of the pressure transient curves observed in the well bore cavity or at the injection pump. Nevertheless, the hydraulic fracturing process is an extremely complex dynamic phenomenon characterized by rapid variations in material properties as well as the flow region geometry with time. Consequently, a unique determination of the relationships between inflections and breaks in the slopes of the pressure transient curves on the one hand and the least principal stress on the other is not always easy. Any investigation that can provide insights in to elucidating the relationships between the pressure transient curve of a bydraulic fracturing experiment and the in situ stresses is therefore of considerable practical interest.

Many previous workers have carried out theoretical investigations on the mechanics of the hydraulic fracturing process. These theoretical investigations are in general based 
on two seminal contributions. The first, by Hubbert and Willis (1957) relates to the conditions under which a hydraulic fracture will be initiated in bore hole and its orientation. The second, postulated by Griffith during the 1920's, relates to the energy and work relationships that must be satisfied before a solid may rupture. Most of the theoretical investigations carried out in recent years have been strongly inspired by the rock mechanics perspective (e.g. Advani, 1980; Settari and Cleary, 1982; and Cleary et. el, 1983), throwing considerable light on the stress- strain relationships that exist during the propagation of a hydraulic fracture. Yet, the most striking aspect of the hydraulic fracturing process is that the fracturing fluid is the mediating agent that stores and transports the energy from the injection pump to the fracture tip. It is therefore appropriate that the currently available rock mechanics perspectives on the hydraulic fracturing process are complemented by an investigation that focusses attention on the fluid dynamics.

Since the early 1930's the hydrodynamics of the flow of fluids to wells has been an active field of investigation for hydrogeologists, civil engineers and petroleum engineers. A voluminous literature and knowledge available in this field treats the transient fluid flow problem as a initial-boundary value problem characterized by the parabolic partial differential equation. The present work has been motivated by a desire to contribute insights into the understanding and interpretation of the hydraulic fracturing process by focussing attention on the fluid pressure evolution as governed by the parabolic partial differential equation.

\subsection{Purpose and Scope}

A problem that has already been analysed in the field of petroleum reservoir engineering which has the closest connection to hydraulic fracturing is that of flow to a well piercing a formation with a single vertical fracture. Even for this problem, solutions have been obtained by treating the material properties (permeability, capacity) and the fracture geometry to be invariant in time (linear parabolic equation). In comparison, the hydraulic fracturing problem is far more complex; the fracture properties as well as the fracture geometry vary in time. The only rational way of even attempting to solve the 
non linear parabolic equation governing the hydraulic fracturing process is to resort to numerical techniques.

The purpose of the present work is to use a numerical approach to analyse the fluid flow field that accompanies the hydraulic fracturing process. The aim is not only to develop a general understanding of the hydrodynamics of the process, but also to provide insights that would help improve our ability to use the hydraulic fracturing experiment as a tool to estimate in situ tectonic stresses, especially the least principal stress, in the horizontal plane.

The entire study is restricted to the consideration of but one fracture geometry, namely a vertical fracture of constant height that extends symmetrically in either direction from the bore hole (a vertical, rectangular fracture). The consideration of fractures of other shapes(e.g. a penny shaped fracture) is beyond the scope of this work. The investigation is restricted to Mode $I$ type of fractures and fracture lengths are limited to 10 meters. As already suggested, only the fluid flow equation is solved. The deformation parameters that are essential to solve the fluid flow problem, namely, fracture compressibility, and fracture void volume are estimated on the basis of elasticity theory. The present work is divisible in to two major parts. The first is the development of a theory for the hydrodynamics of hydraulic fracture propagation and the development of a computational algorithm to implement the theory. The second is the application of the algorithm to a series of hypothetical problems to gain an understanding of the consequences of the theory. 


\section{THEORETICAL CONSIDERATIONS}

In general, two approaches are available to analyze the propagation of hydraulic fracture. The first is based on the evaluation of the stress intensity at the fracture tip and the interaction between the stress intensity and the fluid pressure in the fracture. The second approach, originally suggested by Griffith, recognizes that work must be done to overcome rock cohesion and create a new fracture surface. The basic postulate of this approach is that for a crack to propagate, the derivative of the elastic energy stored in the rock with respect to the crack area must exceed the rock toughness. Here, the toughness of the rock denotes the energy required to create a unit fracture surface area. In the present work we will follow this second approach. Part of the reason for this choice is that the present work focusses attention on the fluid flow phenomenon rather than on the rock deformation process. In so far as the fluid is concerned, its dynamic response is governed by the spatial and temporal changes in void volume within the fracture and the surrounding rock. Therefore, as long as one can make reasonable estimates on the compressibility of these materials, one may reasonably dispense with the task of carrying out a detailed stress strain analysis. Once we take this approach, we may effectively implement the fracture propagation by using the aforesaid energy balance approach that stems from Griffith's criterion. An energy balance approach was implemented by Palen (1980) to model the hydrodynamics of a hydraulic fracture. Palen used the Integral Finite Difference Approach (IFDM; Narasimhan and Witherspoon, 1976) to numerically simulate the hydraulic fracturing process. He applied the model to interpret field data from a set of experiments conducted at Monticello in South Carolina by M.D. Zoback (Narasimhan and Palen, 1981). In the present work an approach similar to that of Palen's is followed. But the actual evaluation of the available energy and the implementation of the fracture propagation process is substatially different from the scheme developed by Palen. 


\subsection{Model Assumptions}

Before describing the theory of the mathematical model, it is appropriate to list the assumptions and the nature of the particular class of problems that are the concerns of the present study. These assumptions are:

1. The hydraulic fracture is a vertical plane oriented perpendicular to the least principal horizontal stress. Its maximum length is 10 meters.

2. The fracture height is the same as the packer interval and the host rock is a homogeneous elastic medium.

3. The newly created fracture is dry as soon as it is formed and a finite time will elapse before water enters and pressurizes it.

4. The stiffness of the fracture can be estimated from elastic theory of rock deformation.

The theoretical model used in the present work is founded on the transient fluid flow equation governing fluid flow in deformable porous media. This equation is supplemented by criteria for energy balance and fracture extension. A special feature of the hydraulic fracturing problem is that the geometry of the flow region changes with time whereas the classical problem of fluid flow in porous media applies to systems with fixed geometry. Therefore, it is convenient to discuss the theoretical details of the model in two parts, namely, the fuid flow problem and the fracture propagation problem.

\subsubsection{The Fluid Flow Problem}

For any arbitrary elemental volume in a medium, be it comprised of a fracture or of porous material, one could write the following equation of mass conservation (e.g. Narasimhan, 1982)

$$
\int_{\Gamma_{l}} \frac{\overline{\mathrm{K}} \rho \mathrm{g}}{\mu} \nabla(\mathrm{z}+\psi) \cdot \overrightarrow{\mathrm{n}} \mathrm{d} \Gamma+\rho \mathrm{G}_{l}=\mathrm{M}_{\mathrm{c}, \mathrm{l}} \frac{\partial \psi_{l}}{\partial \mathrm{t}}
$$


In the above integral representation,

$\rho$ is fluid density,

$\bar{k} \quad$ is the average permeability at the surface segment $\mathrm{d} \Gamma$

g is acceleration due to gravity

$\mu \quad$ is the dynamic coefficient of viscosity

$\mathbf{z}$ is elevation

$\psi \quad$ is pressure head

$\mathrm{d} \Gamma \quad$ is a segment of the closed surface $\Gamma_{1}$ volume $l$ and $m$

$\Gamma_{1} \quad$ is the closed surface bounding the elemental volume 1

$G_{1}$ is the source term denoting the mass rate of injection of fluid into the elemental volume 1

$\mathrm{M}_{\mathrm{c}, 1} \quad$ is the Fluid Mass Capacity of the elemental volume 1, defined as the mass of water released from or taken into storage by elemental volume 1 when the average pressure head over that elemental volume changes by unity (Narasimhan and Witherspoon, 1977)

When (1) is applied to a volume element that is a fracture, we will assume that the. fracture permeability is dependent on the square of the fracture aperture, $w_{f}$. In particular we will assume that

$$
k_{f}=\frac{w_{f}^{2}}{12}
$$

For a material that is fully saturated with water,

$$
M_{c, l}=V_{s} \rho g\left(a_{v}+e \beta\right)
$$

where $\beta$ is the compressibility of water and, $a_{v}=-\mathrm{de} / \mathrm{d} \sigma^{\prime}$ in which e is void ratio and $\sigma^{\prime}$ is the effective stress. For a fracture, $a_{v}$ is a measure of the fracture stiffness or fracture compliance. If we associate a fictitious solid volume $V_{8}$ with a fracture element such that $V_{s}$ equals the wall area of the fracture element times unity, then the void ratio of 
the fracture is numerically equal to its aperture. Consequently, the rate of fracture closure with effective stress is numerically equal to $a_{v}$. We shall follow this convention throughout the present work. This manipulation conveniently enables the computational treatment of a discrete fracture element in exactly the same way as an elemental volume in a porous material.

Equation 1 is an integral representation of the initial- boundary value problem. We choose this integral representation in preference to the differential equation because one can directly proceed from this governing equation to a numerical algorithm by discretizing the spatial and temporal domains of the integral. In practice, a very convenient way of developing such a numerical algorithm is the Integral Finite Differnce Method (IFDM; Narasimhan and Witherspoon, 1976). Using the IFDM, Narasimhan et el. (1978), developed a computer algorithm called TRUST to solve the governing equation 1 in general three dimensions under conditions of heterogeneity or anisotropy. This algorithm and a simplified version of it restricted to fully saturated systems (TERZAGI) have been verified extensively (Narasimhan et al., 1978; Narasimhan, 1982) as applied to porous media, fractured media and fractured porous media. The details of the algorithm can be found in Narasimhan et. el. (1978).

In the implementation of equation 1 using an algorithm such as TRUST, the assumption is that during each time step the material properties and the flow region geometry are known. Should the material properties vary in time, one commonly resorts to the quasi linearization procedure in which one uses approriately estimated timeaveraged values of the material properties of interest. For the hydraulic fracturing problem, the geometry of the fracture is a function of time. We employ a similar quasilinearization approach to handle the time-dependent geometry of the fracture. Accordingly, for each volume element representing a fracture, we shall use its known geometry at the beginning of a time step to solve the governing equation for that particular time step. 


\subsubsection{Criteria for Fracture Propagation}

Consider a vertical hydraulic fracture schematically represented in Figure 1 . The fracture has a beight $H_{f}$ and length $X_{f}$. When the length of the fracture is smaller than its height, we assume that the fracture has an elliptical cross section in a horizontal plane through midsection. As the fracture length exceeds its height, we assume that the cross section of the fracture will more closely resemble a parallel plate configuration in this plane and an ellipse in the vertical plane. Very close to the fracture tip the fracture will have a parabolic shape. In the present development we do not take into account the shape of the fracture tip

We now wish to estimate the compressibility of the fracture as a function of $X_{f}$ and the elastic properties of the rock. Also, we need to quantify Griffith's fracture extension criterion as applied to the particular geometry of the fracture.

We consider two situations in regard to the stresses acting on the fracture. In the first case the fluid pressure in the fracture, $p_{f}$, is less than the least principal stress and the effective stress normal to the fracture, $\sigma_{\mathrm{n}}{ }^{\prime}$, is greater than zero. In the second case, when $p_{\mathrm{f}}$ exceeds $\sigma_{\mathrm{h}, \min }, \sigma_{\mathrm{n}}{ }^{\prime}$ is less than zero. In so far as deformation is concerned, the fracture will be far stiffer (less compressible) when $\sigma_{\mathrm{n}}^{\prime}>0$ than when $\sigma_{\mathrm{n}}^{\prime}<0$. Also, as $\mathrm{p}_{\mathrm{r}}$ exceeds $\sigma_{\mathrm{n}}$, it will soon approach a critical value as dictated by Griffith's criterion at which the fracture will abruptly propagate. We will call the excess of $\mathrm{p}_{\mathrm{f}}$ over $\sigma_{\mathrm{h}, \mathrm{min}}$ the over pressure, $p_{\text {op }}$. We now consider these two conditions separately.

\section{Condition 1.}

We assume that as the fracture forms and extends, the newly created fracture segment starts dry and $\sigma_{n}{ }^{\prime}=\sigma_{h, m i n}$. Under this condition, both the aperture and the compressibility of the fractures will be very small. The magnitudes of these quantities are determined by as yet poorly understcod factors. We will assume that the aperture, $w_{f}$ of the newly formed fracture segment will be of the order of 10 to 20 microns or less and the the fracture compressibility, as defined by

$$
a_{v, f}=-\frac{d w_{f}}{d \sigma^{\prime}}
$$


will be more than an order of magnitude smaller than the compressibility of water.

\section{Condition 2.}

When $\mathrm{p}_{\mathrm{f}}>\sigma_{\mathrm{h}, \min }$ we will use the principles of elasticity theory to estimate $a_{v, f}$ as well as $p_{\text {op }}$.

Consider a fracture of length $X_{f}$ and height $H_{f}$. The wall area of the fracture, $A_{f}$ equals $X_{f}$ times $H_{f}$ and the void volume, $V_{f}$, of the fracture equals $A_{f}$ times $w_{p}$. For convenience, associate with this fracture a solid volume $V_{s}$ equal to $A_{f}$ times unity. Then,

$$
a_{v, f}=-\frac{d e_{f}}{d \sigma^{\prime}}=-\frac{\frac{d V_{f}}{V_{s}}}{d \sigma^{\prime}}=-\frac{d w_{f}}{d \sigma^{\prime}}
$$

For an elliptical fracture, $w_{f}$ in equation 5 is interpreted as the mean aperture of an elliptical crack. Based on the theory of elasticity, Jaeger and Cook (1977;p 326) show that the energy stored in an elliptical crack which is pressurized from within by water can be represented by,

$$
\mathrm{W}_{\mathrm{c}}=\frac{\pi \mathrm{X}_{\mathrm{f}}^{2} \mathrm{H}_{\mathrm{f}} \mathrm{op}^{2}}{\mathrm{E}^{\prime}}
$$

where $W_{c}$ is the energy stored and $p_{o p}$ is the over pressure. For plane strain, $E^{\prime}$ equals $\frac{E}{\left(1-\nu^{2}\right)}$ where $E$ is Youngs Modulus and $\nu$ is Poisson's ratio. Under conditions of equilibrium, this energy must be equal to the energy in the fluid,

$$
W_{c}=\int_{0}^{P_{o p}} p_{o p} d V_{p}
$$

We now introduce the well known expression for effective stress in the fracture,

$$
\sigma^{\prime}=\sigma_{\mathrm{h}, \min }-\mathbf{p}
$$

If we assume, as we shall throughout the present work, that $\sigma_{\mathrm{h}, \mathrm{min}}$ is constant, then,

$$
\mathrm{d} \sigma^{\prime}=-\mathrm{dp}
$$

In view of (5) and (9) we may rewrite (7) as 


$$
W_{c}=2 X_{f} H_{r} a_{v, r} \int_{0}^{P_{o p}} p_{o p} d p=X_{r} H_{r} a_{v, l} p_{o p}^{2}
$$

Comparing (6) and (10), it is easy to see that

$$
a_{\mathbf{v}, \mathrm{f}}=\frac{\pi \mathrm{X}_{\mathrm{f}}}{\mathrm{E}^{\prime}}
$$

Now we consider the criterion for fracture extension. Let $G_{c}$ denote the total energy required to create a unit fracture surface area by extending the fracture. We recognize that this term also includes the energy required to overcome the resistance at the crack tip due to such factors as the development of a process zone at the fracture tip and any other dissipative phenomena. $G_{c}$ is known as the crack extension force and is related to the critical stress intensity fracture, $K_{i c}$ by the relation, $G_{c}=\frac{K_{i c}^{2}}{E^{\prime}}$. One way of stating Griffith's criterion for fracture propagation is that,

$$
\frac{d W_{c}}{d A_{f}} \geq G_{c}
$$

Applying this criterion to (6), we readily see that

$$
\frac{\mathrm{dW}_{\mathrm{c}}}{\mathrm{dA_{ \textrm {f } }}}=\frac{\pi \mathrm{X}_{\mathrm{f}} \mathrm{p}_{\mathrm{op}}^{2}}{\mathrm{E}} \geq \mathrm{G}_{\mathrm{c}}
$$

and, we directly get the following expression for $p_{o p}$,

$$
p_{\mathrm{op}}=\sqrt{\frac{\mathrm{G}_{\mathrm{c}} \mathrm{E}^{-}}{\pi \mathrm{X}_{\mathrm{f}}}}
$$

Thus, Grifith's criterion for fracture propagation is equivalent to the statement that the fluid pressure near the fracture tip must exceed a certain over pressure in order to extend the fracture.

We now consider the segment of the fracture beyond $X_{f}=H_{f}$. Whereas $W_{c}$ has a parabolic relation to $X_{f}$ in (6) for an elliptical crack, $W_{c}$ is related linearly to $X_{f}$ for a crack bound by parallel walls. Thus,

$$
\mathrm{W}_{\mathrm{c}}=\frac{\pi\left(\mathrm{X}_{\mathrm{r}}-\mathrm{H}_{\mathrm{f}}\right) \mathrm{H}_{\mathrm{f}}^{2} \mathrm{p}_{\mathrm{op}}^{2}}{2 \mathrm{E}^{\prime}}
$$


In view of (5) we can easily show that

$$
a_{v, f}=\frac{\pi H_{f}}{E}
$$

Also,

$$
\frac{d W_{c}}{d A_{f}}=\frac{\pi H_{f} p_{o p}^{2}}{2} E^{\prime} \geq G_{c}
$$

and we get the expression for $p_{o p}$

$$
p_{o p}=\sqrt{\frac{2 G_{c} E^{\prime}}{\pi H_{r}}}
$$

The derivations given above provide the overall logical base to simulate the propagating hydraulic fracture in the present work. We now pass on to describe the numerical algorithm that seeks implement the above derivations. 


\section{THE NUMERICAL ALGORITHM}

For the computational aspects of the present study the algorithm TRUST (Narasimhan et al. (1978)) is the starting point. Since the hydraulic fracturing problem is concerned with only purely saturated water flow, the TRUST algorithm was first simplified by removing all complexities related to handling variably saturated flow. The modified version was then expanded to handle the hydraulic fracturing process already described. The resulting computer program has been given the name HUBBERT in honor of M.K. Hubbert who pioneered the theoretical analysis of the hydraulic fracturing process. This program, based on the IFDM (Narasimhan and Witherspoon, 1976), considers flow in a two dimensional system with a well of finite radius at the center and a vertical hydraulic fracture extending symmetrically on either side as a function of time to a maximum distance of 10 meters. In principle, the program can be modified and expanded to handle more complex fracture geometries in general three dimensions.

\subsection{The Discrete Equations}

For any elemental volume 1 in the flow region, one could directly discretize (1) and write,

$$
\begin{aligned}
& \sum_{m} \rho \frac{k_{\mathrm{lm}} \rho \mathrm{g}}{\mu}\left[\frac{\left(\mathrm{z}_{\mathrm{m}}-\mathrm{z}_{\mathrm{l}}\right)+\left(\psi_{\mathrm{m}}-\psi_{\mathrm{l}}\right)}{\mathrm{d}_{\mathrm{lm}}+\mathrm{d}_{\mathrm{ml}}}\right]+\sum_{\mathrm{b}} \rho \frac{\mathrm{k}_{\mathrm{lb}} \rho \mathrm{g}}{\mu}\left[\frac{\left(\mathrm{z}_{\mathrm{b}}-\mathrm{z}_{\mathrm{l}}\right)+\left(\psi_{\mathrm{b}}-\psi_{\mathrm{l}}\right)}{\mathrm{d}_{\mathrm{lb}}}\right] \Delta \Gamma_{\mathrm{lb}}+\rho \mathrm{G}_{\mathrm{l}} \\
& =\mathrm{M}_{\mathrm{c}, \mathrm{l}} \frac{\Delta \psi_{\mathrm{l}}}{\Delta} \mathrm{t}
\end{aligned}
$$

where,

m is an elemental volume with which 1 has a common interface,

b is a boundary element representing external conditions,

$\mathrm{k}_{\mathrm{lm}} \quad$ is the mean permeability at the interface, 
$n_{I m}$ is the unit normal directed away from element 1 ,

$\Delta \Gamma_{\mathrm{lm}}$ is the area of the interface between $\mathrm{l}$ and $\mathrm{m}$,

$\mathrm{d}_{\mathrm{lm}}$ are distances from the interface respectively to the nodal points associated with elements 1 and $m$,

$\Delta \psi_{1}$ is the change in average pressure head over element I during the time interval $\Delta t$.

In (19), the summation over $m$ takes in to account all fluxes entering in to 1 through all interfaces interior to the flow domain, The summation over b takes into account fluxes entering into 1 from all Dirichlet boundary segments at which $z_{b}$ and $\psi_{b}$ are specified as functions of time. The source/sink term $\rho G_{l}$ in (19) takes into account all source terms as well as the Neumann bounda. segments at which the fluid fluxes are prescribed as functions of time.

Furthermore, as pointed out by Narasimhan (1982), equation 19 applies equally well to a volume element that consists of a porous material or one that consists of a fracture segment. One has to merely pay attention to the nature of the parameters $k_{1 m}$ and $M_{c, l}$ : For the case in which both 1 and $m$ are fractures, one may use (2) to estimate $\mathrm{k}_{\mathrm{Im}}$. In the present work, we use the estimated average aperture at the interface between 1 and $\mathrm{m}$ for this purpose. In the case when a fracture element 1 communicates with a rock element $m$, we take advantage of the knowledge that when the permeability changes abruptly at an interface perpendicular to the flow path the lower permeability dominates. Accordingly, we shall set $k_{l m}=k_{\text {rock }}$ for this case. Finally, to calculate the fluid mass capacity of a fracture element 1 , we shall us (3) in the context of (5), (11) and (16).

By using the time-averaged expressions,

$$
\psi_{\mathrm{m}}=\psi_{\mathrm{m}}^{0}+\lambda \Delta \psi_{\mathrm{m}}
$$




$$
\psi_{1}=\psi_{1}^{\circ}+\lambda \Delta \psi_{1}
$$

where $\psi_{\mathrm{m}}^{\circ}$ and $\psi_{1}^{\circ}$ are pressure heads at $\mathrm{m}$ and $l$ at the beginning of the time interval and $0.5<\lambda<1$.Substituting these into (19), one obtains a set of linear algebraic equations which need to be solved for $\Delta \psi_{1}$. In program HUBBERT this is achieved with the help of the matrix solver MA28 (Duff, 1977). The computational details of HUBBERT are very similar to that of TRUST (Narasimhan et al., 1978). Suffice it to mention here that the time step is automatically controlled within the algorithm. Normally, the problem is started with a very small time step determined by the time constant of the fastest reacting volume element in the system. For this purpose, the time constant is defined as,

$$
\Delta t_{l}=\frac{M_{c, l}}{\sum_{m} U_{l m}+\sum_{b} U_{l b}}
$$

in which the conductances $U_{I m}$ and $U_{l b}$ are defined by

$$
\begin{gathered}
\mathrm{U}_{\mathrm{lm}}=\sum_{\mathrm{m}} \rho \frac{\mathrm{k}_{\mathrm{lm}} \rho \mathrm{g}}{\mu} \frac{\Delta \Gamma_{\mathrm{lm}}}{\left(\mathrm{d}_{\mathrm{lm}}+\mathrm{d}_{\mathrm{ml}}\right)} \\
\mathrm{U}_{\mathrm{lb}}=\sum_{\mathrm{b}} \rho \frac{\mathrm{k}_{\mathrm{lb}} \rho \mathrm{g}}{\mu} \frac{\Delta \Gamma_{\mathrm{lb}}}{\mathrm{d}_{\mathrm{lb}}}
\end{gathered}
$$

The time step is then gradually increased every succeeding time step by no more than a factor of two. If during the evolution of the system, very rapid changes in $\psi$ are encountered, the time step is automatically cut in half and the calculations repeated. In the present work, the following additional control has been added. The time step is automatically scaled down by a factor of $10^{-5}$ whenever the fracture has abruptly extended or immediately following an injection, shutin or a bleed off event.

\subsection{Fracture Propagation}

We consider the simulation of fracture propagation in two parts. The first is the creation of the very first fracture segment and the second is the propagation of subsequent fracture segments. 


\subsubsection{The First Fracture Segment}

In the present work we do not consider the complex processes that occur near the well as the breakdown pressure is exceeded and a new fracture growth is initiated. Instead, we arbitrarily assume that once the breakdown pressure $p_{b}$ is exceeded at the well bore, $a$ one-meter long fracture segment is immediately created. Thus, $p_{b}$ is an input parameter in the computational model.

Obviously, the fracture has formed at the expense of energy stored in the well bore. According to Hubbert and Willis (1957), the compressive stress at the location of the well bore perimeter where the fracture is initiated is given by

$$
\sigma_{\mathrm{c}}=3 \sigma_{\mathrm{h}, \min }-\sigma_{\mathrm{h}, \max }
$$

Therefore, it is reasonable to assume that only the elastic energy stored in the water in excess of $\sigma_{c}$ upto $\mathrm{p}_{b}$ is available to create the new fracture surface.

At this juncture it is useful to introduce the notion of "Efficiency", denoting the percentage of the available energy that is actually expended in creating the new fracture surface. Thus,

$$
\text { Eficiency }=\frac{\mathrm{G}_{c} \mathrm{H}_{\mathrm{f}}}{\mathrm{W}_{\text {avail }}}
$$

where,

$$
\mathrm{W}_{\mathrm{avail}}=\int_{0}^{\mathrm{Pop}_{\mathrm{p}}} \mathrm{pdV}
$$

in which,

$$
p_{o p}=p_{r}-\sigma_{c}
$$

In the numerical simulations we drop the pressure in the well bore by an amount equal to Efficiency times $\left(\mathrm{p}_{\mathrm{b}}-\sigma_{\mathrm{c}}\right)$ as soon as the first fracture element is created.

As soon as the new fracture is created, we assume that it is dry and the fluid pressure inside the newly created element is zero. Also, we assume that the aperture and compressibility of the fracture, namely, $e_{o, f}$ and $a_{v, f}$, are prescribed and very small. 
This dry fracture will initially fill up with water at zero pressure. Once the fracture is fully saturated, its fluid mass capacity will drastically decrease, as dictated by its $a_{v, f}$ and the pressure inside the fracture will rise rapidly.

Once the pressure inside the fracture exceeds $\sigma_{\mathrm{h}, \min }$ its compressibility will abruptly increase as dictated by (11) and the pressurization process will be greatly slowed down. The pressure will build up in the fracture until it exceeds a magnitude of $p_{o p}+\sigma_{h, m i n}$. At this time the fracture is ready to extend once again.

\subsubsection{Subsequent Fracture Segments}

A new fracture segment is ready to be created when the fluid pressure in the fracture everywhere exceeds $\left(\sigma_{h, \min }+p_{o p}\right)$. The actual extent of the new surface created will be dictated by the amount of energy stored in the water.

We now derive an expression for the energy stored in water between zero and the over pressure, $\mathrm{p}_{\text {op }}$. Let $\beta$ be the compressibility of water, assumed to be constant. Then, the volume of a given mass of water at pressure $p$ is,

$$
\begin{gathered}
\mathrm{V}=\mathrm{V}_{\mathrm{o}} \mathrm{e}^{-\beta\left(\mathrm{p}-\mathrm{p}_{0}\right)} \\
\mathrm{dV}=-\beta \mathrm{V}_{0} \mathrm{e}^{-\beta\left(\mathrm{p}-\mathrm{p}_{0}\right)}
\end{gathered}
$$

Substituting (29) into (7) we get,

$$
W_{c}=-V_{o} \beta \int_{0}^{P_{o p}} p e^{-\beta\left(p-p_{0}\right)} d p
$$

From the table of integrals,

$$
\int x e^{2 x}=\frac{e^{2 x}}{a^{2}}(a x-1)
$$

Therefore,

$$
\int p e^{-\beta p} d p=-\frac{e^{-\beta p}}{p^{2}}(1+\beta p)
$$


In view of (32), (30) leads to,

$$
\mathrm{W}_{\mathrm{c}}=\left.\mathrm{V}_{\mathrm{o}} \beta \mathrm{e}^{\beta \mathrm{P}_{\mathrm{o}}}\left[\frac{\mathrm{e}^{-\beta \mathrm{P}}}{\beta^{2}}(1+\beta \mathrm{p})\right]\right|_{0} ^{\mathrm{P}_{o \mathrm{p}}}=\frac{\mathrm{V}_{\mathrm{o}}}{\beta}\left[\mathrm{e}^{-\beta \mathrm{p}_{\mathrm{op}}}\left(1+\beta \mathrm{p}_{\mathrm{op}}\right)-1\right]
$$

Equation (33) is an expression for calculating the energy in a constant mass of water. In the present study we consider the water contained only in the well bore and the fracture in calculating the available energy using (33).

\subsection{The Process of Fracture Extension}

We now consider the process by which a new fracture surface is created at the expense of energy stored in the water. We assume that the new fracture surface is created instantaneously. Because the fracture surface is created by expending energy from the water, it follows that the pressure in the well bore and in the fracture must instantaneously fall by an appropriate amount. Consequent to the fall in water pressure, water must expand slightly, leading a small increase in fracture aperture. This aperture increase is caused by doing work against $\sigma_{\mathrm{h}, \mathrm{min}}$. Secondly, some of the released energy must be lost as radiative energies (e.g., acoustic; seismic). Thirdly, Majer and Doe(1986), suggest based on observations in the laboratory and in the field that the abrupt creation of a hydraulic fracture is accompanied by harmonic tremors as the walls vibrate. Finally, it is likely that energy will also be expended from the fluid due to other unknown causes of a thermodynamic nature. Therefore, one should expect that only a portion of the available energy is actually expended towards opening a new fracture surface. We shall use the term Efficiency to denote the ratio of the energy actually consumed in opening the fracture to the total available energy, expressed as a per cent. Thus,

$$
\text { Efficiency }=\frac{G_{c} H_{p} \Delta X_{f}}{W_{c}}
$$

where $\Delta \mathrm{X}_{\mathrm{f}}$ is the length of the newly created fracture segment. No reliable information is currently available on the magnitude of this Efficiency either from field data or from experimental dara. Therefore, for purposes of the present work we shall arbotrarily assume that the Effiency is $20 \%$. 
In view of the above we may now describe the computational procedure involved in simulating a fracture that grows in time. At the beginning of every time step, a check is made as to whether the fluid pressure at the fracture tip exceeds $\sigma_{h, \min }$ by an amount equal to pop. If this condition is satisfied, we then compute the length of the newly created fracture segment by,

$$
\Delta \mathrm{X}_{\mathrm{f}}=\frac{\left(\mathrm{W}_{\mathrm{c}}\right)(\text { Efficiency })}{\left(\mathrm{G}_{\mathrm{c}} \mathrm{H}_{\mathrm{f}}\right)}
$$

Concomitant with the increase in fracture surface, the pressure in the well bore and in the fracture must fall by an amount equal to pop. Immediately, the size of the time step is dropped by 5 orders of magnitude to minimise the rapid changes that will accompany a sharp change in the forcing function.

One additional feature needs to be mentioned at this juncture. Inherently the newly created fracture surface must have rough walls. For a rough-walled fracture it is quite difficult to define a mean aperture. In a rough-walled fracture, the void volume will be dominated by the large apertures while the permeability will be dominated by the necks and small apertures. In the present work we will assume that the compressibility estimates as well as $e_{o, r}$ are measures relevant to the void volume. If so, one has to use only a fraction of the estimated $w_{f}$ towards calculating $k_{f}$ using (2). The ratio between the aperture that defines permeability and that which defines void volume is a parameter that is of relevance. Thus,

$$
b_{\text {ratio }}=\frac{w_{\mathrm{f}, \mathbf{k}}}{w_{\mathrm{r}}}
$$

where $w_{f, k}$ is the aperture that is relevant to estimating the permeability of the fracture. 


\section{APPLICATION AND RESULTS}

The algorithm HUBBERT was developed in order to gain insights into the hydrodynamics of the hydraulic fracturing process itself in general and to throw additional light on some questions relating to the interpretation of pressure transient data in particular. In the present work, these goals are achieved by a series of parametric studies on hypothetical hydraulic fracturing problems. Because we are dealing with a highly nonlinear problem with many variables, it is neither possible to reduce the problem to few dimensionless variables, nor is it possible to carry out exhaustive studies on all possible parametric variations. Only selected combinations of parametric studies have been conducted, in keeping with the resources and the time available.

One of the first steps in developing and applying a new algorithm is that of verification. In the absence of any known solutions to the hydraulic fracturing problem, it is not feasible to verify HUBBERT against known solutions. Therefore, we take the next best step of verifying the algorithm against a known solution to the problem of a well piercing an aquifer with a single vertical fracture. The descriptions that follow deal first with the task of verification, followed by the results of the parametric studies.

Program HUBBERT is written in the Fortran language. All the calculations of the present study were carried out on a VAX 8500 computer of the Computer Center at the Lawrence Berkeley Laboratory. The same discretized mesh grid (Figure 2) were used for all the problems. This grid has 316 elemental volumes and 586 interfaces between between elemental volumes. The number of time cycles varied from less than 500 to 2000 according to the specific nature of each problem. The CPU time was usually about 5 minutes but seldom more than 10 minutes.

\subsection{Verification of the Algorithm}

The problem of transient flow to a well piercing an aquifer with a single vertical fracture has been studied by Cinco-Ley et al. (1978). In particular, these authors obtained semi-analytical solutions for finite conductivity fractures. As is customary in reservoir engineering literature, they conveniently presented their results in terms of 
three non-dimensional variables:

dimensionless time $=\frac{\mathrm{Kt}}{\mathrm{S}_{\mathrm{s}} \mathrm{X}_{\mathrm{f}}^{2}}$

dimensionless pressure $=\frac{2 \pi \mathrm{KH}_{\mathrm{f}} \Delta \psi}{\mathrm{Q}}$

dimensionless fracture conductivity $=\frac{w_{\mathrm{f}} \mathrm{K}_{\mathrm{f}}}{\pi \mathrm{K}_{\mathrm{X}_{\mathrm{f}}}}$

in which, $K=\frac{\mathrm{k} \rho \mathrm{g}}{\mu}$ is hydraulic conductivity, $\mathrm{S}_{\mathrm{s}}=\frac{\rho \mathrm{g}}{1+\mathrm{e}}\left(\mathrm{a}_{\mathrm{v}}+\right.$ ebeta), and $\mathrm{Q}$ is flow rate treated as constant. In the above expressions, both $K$ and $S_{8}$ are properties of the rock.

To verify the HUBBERT algorithm, the IFD mesh shown in Figure 2 was used. Incidentally, this very same mesh was used in all the other hydraulic fracturing simulations in the present work. For the verification problem, a 10-meter long vertical fracture was considered. The results of the numerical experiments are shown compared with the analytic results of Cinco-Ley (1978) in Figure 3. The results presented pertain to a well of negligible well bore storage: As can be seen, the agreement between the analytical and the numerical results is reasonable, providing a measure of credibility to the algorithm in general and the discretized mesh in particular.

\subsection{Parametric Studies}

All the runs to be described below were carried out using the IFD mesh shown in Figure 2. In the figure, nodes $100,200 \ldots 2000$ represent volume elements that will become fracture elements during the course of the fracturing process. The well at the center is treated as volume element. The 10 meter long surface pipe and the 300 meter long connecting pipe were each treated as a separate volume element. Fluid injection and bleed off were implemented through the volume element representing the surface pipe. 
The numerical experiments carried out in the present study can be divided into four categories, Cases $1-4$, as shown below:

Category 1 Constant Rate Injection

Category 2 Constant Pressure Injection

Category 3 Punctuated Injection, Constant Rate

Category 4 Punctuated Injection, Step Rate

The cases in categories I and II were designed to gain a general understanding of the dynamics of hydraulic fracturing under constant injection rate (Category 1) and Constant Pressure (Category 1I). Cases under Category 1II involved several periods of injection separated by periods of shut in and bleed off. This pattern of punctuated injection is often followed in field experiments. For this reason, the flow rates used in these cases were in the range commonly used in field experiments. The purpose of these experiments was to gain insights into the nature of the shut in curves and to investigate their reliability in interpreting for the least principal stress. Category $1 \mathrm{~V}$ experiments involved puntuated, step-wise injection rate. The purpose of these experiments was to establish whether the injection rate versus injection pressure relation can be reliably used to estimate the least principal stress. The parameters used for each of the different runs are detailed in Table 1.

\subsubsection{Constant Rate Injection}

The runs made in this category constituted the first set of problems investigated with the newly constructed model. Three injection rates were considered: 2 Ips (Case I1); 8 lps (Case I-2); and 4 lps (Case I-3).

The variation of the pressure head in the well bore as a function of time is shown in Figure $4 \mathrm{~A}$ for Case I-1 with an injection rate of 2 lps. Breakdown occurred at 4.975 seconds at which time the pressure head in the well bore dropped by nearly $157 \mathrm{~m}$. However, the pressure head builds back very quickly as shown by the downward spike in the figure. Subsequently, as water begins to flow into the newly formed fracture, the well bore depressurizes rapidly. At 5.064 seconds, when the well bore pressure head was 
seconds at which time the pressure head in the well bore dropped by nearly $157 \mathrm{~m}$. However, the pressure head builds back very quickly as shown by the downward spike in the figure. Subsequently, as water begins to flow into the newly formed fracture, the well bore depressurizes rapidly. At 5.064 seconds, when the well bore pressure head was $1256 \mathrm{~m}$, the fracture propagates to $2.037 \mathrm{~m}$, even as the well bore was depressurizing. By 5.797 seconds, the third fracture event is ready to occur. The well bore has already depressurized to $643.2 \mathrm{~m}$, within $20 \mathrm{~m}$ of the least principal stress $(624.4 \mathrm{~m})$. During the third event the fracture extends only by $0.03 \mathrm{~m}$. The reason for the sudden decrease in fracture extension from $1.037 \mathrm{~m}$ during event 2 to $0.03 \mathrm{~m}$ during event 3 is that the energy available for fracturing is dominated by the energy content of the well bore which acts as a capacitor for energy. At event 2 the pressure is well above the least principal stress, despite the fact that the well bore is depressurizing. Hence the large available energy and the large propagation length. Figure $4 \mathrm{~A}$ clearly illustrates that the fracture propagation process is characterized by discrete events, separated by periods of quiescence. Field observations using seismometers support the results of the model. Figure 5 shows typical occurrence rate of seismic activity during hydraulic fracturing experiments on a salt block observed by Majer and Doe (1986). These authors especially draw attention to the fact even in the case of salt the hydraulic fracturing process is characterized by brittle failure, giving rise to banded seismic signals characterized by alternating event bursts separated by periods of quiescence.

Note from Fig. 5 that the interval between successive fracture events in the salt block experiment is of the order of $0.01 \mathrm{sec}$. For the various cases studied in the present work, the inter fracture time interval varied from less than $0.02 \mathrm{sec}$. to about 2.8 sec., depending upon the features of particular problem. In the salt block experiment, the block was $30 \mathrm{~cm}$ by $30 \mathrm{~cm}$ by $45 \mathrm{~cm}$ with a $2.5 \mathrm{~cm}$ hole in the center. Clearly, the energy capacitance of the bore hole in this experiment is far smaller than the capacitance of the field-scale bore hole considered in the prsent study. Although the $300 \mathrm{cp}$ oil used as the fracturing fluid in the salt block experiment would cause to slow down the fracturing process, the inter event interval for the salt block experiment should still be expected to be smaller than those calculated in the present study. Qualitatively, 
therefore, it appears that the fracture response times obtained in the present study are reasonable.

In the Case I-1 experiment the fluid injection lasted for 60 seconds during which the fracture propagated in 30 discrete events. For the same case, Figure $4 \mathrm{~B}$ shows the fluid pressure evolution in the fracture at a location $0.5 \mathrm{~m}$ from the well bore. Here we see the rapid pressurization of the nascent fracture and the sudden drop in pressure accompanying event 2 , within about a tenth of a second after event 1 . Figure $4 \mathrm{C}$ shows that the fracture grows in discrete events attaining a maximum length of $3.014 \mathrm{~m}$ at the end of 60 seconds.

It is pertinent at this juncture to look at the energy relations involved. Note that we are considering a fracture at a depth of $300 \mathrm{~m}$ below land surface. We have assumed an average density of $2600 \mathrm{k} / \mathrm{m}^{3}$ for the rock and that $\sigma_{\mathrm{h}, \min }=0.8 \times \sigma_{\mathrm{v}}$. If we further assume that $\sigma_{\mathrm{h}, \max }=1.1 \times \sigma_{\mathrm{v}}$, then $\sigma_{\mathrm{c}}$ described in equation 25 is equivalent to $1014 \mathrm{~m}$ of water head. The energy contained in the well bore between this and the breakdown pressure of $1800 \mathrm{~m}$ head amounted to 579.9 Joules. Of this, 60 Joules was expended in creating the 1 meter-long, $3 \mathrm{~m}^{2}$ fracture surface. This suggests an Efficiency of about 10.35 per cent. Also, the $786 \mathrm{~m}$ difference between $\sigma_{c}$ and the breakdown pressure is equivalent to a tensile strength of $7.7 \mathrm{MPa}$ for the rock, which appears physically realistic.

It is of interest from Figures $4 \mathrm{~A}$ through $4 \mathrm{C}$ that the intervals between successive fracture events are not uniform. Although not readily discernible from the figure, the computer printouts indicate that the inter-event frequency gradually increases with time. At the beginning of Case I-1 the interval was 0.2 seconds and it had gradually increased to 2.6 seconds by event 30 at 60 seconds. The fact that the interval increases with time seems physically reasonable. As the fracture grows it takes longer to pressurize due to its increased volume. For the same reason, more energy is stored in the system as the fracture grows. Hence, it is likely that as time progresses, larger discrete events will be separated by longer intervals. This reasoning seems to corroborated by field observations related to seismic events associated with natural earthquakes. Although the stick-slip 
events of earthquake failure is different in nature from that of a propagating hydraulic fracture, there is reason to believe that they may have a common basis in regard to the storage and release of energy.

For Case I-1 the computations indicated that the over pressure, $\mathrm{p}_{\mathrm{op}}$, was $25.73 \mathrm{~m}$ at a fracture length of $1 \mathrm{~m}$ and had declined to $14.94 \mathrm{~m}$ at a fracture length of $2.965 \mathrm{~m}$. When $\mathrm{X}_{\mathrm{f}}$ exceeds $3 \mathrm{~m}$ (the height of the fracture), the fracture shape changes, as also the expression governing $p_{o p}$ and fracture geometry. As a result, the over pressure increases to $\mathbf{1 4 . 9 4} \mathrm{m}$ for $\mathrm{X}_{\mathrm{f}}>3 \mathrm{~m}$ and remains fixed at that value according to equation (18).

As a consequence of the model assumptions, the compressibility of the fracture increases from $3.14 \times 10^{-10} \mathrm{~Pa}^{-1}$ for the one meter fracture to $9.42 \times 10^{-10} \mathrm{~Pa}^{-1}$ for the 3.01 m fracture at event 60 .

Figure $4 \mathrm{~A}$ through $4 \mathrm{C}$ typically illustrate the dynamics of fracture propagation consequent to constant injection rate. To illustrate the effect of flow rate on the pressure response in the well bore, we present Figure 6, the well bore response curve for Case I-2 with a flow rate of $8 \mathrm{lps}$, four times large than that of Case I-1. It is interesting to note from this figure that the well bore continues to pressurize even after breakdown has occurred. The pressure builds up to over $2000 \mathrm{~m}$ brfore the flow into the fracture causes the well to depressurize. Also, the higher flow rate causes large pressure differences between the well bore and the fracture tip. Consequently, more energy is available for fracture growth.

That the fracture propagation is directly related to injection rate is illustrated in Figure 7 in which fracture length as a function of time is shown for three different flow rates. It is clear that fracture propagates farther and more frequently as injection rate is increased.

In so far as minifrac experiments are concerned, flow rates of 2 lps or more are large. Field experiments usually involve injection rates of 1 lps or less. Nonetheless, the cases studied under Category I do provide insights into the dynamics of hydraulic fracturing. 
As already mentioned, the parameters used in the various cases are presented in Table 1. As is obvious from the table, many time-dependent variables are relevant to the problem of hydraulic fracturing. An exhaustive study of the sensitivity of the system to all the parameters is a time consuming task. Instead of embarking on such a task, a few parametric variations were tried in Case I-3, in which the injection rate was 4 lps. Using Case I-3 as the standard, the effects of varying Efficiency, $G_{c}, k_{\text {rock }}$ and well bore capacity were investigated. The results are shown in Figure 8 , which shows fracture length as a function of time. It is seen that increase in Efficiency significantly hastens the fracturing process. At the present time, no data are available to indicate how efficient the hydraulic fracturing process is in terms of energy expenditure. It appears that this issue may have to be addressed seriously if rigorous treatment of the hydraulic fracturing process is desired.

As one may expect, Figure 8 indicates that increased surface energy as well as increased permeability of the host rock cause the fracture propagation to slow down. Figure 8 especially highlights the importance of the well bore as a capacitor in controlling fracture propagation. The case shown in Figure 8 identified as "half well bore cap" was run by simply reducing the well bore volume by half. Figure 8 shows that as the capacity is decreased, the well bore charges up and realeases energy very quickly. As a result, the fracture extension events occur frequently but the magnitude of extension is diminished.

\subsubsection{Constant Pressure Injection}

In the cases studies in Cateogory $I$, the fluid injection rate was constant. As a contrast it is instructive to investigate the dynamics of the fracture when the fluid pressure is maintained at a prescribed magnitude at the injection pump. To this end; two cases were studied, Case II-1 and Case II-2. Both these cases started with a constant injection rate of 2 lps. This rate was continued for a little over 5 seconds by which time the first fracture segment had already been created and the pressure head in the well had already dropped to about $1000 \mathrm{~m}$. At this time, the hydraulic head in the volume element representing surface plumbing was fixed at $700 \mathrm{~m}$ for Case II-1 (650 $\mathrm{m}$ for Case II-2), by 
connecting that element to a boundary node. This simulated a constant pressure head of $400 \mathrm{~m}$ at the injection pump. Recall that the least principal stress has been assumed to be equivalent to about $624 \mathrm{~m}$.

In Figure 9A we show the injection rate as a function of time at the pump over a small interval of time immediately preceding and succeeding the instant at which the constant head condition was imposed. The corresponding well bore transients are shown in Figure 9b and the fracture length evolution in Figure 9D. The pressure history in the fracture at a location $0.5 \mathrm{~m}$ from the well bore is shown in Figure 9C. Figure 9A shows that the injection rate remains constant for less than 0.4 seconds following the imposition of the constant heads, after which the injection rate dramatically increases in a series of incremental steps, separated by decay in between the step-wise increases. It appears that as each new fracture segment is created the increase in the fracture aperture (and hence, the fracture permeability) and the fracture volume cause the injection rate to rise at the pump.

Figure 9B shows that although the pressure is held constant at the pump, the dramatic continuous increase in permeability in a fracture that is continuously propped open by the pump enables the water to flow as freely into the fracture as it can flow in to the well bore from the pump. As a result, the pressure in the well bore gradually drifts downwards as a function of time. One of the consequences of maintaining constant pressure at the pump is that the pressures in the well bore and in the fracture remain well above the least principal stress (Figures $9 B$ and 9C), leading to an enhancement of fracture permeability. Figure 9D illustrates that the flow rate increase following 5.4 seconds is reflected in an accelarated fracture propagation.

The corresponding Figures for Case II-2, in which the the hydraulic head was maintained at $650 \mathrm{~m}$, are given in Figures $10 \mathrm{~A}$ through $10 \mathrm{D}$.

Both cases II-1 and II-2 show that constant pressure injection at heads in excess of the least principal stress lead to an ever-increasing flow intake rate at the pump and consequently, very rapid and very frequent fracture propagation. In both these cases the interval between successive events was of the order of 0.01 seconds. One would suspect 
that these cases indicate the type of phenomena that can be expected during Massive Hydraulic Fracturing (MHF). According to Thomas Doe (personal communication, 1987) this type of pressure transient patterns are sometimes observed during mini-frac experiments.

\subsubsection{Punctuated Injection}

All the experiments performed under category III consisted of four constant-rate injection cycles separated by three periods of shut in and bleed off. In each case the injection period lasted 60 seconds, the shut in period, 60 seconds and the bleed off period, 180 seconds.

Cases III-1 and III-2 involved a constant injection rate of 0.2 lps. For case III-3, the rate was 0.4 lps and for case III-4, the rate was 1 lps. Cases III-1 and III-2 were also used to investigate the importance of the assumed aperture and compressibility of the newly formed fracture, when its fluid pressure is less than $\sigma_{\mathrm{b}, \min }$.

For cases III-1 and III-1B, the fracture compressibility was assumed to be $3 \times 10^{-11} \mathrm{~Pa}^{-1}$ while for cases III-2 ans III-2B, it was assumed to be $1 \times 10^{-11} \mathrm{~Pa}^{-1}$. The initial aperture of the nascent fracture was assumed to be 20 microns for cases III-1 and III-2. It was assumed to be 10 microns for cases III-1B and III-2B. The flow rate history for a typical punctuated injection pattern is shown in Figure 11. In this figure, the rate of injection is constant at 0.2 lps.

We first consider the sensitivity of the well bore pressure response to the assumed compressibility and aperture. In Figure $12 \mathrm{~A}$ is presented the well bore pressure response history for case III-1. Figure 12B is a similar plot for case III-2B. As Table 1 shows, these two cases constitute two extreme conditions. CasellI-1 represents a relatively soft, wide fracture while case III-2B represents a stiff, narrow fracture.

A striking feature of Figure $12 \mathrm{~A}$ is that for all the cycles the shut in curve shows a prominent break in the curve at the least principal stress. This break clearly helps identify the least principal stress in an unambiguous fashion. In contrast, Figure 12B shows a substantially different pressure transient pattern, characterized by pronounced peaks in 
the reinjection curves. In Figure 12A, the least principal stress can be estimated from either the reinjection data or from the shutin data. It appears as though a softer, open fracture is more conducive to the identification of the least principal stress from pressure transient data.

The fact that Figures $12 \mathrm{~A}$ and $12 \mathrm{~B}$ look noticeably different in pattern suggests that a knowledge of the aperture and compressibility of the nascent fracture may be important in quantifying the hydraulic fracturing process. As an added example, we show in Figure 12C, the well bore pressure transient history for case III-2 $\left(\mathrm{a}_{\mathrm{v}, \mathrm{f}}=1 \times 10^{-11} \mathrm{~Pa}^{-1}\right.$, aperture $=20$ microns. This curve too shows a pronounced peaked nature of the reinjection curve. Note that for case III-2B the shut in curve remains consistently above the least principal stress until bleed off is commenced. However, both Figures $12 \mathrm{~A}$ and $12 \mathrm{C}$ show that the shut in pressure intersects the least principal stress. It is not clear, in the case of case III-2B, if the shut in period was not long enough or if the avrage pressure of the system at shut in remains high because of the relatively small volume of the stiff, narrow initial fracture. The pressured head in the fracture element at a location $0.5 \mathrm{~m}$ away from the well bore is shown in Figures $13 \mathrm{~A}, 13 \mathrm{~B}$ and $13 \mathrm{C}$.

A little digression is in order here. The basis for using hydraulic fracturing as a tool to estimate in situ stresses is that as the fluid pressure in the fracture equals and exceeds the least principal stress, the stiffness of the fracture decreases drastically. As a result, the fluid mass capacity of the fracture given by (3) increases significantly. It is therefore necessary to verify that the algorithm indeed simulates this feature properly. To this end Figure 14 shows, for one particular case, the fluid mass capacity of the fracture element nearest the well bore as a function of fluid pressure. Note that the figure shows an step like increase in the capacity function as the fluid pressure exceeds the least principal stress of $624 \mathrm{~m}$. As a related information, we show in Figure 15 the variation in the fracture aperture for the same fracture element, as a function of fluid pressure. As required by theory we do see a sharp increase in the aperture as the fluid pressure exceeds least principal stress. In Figure 15 the kink in the ascending portion of the curve is of interest. This kink illustrates the fact that as the fluid pressure falls within the fracture at the instant of fracture extension, water has to expand. To accomodate this the fracture 
aperture must increase. This magnitude of this increase will of course be very small because the magnitude of the pressure drop is quite small (approximately $20 \mathrm{~m} \cdot \mathrm{head}$ ).

We now pass on to consider the effect of injection rate on the pressure transients in the well bore. In Figures 16A, 16B and $16 \mathrm{C}$ are presented,respectively, the well bore response for three different flow rates: 0.2 lps (Case III-2); 0.4 lps (Case III-3); and 1.0 lps (Case III-4). In all these cases the aperture and the compressibility of the newly formed fracture was assumed to be 20 microns and $1 \times 10^{-11} \mathrm{~Pa}^{-1}$. Apart from the fact that the fracture propagates further and more frequently at higher flow rates, the figures illustrate that the reinjection curve becomes more and more peaked as the flow rate increases. Also, for Case III-4 (Figure $16 \mathrm{C}$ ), the shut in pressure does not fall below the least principal stress.

We now take a closer look at the pressure transients by plotting the results on an expanded scale as shown in Figures $17 \mathrm{~A}$ through $17 \mathrm{C}$. These figures show the reinjection and shut in data for the second injection cycle for cases III-1, III-2 and III-4. Of these, Figure 17A perhaps represents what one would like to obtain in a minifrac experiment: the reinjection curve significantly bends over exactly at the least principal stress. The point of the break in slope unambiguously indicates the least principal stress. In constrast, Figure 17B shows that the reinjection curve cuts right across the least principal stress line without any break in the slope. Indeed one cannot use the reinjection portion of the curve in Figure 17B to estimate the least principal stress. This effect is even more pronounced in the case of Figure 17C. Looking at the shut in portions of the curves in Figures $17 \mathrm{~A}$ through $17 \mathrm{C}$, we see that both Figures $17 \mathrm{~A}$ and $17 \mathrm{~B}$ clearly show a break in slope as the shut in curve crosses the least principal stress line and unambiguously define the least principal stress. However, the shut in pressure is featureless in Figure $17 \mathrm{C}$ becuase the shut in pressure in this case does not fall below the least principal stress during the shut in period. The inference that one could draw from Figures $17 \mathrm{~A}$ through $17 \mathrm{C}$ is that low flow rates and compliant fractures are more conducive to preserving slope breaks in reinjection and shut in curves than high flow rates and stiff fractures. 
In conventional interpretation of hydraulic fracture data one assumes for simplicity that the fracture remains essentially closed (zero aperture ?) when the fluid pressure within the fracture falls below the least principal stress. Nevertheless the parameteric results presented above suggest that a knowledge of the aperture and compressibility of the nascent fracture may in fact be essential for a detailed understanding of the hydraulic fractruring process.

\subsubsection{Step-Rate Injection}

Finally, we investigate the possibility of estimating the least principal stress through a step-rate injection test on an already-created hydraulic fracture. The logic behind this experimental procedure is as follows. Although the fracture tends to close appreciably when the fluid pressure in the fracture falls below the least principal stress, the permeability of the fracture could still be significantly larger than the surrounding rock. As a result, the fracture can accept measurable quantities of water at injection pressures which remain less than the least principal stress. Therefore, under conditions when the injection pressure in the well bore remains less than $\sigma_{h \text {,min }}$, one would expect the injection rate to increase directly with increased injection pressure. However, when the injection pressure equals or exceeds the least principal stress, the greatly enhanced fracture permeability and the initiation of the fracturing process will prevent excessive injection pressures, independent of the flow rate. Thus if one were to carry out a steprate injection test on an existing hydraulic fracture, one should be able to identify least principal stress by observing the corrletion between injection rate and injection pressure, Least principal stress will be that pressure at which injection pressure becomes independent of injection rate.

Towards testing the aforesaid line of reasoning, two experiments (Cases IV-2A and IV-2) were conducted. In both cases the same parameters as that of Case III-2 were used. Both cases were started with a constant rate injection of 0.2 lps for 60 seconds to create a fracture. Following this, a 60-second shut in and a 30 second bleed off were allowed. Beyond this initial cycle, Case IV-2A and IV-2 were subjected to different step-rates of injection. In Case IV-2A the flow rates were, $0.002 \mathrm{lps}, 0.004 \mathrm{lps}, 0.008 \mathrm{lps}$ and $0.02 \mathrm{lps}$ 
and each of these steps lasted for 600 seconds. In case IV-2, the flow rates were $0.02 \mathrm{lps}$, $0.04 \mathrm{lps}, 0.08 \mathrm{lps}$ and $0.01 \mathrm{lps}$. Each of these rates was maintained for 60 seconds before shutting the pump in. The injection histories for each of these cases are given in Figures 18A and 18B. The corresponding pressure transients observed at the well bore are given in Figures 19A and 19B.

In a broad sense the results shown in Figures $19 \mathrm{~A}$ and $19 \mathrm{~B}$ do support the current reasoning that step rate tests can be useful in identifying least principal stress. Indeed, the figure show that for rates in excess of 0.02 lps in the problem of interest, the injection pressure is dictated by the least principal stress plus a small over pressure. However, on a careful look at the figures we note an additional point of interest. Note that in Case IV-2A the 0.02 lps rate was maintained for 600 seconds whereas in Case IV-2, the same rate was maintained only for 60 seconds. A consequence of this variation in duration of injection is that in Figure 19A the injection pressure for the 0.02 lps rate reaches least principal stress whereas in Figure 19B it does not. The point worth recognizing here is that the notion of an injection pressure corresponding to an injection rate in a transient problem is a qualitative one. If we have a fracture of finite length in a relatively tight rock, the pressure will eventually build up to the least principal stress whatever be the flow rate, because the fracture volume is finite. Therefore, some caution may be in order before one relies too heavily on the step-rate injection test as a means of estimating least principal stress.

\subsubsection{Threshold Injection Rate}

The notion of step-rate injection discussed above can be viewed from a different perspectIVe. Recognize that when $p_{f}<\sigma_{h, \text { min }}$, the fracture may still have significant permeability in comparison to the rock. Therefore, it is reasonable to expect that at appropriately low injection rates the fracture will effectIVely transmit to the rock all the injection fluid that is entering it (the fracture), with the fluid pressure remaining very much below the over pressure. In other words, the fluid pressure will never sufficiently build up in the fracture to lead to fracture extension. The inference then is that the 
fracture can propagate only if the injection rate exceeds a threshold value. The magnitude of this threshold pressure will be dominantly controlled by the fracture length and the rock permeability.

The notion of threshold injection rate was investigated with two cases, namely, Case IVA and Case IV-5. In both cases punctuated injection was used and the injection patterns were identical. The 300 -second injection periods were separated by periods of shtuin and bleed off. The rates used were, $0,0025 \mathrm{lps}, 0.005 \mathrm{lps}, 0.01 \mathrm{lps}$ and $0.025 \mathrm{lps}$. In case IVA the fracture length was $5.17 \mathrm{~m}$ and the rock permeability was $5 \times 10^{-15} \mathrm{~m}^{2}$. In case IV-5, the fracture length was $2.85 \mathrm{~m}$ and the rock permeability, $1 \times 10^{-15} \mathrm{~m}^{2}$. The other parameters were identical for both cases and are shown in Table 1.

The well bore pressure responses for both cases are shown in Fig. 20A (case IV-4A) and Fig. 20B (case IV-5). Becuase of the higher rock permeability and the larger fracture surface, the well bore pressure for case IV-4A (Fig. 20A)never builds up above the least principal stress. Thus, the fracture does not extend in this case. In case IV-5 (Fig. 20B), however, both the shorter fracture and the smaller rock permeability are conducive to a build up of the well bore pressure beyond $\sigma_{h, \min }$, leading to fracture extension for the flow rate of $2 \times 10^{-5} \mathrm{lps}$.

In a qualitative sense, both case IV-4A and IV-5 lend credibility to the notion of a threshold injection rate. Nevertheless, a note of caution is appropriate here. If one looks at any of the presure transient segments in FIgs. 20A and 20B, one finds that these transients show, for the periods of injection, a gradual increase in the well bore pressure with time. The problem is therefore truly transient and not steady state. Hence if the injection rate were to be maintained for a long enough period (the smaller the flow rate, the longer the period), the pressures would have built up sufficiently to cause fracture extension. Therefore, one can not precisely define a threshold injection rate in terms of quantity. However, one may use threshold injection rate as a qualitative concept of some practical utility. If, during the injection phase, the presure transient curve is "close" to being horizontal, then that injection rate cannot lead to fracture extension. 


\section{SUMMARY AND DISCUSSION}

In the present work we have developed a numerical algorithm, HUBBERT, to simulate the hydrodynamics of a propagating vertical, rectangular fracture in an elastic porous medium. Based on the IFD method, this algorithm assumes fracture geometry to be prescribed. The breakdown and the creation of the incipient fracture is carried out according to the Hubbert-Willis theory. The propagation of the fracture is based on the criterion provided by Griffith, based on energy considerations. The deformation properties of the open fracture are based on simple elasticity solutions. The fracture is assumed to have an elliptical shape to a distance equal to the fracture height, beyond which the ashape is assumed to be parallel plate.

A consequence of Griffith's criterion is that the fracture must propagate in discrete steps. In this discrete process the well bore acts as an energy capacitor. In mini fractures, the void volume in the fracture is usually much smaller than that of the well. Hence, the capacitor effect is dominated by the well bore. The propagation of the fracture itself is assumed to be an instantaneous phenomenon. At this instant energy is released accompanied by a pressure decline. The pressure decline, in turn requires that water expands. This expansion must be accompanied by a small increase in the fracture aperture. The released energy must do different kinds of work during the fracture extension. Work must be done against the least principal stress to increase the fracture aperture. Work must also be done, if any harmonic tremors of the wall are created as suggested by Majer and Doe (1986). Energy will also be lost in the form of seismic and acoustic radiation. For these reasons, one could conclude that only a fraction of the available energy goes actually towards creating a new fracture surface.

The parametric studies carried out suggest that for a clear understanding of the hydrodynamics of the hydraulic fracture many hitherto unrecognized parameters must be better understood. Among these parameters one might mention, efficiency, aperture of the newly formed fracture, stiffness of the newly formed fracture, relation between fracture aperture and permability, and well bore compliance. The results of the studies indicate that the patterns of pressure transients and the magnitudes of fracture length 
appear to conform to field observations. In particular, the discrete nature of fracture propagation as well as the relevant time scales of interest inferred from the present work seem to be corroborated by seismic monitoring in the field. The results suggest that the estimation of least principal stress can be relably made either with shut in data or with reinjection data provided that injection rates are very small. How small is small will have to be investigated as a separate issue. Difficulties in the interpretation process may be encountered if the newly formed fracture is very stiff or has a very small aperture. The use of step-rate test for in situ stress estimation may have to be looked into greater detail.

There exist two important issues related to in situ stress measurement that have not been addressed in the present work. These relate to a) fracture reopening pressure and b) the estimation of maximum principal stress. Both these issues require for their resolution the incorporation of the stress field very close to the bore hole in to the numerical algorithm. In principle this could be computationally achieved by modifying the present algorithm.

The algorithm proposed in the present work can be useful in interpreting field data. 


\section{NOTATION}

a compressibility of a porous material

$a_{y, f}$ compressibility of a fracture

$A_{f}$ area of fracture wall

$b_{\text {ratio }}$ aperture ratio, $\frac{w_{f, k}}{w_{f}}$

$d_{l b}$ distance from node $l$ to the interface $l b$

$d_{1 m}$ distance from node $l$ to the interface $I m$

e void ratio of a porous material

e void ratio of a fracture

$e_{o, f}$ initial void ratio of nascent fracture

E Youngs Modulus

$E^{\prime} \quad \frac{E}{\left(1-\nu^{2}\right)}$

g accelaration due to gravity

$G_{c}$ crack extension force

$G_{l}$ volumetric injection rate

$\mathrm{H}_{\mathrm{f}}$ height of vertical fracture

k permeability of a porous material

$k_{f} \quad$ permeability of a fracture

$k_{\operatorname{lm}}$ mean poermeability at interface $\mathrm{lm}$

$\bar{k} \quad$ mean permeability 
K hydraulic Conductivity of rock

$M_{c, 1}$ fluid Mass Capacity of element l

$\overrightarrow{\mathbf{n}}_{\operatorname{lm}}$ unit outer normal to interface lm

p fluid pressure

Pb breakdown pressure

Pf fluid pressure in fracture

po reference fluid pressure

pop over Pressure in fracture

Q volumetric injection rate

$\mathrm{S}_{\mathrm{s}}$ specific Storage Coefficient of the rock

$\Delta t_{1}$ stable time step for element 1

$\mathrm{U}_{\mathrm{lm}}$ conductance of interface $\mathrm{lm}$

$\mathrm{U}_{\mathrm{lb}}$ conductance of interface $\mathrm{lb}$

$V_{f}$ void volume of the fracture

$V_{\circ}$ reference volume

$\mathrm{V}_{\mathrm{s}}$ volume of solids in an element

$w_{f}$ aperture of fracture

$w_{\text {f }}$ aperture used in estimating permeability $W_{c}$ energy stored in the rock around a fracture

$\mathrm{X}_{\mathrm{f}}$ fracture Length 
z elevation

$z_{1}$ elevation of element 1

$\beta$ compressibility of water

$\Gamma_{1}$ surface bounding element 1

$\Delta \Gamma_{1}$ a surface segment

$\lambda$ time-averaging weight

$\mu$ viscosity of fluid

• Poisson's Ratio

$\rho \quad$ fluid density

$\sigma \quad$ stress

$\sigma_{c}$ a critical stress, locally defined

$\sigma_{\mathrm{n}} \quad$ normal stress

$\sigma \quad$ effective stress

$\sigma_{\mathrm{h}, \min }$ least Principal Horizontal Stress

$\sigma_{\mathrm{h}, \max }$ maximum Principal Horizontal Stress

$\psi \quad$ pressure head

$\psi_{1}$ average pressure head over element 1 


\section{ACKNOWLEDGEMENTS}

My sincere thanks are due to Mark D. Zoback and Neville G. W. Cook for many. discussions on hydraulic fracturing. Based on field experience, Mark provided insights in to the type of pressure transient issues that are of relevant with reference to in situ stress measurement. Applying the theory of elasticity, Neville provided thoughts on the interactions between energy, stress and fluid pressure in the vicinity of a fracture. These were valuable in the formulation of the model used in the present study. Thanks are also due to E.L. Majer and T.W. Doe. Ernie shared his knowledge of the process of hydraulic fracturing as observed through seismic instruments and Tom briefed me on his experiences with creating hydraulic fractures both in the laboratory and in the field. All the four mentioned above reviewed this report and gave constructive criticisms.

Partial support for this work, mainly in the form of computer time, was provided by the U.S. Department of Energy through Contract No. DE-AC03-76SF00098, by the Assistant Secretary for Energy Research, Office of Basic Energy Sciences, Division of Engineering and Geosciences. 


\section{REFERENCES}

Advani, S.H., Finite Element Model Simulations Associated with Hydraulic Fracturing, SPE/DOE 8941, Soc. Pet. Eng., AIME, Symposium on Unconventional Gas Recovery, 1980

Cinco-Ley, H, F. Samaniego and A. Dominguez, Transient Pressure Behavior for a Well with a Finite Conductivity Vertical Fracture, Soc. Pet. Eng. J., 253-264, August, 1978

Cleary, M.P., M. Kavvadas and K.Y. Lam, Development of a Fully Three Dimensional Simulator for Analysis and Design of Hydraulic Fracturing, SPE/DOE 11631, Soc. Pet. Eng. AIME, Symposium on Low Permeability, 1983

Duff, I.S, MA28 - A Set of Fortran Subroutines for Sparse Unsymmetric Linear Equations, Report No. AERE-R-87, Department of Atomic Energy, Harwell, England, 1977

Hubbert, M.K. and D.G. Willis, Mechanics of Hydraulic Fracturing, Trans. Amer. Soc. Mining Eng., 210, 153-168, 1957,

Jaeger, J.C. and N.G.W. Cook, Fundamentals of Rock Mechanics, Chapman and Hall, London, Second Edition, 1976.

Majer, E.L. and T.W. Doe, Studying Hydrofractures by High Frequency Seismic Monitoring, Int. J. Rock Mech., 29 (3),185-199, 1986

Narasimhan, T.N., Multidimensional Numerical Simulation of Fluid Flow in Fractured Porous Media, Water Resources Res., 18(4), 1235-1247, 1982

Narasimhan, T.N., A.L. Edwards and P.A. Witherspoon, Numerical Model for Saturated-Unsaturated Flow in Defprmable Porous media, Part II: The Algorithm, Water Resources Res., 14(2), 255-261, 1978

Narasimhan, T.N. and P.A. Witherspoon, An Integrated Finite Difference Method for Analyzing Fluid Flow in Porous Media, Water Reousrces Res., 12(1), 57-64, 1976

Narasimhan, T.N. and P.A. Witherspoon, Numerical Model for Saturated-Unsaturated Flow in Deformable Porous Media, 1. Theory, Water Resources Res., 13(3), 657$664,1977$.

Narasimhan, T.N. and W.A. Palen, Interpretation of Hydraulic Fracturing Experiment, Monticello, South Carolina, Geophys. Res. Letters, 8(5), 481-484, 1982

Palen, W. A., The Roles of Pore Pressure and Fluid Flow in the Hydraulic Fracturing Process, Doctoral Dissertation, Mechanical Engineering, University of California, Berkeley, 1980. 
Settari, A. and M.P. Cleary, Three Dimensional Simulation of Hydraulic Fracturing, Paper No. 10504, Soc. Pet. Eng. AIME, 1982

Zoback, M.D. and B. C. Haimson, Proceedings of Workshop XVII, Workshop on Hydraulic Fracturing Stress Measurements, Monterey, California, December 2-5, 1981, U.S. Geological Survey Open File Report 82-1075, 1982 


\section{Table 1}

\section{Parameters Used in the Simulations}

Part I. Fixed Parameters

\begin{tabular}{|c|c|}
\hline Fracture & $\begin{array}{l}\text { Maximum length, } 10 \mathrm{~m} \\
\text { Height, } 3 \mathrm{~m}\end{array}$ \\
\hline Well & $\begin{array}{l}\text { Radius, } 0.075 \mathrm{~m} \\
\text { Permeability } 7.81 \times 10^{-5} \mathrm{~m}^{2}\end{array}$ \\
\hline Surface Pipe & $10 \mathrm{~m}$ long, $0.05 \mathrm{~m}$ radius \\
\hline Connector Pipe & $300 \mathrm{~m}$ long, $0.05 \mathrm{~m}$ radius \\
\hline Water & $\begin{array}{l}\text { Compressibility, } 4.1 \times 10^{-10} \mathrm{~Pa}^{-1} \\
\text { Viscosity } 10^{-3} \mathrm{~kg} / \mathrm{m} \cdot \mathrm{s} \\
\text { Density } 1000 \mathrm{~kg} / \mathrm{m}^{3}\end{array}$ \\
\hline Rock & $\begin{array}{l}\text { Youngs Modulus, } 2 \times 10^{10} \mathrm{~Pa} \\
\text { Porosity, } 0.05 \\
\text { Void Ratio, } 0.0526 \\
\text { Specific Storage } 2 \times 10^{-6} \mathrm{~m}^{-1}\end{array}$ \\
\hline $\begin{array}{l}\text { Breakdown Pressure Head } \\
\text { Total Stress at Fracture }\end{array}$ & $\begin{array}{l}1800 \mathrm{~m} \\
\sigma_{\mathrm{v}}=7.649 \times 10^{6} \mathrm{~Pa} \\
\sigma_{\mathrm{H}, \min }=6.119 \times 10^{6} \mathrm{~Pa}\end{array}$ \\
\hline $\begin{array}{l}\text { BRAT10 } \\
\text { Acceleration due to gravity }\end{array}$ & $\begin{array}{l}0.8 \\
9.80667 \mathrm{~m} / \mathrm{s}^{2}\end{array}$ \\
\hline
\end{tabular}




\begin{tabular}{|c|c|c|c|c|c|c|c|c|c|}
\hline \multicolumn{10}{|c|}{$\begin{array}{l}\text { Table } 1 \text { (cont.) } \\
\text { Parameters Used in the Simulations } \\
\text { Part 2. Variable Parameters }\end{array}$} \\
\hline \multirow[b]{2}{*}{ Case } & \multirow[b]{2}{*}{ Type } & \multicolumn{2}{|c|}{ Fracture } & \multirow[b]{2}{*}{ Efficiency } & \multirow[b]{2}{*}{$\begin{array}{l}\text { Surface Energy } \\
\mathrm{J} / \mathrm{m}^{2}\end{array}$} & \multirow[b]{2}{*}{$\begin{array}{c}\text { Flow Rate } \\
\mathrm{m}^{3} / \mathrm{sec}\end{array}$} & \multirow{2}{*}{$\begin{array}{l}\text { Surface Injection } \\
\text { Pressure } \\
\mathrm{m}, \mathrm{H}_{2} \mathrm{O}\end{array}$} & \multirow[b]{2}{*}{$\underset{\mathbf{m}^{2}}{\mathbf{k}_{\text {rock }}}$} & \multirow[b]{2}{*}{ Remarks } \\
\hline & & $\begin{array}{c}\text { Initial Aperture } \\
\text { m }\end{array}$ & $\underset{\mathrm{Pa}^{-1}}{\mathrm{av}}$ & & & & & & \\
\hline $1-1$ & $\begin{array}{l}\text { Constant } \\
\text { Injection Rate }\end{array}$ & $2 \times 10^{-5}$ & $3 \times 10^{-11}$ & 0.2 & 20 & $1 \times 10^{-8}$ & variable & $10^{-17}$ & $\cdot$ \\
\hline $1-2$ & $\begin{array}{l}\text { Constant } \\
\text { Injection Rate }\end{array}$ & $2 \times 10^{-8}$ & $3 \times 10^{-11}$ & 0.2 & 20 & $8 \times 10^{-3}$ & variable & $10^{-17}$ & \\
\hline $1-3$ & $\begin{array}{l}\text { Constant } \\
\text { Injection Rate }\end{array}$ & $2 \times 10^{-6}$ & $3 \times 10^{-11}$ & 0.2 & 20 & $4 \times 10^{-3}$ & variable & $10^{-17}$ & \\
\hline I-3A & $\begin{array}{l}\text { Constant } \\
\text { Injection Rate }\end{array}$ & $2 \times 10^{-5}$ & $3 \times 10^{-11}$ & 0.4 & 20 & $4 \times 10^{-3}$ & variable & $10^{-17}$ & \\
\hline I-3B & $\begin{array}{l}\text { Constant } \\
\text { Injection Rate }\end{array}$ & $2 \times 10^{-6}$ & $3 \times 10^{-11}$ & 0.2 & 40 & $4 \times 10^{-3}$ & variable & $10^{-17}$ & \\
\hline I-3C & $\begin{array}{l}\text { Constant } \\
\text { Injection Rate }\end{array}$ & $2 \times 10^{-6}$ & $3 \times 10^{-11}$ & 0.2 & 20 & $4 \times 10^{-8}$ & variable & $10^{-16}$ & \\
\hline$I-3 D$ & $\begin{array}{l}\text { Constant } \\
\text { Injection Rate }\end{array}$ & $2 \times 10^{-5}$ & $3 \times 10^{-11}$ & 0.2 & 20 & $4 \times 10^{-8}$ & variable & $10^{-17}$ & $\begin{array}{l}\text { well bore } \\
\text { capacity } \\
\text { cut in half }\end{array}$ \\
\hline II-1 & $\begin{array}{l}\text { Constant } \\
\text { Pressure Injection }\end{array}$ & $2 \times 10^{-5}$ & $3 \times 10^{-11}$ & 0.2 & 20 & variable & 700 & $10^{-17}$ & \\
\hline II-2 & $\begin{array}{l}\text { Constant } \\
\text { Pressure Injection }\end{array}$ & $2 \times 10^{-6}$ & $3 \times 10^{-11}$ & 0.2 & 20 & variable & 650 & $10^{-17}$ & \\
\hline III-1 & $\begin{array}{l}\text { Punctuated } \\
\text { Constant } \\
\text { Rate Injection }\end{array}$ & $2 \times 10^{-6}$ & $3 \times 10^{-11}$ & 0.2 & 20 & $2 \times 10^{-4}$ & variable & $10^{-16}$ & \\
\hline III-1B & $\begin{array}{l}\text { Punctuated } \\
\text { Constant } \\
\text { Rate Injection }\end{array}$ & $1 \times 10^{-5}$ & $3 \times 10^{-11}$ & 0.2 & 20 & $2 \times 10^{-4}$ & variable & $10^{-10}$ & \\
\hline
\end{tabular}


$-2$.

\begin{tabular}{|c|c|c|c|c|c|c|c|c|c|}
\hline \multicolumn{10}{|c|}{$\begin{array}{c}\text { Table } 1 \text { (cont.) } \\
\text { Parameters Used in the Simulations } \\
\text { Part 2. Variable Parameters }\end{array}$} \\
\hline \multirow[b]{2}{*}{ Case } & \multirow[b]{2}{*}{ Type } & \multicolumn{2}{|c|}{ Fracture } & \multirow[b]{2}{*}{ Efficiency } & \multirow[b]{2}{*}{$\begin{array}{l}\text { Surface Energy } \\
\qquad \mathrm{J} / \mathrm{m}^{2}\end{array}$} & \multirow[b]{2}{*}{$\begin{array}{l}\text { Flow Rate } \\
\mathrm{m}^{3} / \mathrm{sec}\end{array}$} & \multirow{2}{*}{$\begin{array}{l}\text { Surface Injection } \\
\text { Pressure } \\
\mathrm{m}_{3} \mathrm{H}_{2} \mathrm{O}\end{array}$} & \multirow[b]{2}{*}{$\frac{k_{\text {rot }}}{m^{2}}$} & \multirow[b]{2}{*}{ Remarks } \\
\hline & & $\begin{array}{l}\text { Initial Aperture } \\
\text { m }\end{array}$ & $\stackrel{\mathrm{av}}{\mathrm{Pa}^{-1}}$ & & & & & & \\
\hline III-2 & $\begin{array}{l}\text { Punctuated } \\
\text { Constant } \\
\text { Rate Injection }\end{array}$ & $2 \times 10^{-5}$ & $1 \times 10^{-11}$ & 0.2 & 20 & $2 \times 10^{-4}$ & variable & $10^{-16}$ & \\
\hline III-2B & $\begin{array}{l}\text { Punctuated } \\
\text { Constant } \\
\text { Rate Injection }\end{array}$ & $1 \times 10^{-5}$ & $1 \times 10^{-11}$ & 0.2 & 20 & $2 \times 10^{-4}$ & variable & $10^{-16}$ & \\
\hline III-3 & $\begin{array}{l}\text { Punctuated } \\
\text { Constant } \\
\text { Rate Injection }\end{array}$ & $2 \times 10^{-5}$ & $1 \times 10^{-11}$ & 0.2 & 20 & $4 \times 10^{-4}$ & variable & $10^{-16}$ & \\
\hline III-4 & $\begin{array}{l}\text { Punctuated } \\
\text { Constant } \\
\text { Rate Injection }\end{array}$ & $2 \times 10^{-6}$ & $1 \times 10^{-11}$ & 0.2 & 20 & $1 \times 10^{-8}$ & variable & $10^{-10}$ & \\
\hline Ill-5 & $\begin{array}{l}\text { Punctuated } \\
\text { Constant } \\
\text { Rate Injection }\end{array}$ & $2 \times 10^{-5}$ & $1 \times 10^{-11}$ & 0.2 & 20 & $2 \times 10^{-4}$ & variable & $10^{-16}$ & \\
\hline IV-2 & $\begin{array}{l}\text { Punctuated } \\
\text { Step Rate } \\
\text { Injection }\end{array}$ & $2 \times 10^{-6}$ & $1 \times 10^{-11}$ & 0.2 & 20 & $\begin{array}{l}2 \times 10^{-6} \\
4 \times 10^{-6} \\
8 \times 10^{-6} \\
1 \times 10^{-4}\end{array}$ & variable & $10^{-16}$ & \\
\hline IV-2A & $\begin{array}{l}\text { Punctuated } \\
\text { Step Rate } \\
\text { Injection }\end{array}$ & $2 \times 10^{-5}$ & $1 \times 10^{-11}$ & 0.2 & 20 & $\begin{array}{l}2 \times 10^{-6} \\
4 \times 10^{-6} \\
8 \times 10^{-6} \\
2 \times 10^{-6}\end{array}$ & variable & $10^{-10}$ & \\
\hline
\end{tabular}


Table 1 (cont.)

Parameters Used in the Simulations

Part 2. Variable Parameters

\begin{tabular}{|c|c|c|c|c|c|c|c|c|c|}
\hline \multirow[b]{2}{*}{ Case } & \multirow[b]{2}{*}{ Type } & \multicolumn{2}{|c|}{ Fracture } & \multirow[b]{2}{*}{ Efficiency } & \multirow[b]{2}{*}{$\begin{array}{l}\text { Surface Energy } \\
\mathrm{J} / \mathrm{m}^{2}\end{array}$} & \multirow[b]{2}{*}{$\begin{array}{c}\text { Flow Rate } \\
\mathrm{m}^{3} / \mathrm{sec}\end{array}$} & \multirow{2}{*}{$\begin{array}{c}\text { Surface Injection } \\
\text { Pressure } \\
\text { m, } \mathrm{H}_{2} \mathrm{O}\end{array}$} & \multirow[b]{2}{*}{$\mathbf{k}_{\text {rock }}$} & \multirow[b]{2}{*}{ Remarks } \\
\hline & & $\begin{array}{c}\text { Initial Aperture } \\
\text { m }\end{array}$ & $\underset{\mathrm{Pa}^{-1}}{\mathrm{av}}$ & & & & & & \\
\hline IV-5A & $\begin{array}{l}\text { Punctuated } \\
\text { Step Rate } \\
\text { Injection } \\
\text { Punctuated } \\
\text { Step Rate } \\
\text { Injection }\end{array}$ & $2 \times 10^{-6}$ & $1 \times 10^{-11}$ & 0.2 & 20 & $\begin{array}{c}2.5 \times 10^{-6} \\
5 \times 10^{-6} \\
1 \times 10^{-6} \\
2.5 \times 10^{-6} \\
2.5 \times 10^{-6} \\
5 \times 10^{-6} \\
1 \times 10^{-6} \\
2.5 \times 10^{-6}\end{array}$ & variable & $1 \times 10^{-16}$ & . \\
\hline
\end{tabular}




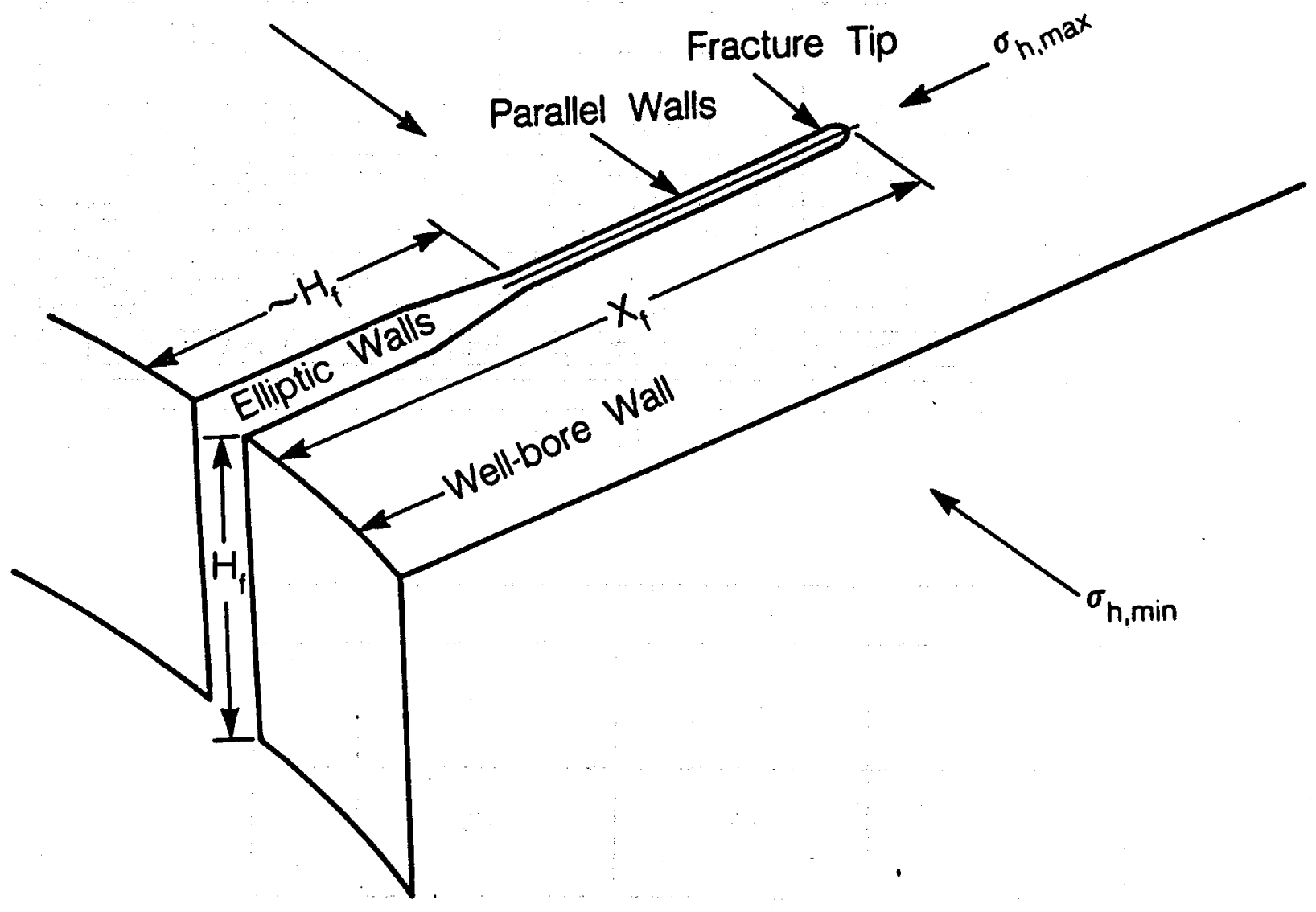

XBL. 873-9981

Figure 1: Schematic representation of a vertical fracture. 
$-50-$

\begin{tabular}{|c|c|c|c|c|c|c|c|c|c|c|c|c|c|c|c|c|}
\hline \multicolumn{17}{|c|}{215} \\
\hline \multicolumn{17}{|c|}{214} \\
\hline \multicolumn{17}{|c|}{213} \\
\hline \multicolumn{17}{|c|}{212} \\
\hline \multicolumn{17}{|c|}{211} \\
\hline \multicolumn{17}{|c|}{210} \\
\hline \multicolumn{17}{|c|}{209} \\
\hline \multicolumn{2}{|c|}{208} & \multicolumn{2}{|c|}{408} & \multicolumn{2}{|c|}{608} & \multicolumn{2}{|c|}{808} & \multicolumn{2}{|c|}{1008} & \multicolumn{2}{|l|}{1208} & 1408 & 1608 & 1808 & \multicolumn{2}{|l|}{2008} \\
\hline 107 & 207 & 307 & 407 & 507 & 607 & 707 & 607 & $907 \mid 1$ & 1007 & 110712 & $207 \mid 1$ & $1307 \mid 1407 / 1$ & $1507 \quad 1607$ & fror 1807 & $1907 \mid 2007$ & \\
\hline 106 & 206 & $\rightarrow+1$ & & - & & & & 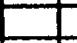 & & 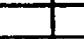 & & 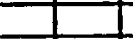 & - & - & 2006 & \\
\hline$\frac{105}{77567}$ & 205 & $\frac{305}{304}$ & & & & & & 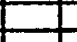 & & $\therefore$ & & $\square$ & 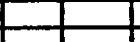 & & 2005 & \\
\hline 77767 & 年5 & $\frac{304}{303}$ & & & & & & & & - & & - & 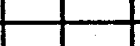 & - & 2004 & \\
\hline & 72 & 302 & & & & & & & & & & & & & $\mid$ & \\
\hline & 71 & 301 & 401 & 501 & 601 & 701 & 801 & 90111 & 1001 & $1101 / 12$ & \begin{tabular}{|l|l|}
201 & 1 \\
\end{tabular} & $130 \mid 1401$ & 15011601 & |1701|1801 & 19012001 & \\
\hline
\end{tabular}

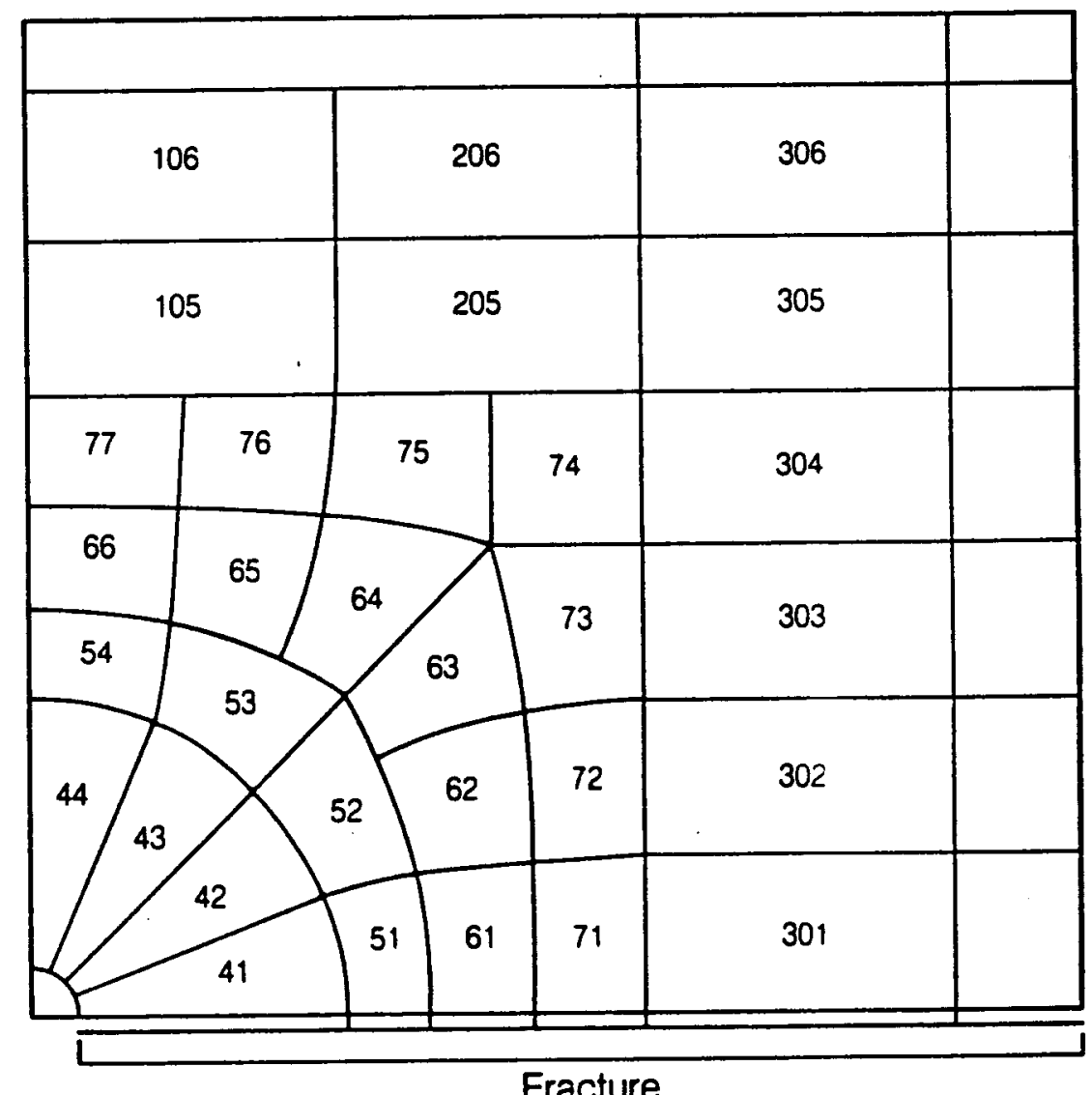

XBL $873-9982$

Figure 2: The IFD mesh used in the simulation studies. 


\section{single vertical fracture cinco-ley solution}

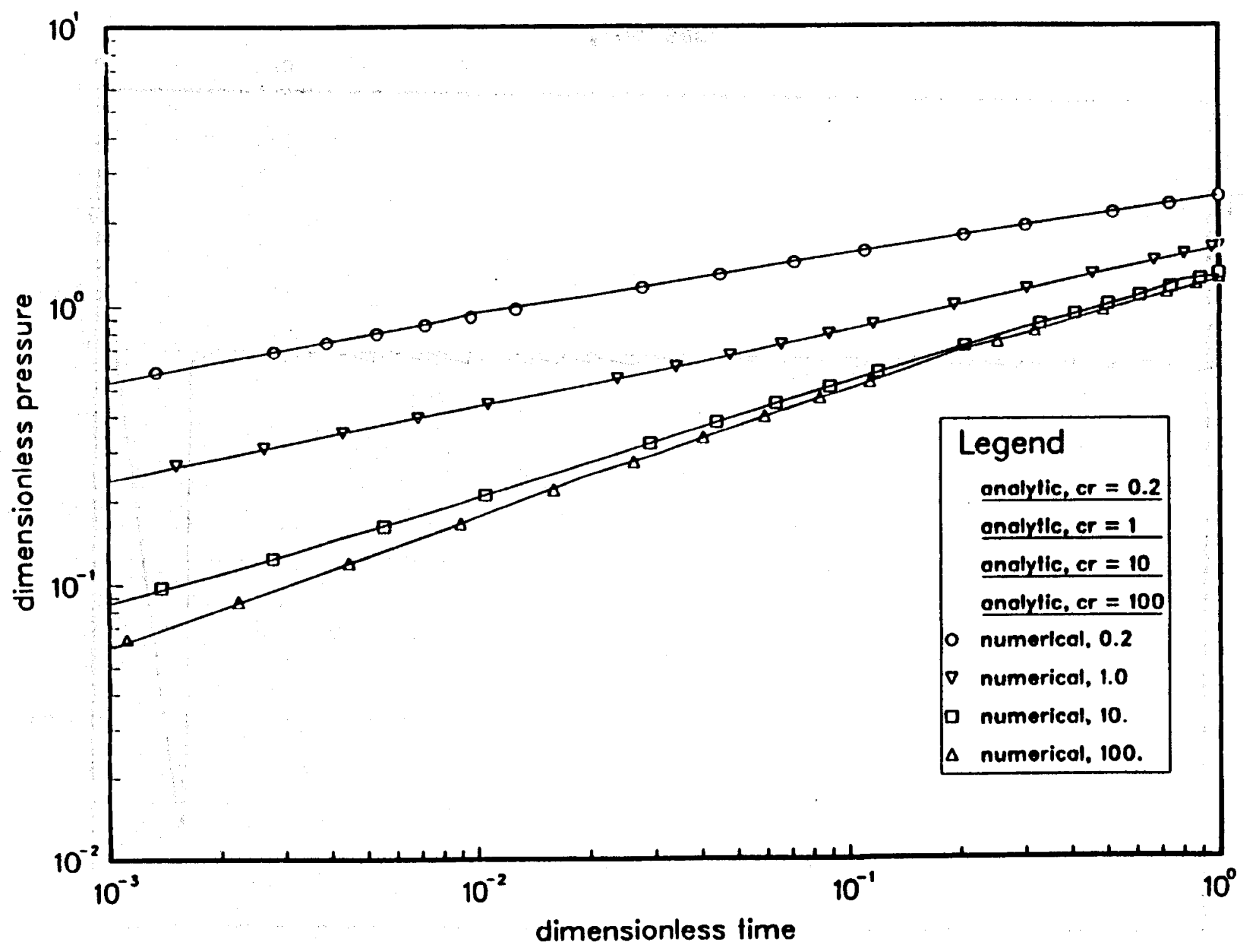

Figure 3: Flow to a well with a single vertical fracture of fixed geometry. Comparison of analytical and numerical results. 


\section{case $1-1$ continuation \\ well bore pr. head}

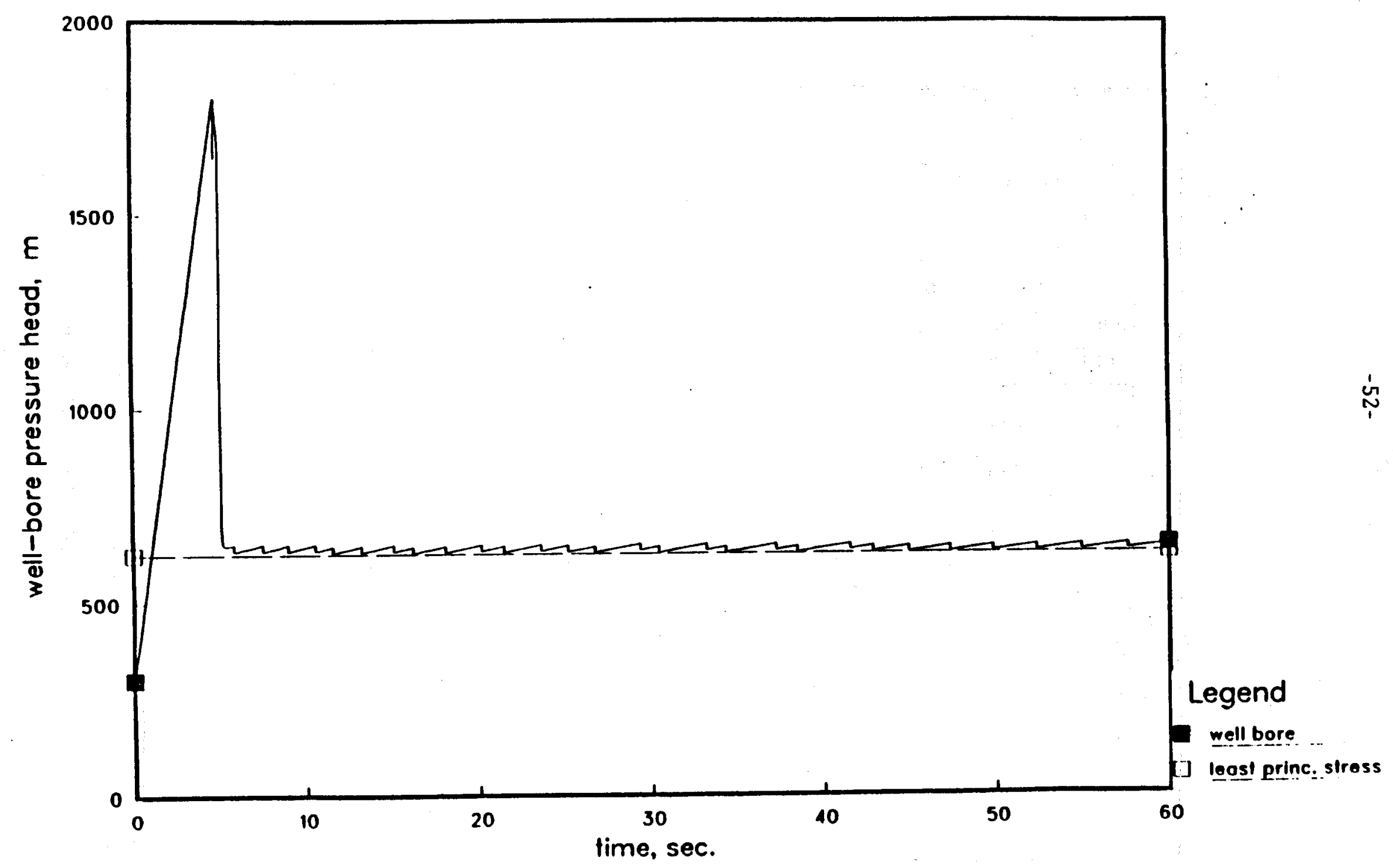

Figure 4A: Case 1-1: Constant flow rate of 2 lps. Well bore pressure head as a function of time. 
case $1-1$ continuation
node 100 pressure head

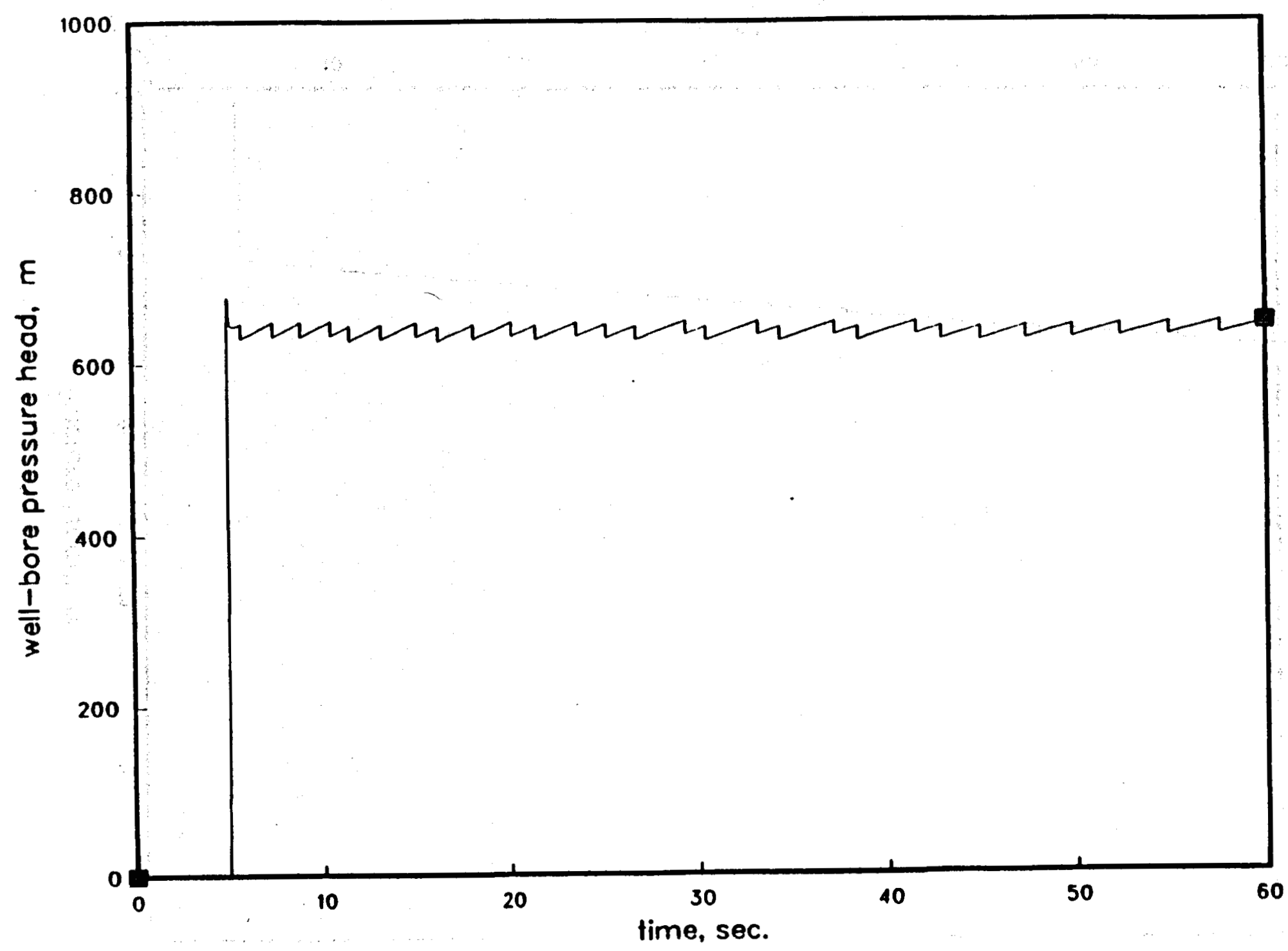

Figure 4B: Case 1-1: Constant now rate of 2 lps. Pressure head in fracture $0.5 \mathrm{~m}$ away from well. 
case $1-1$ continuation frac length versus time

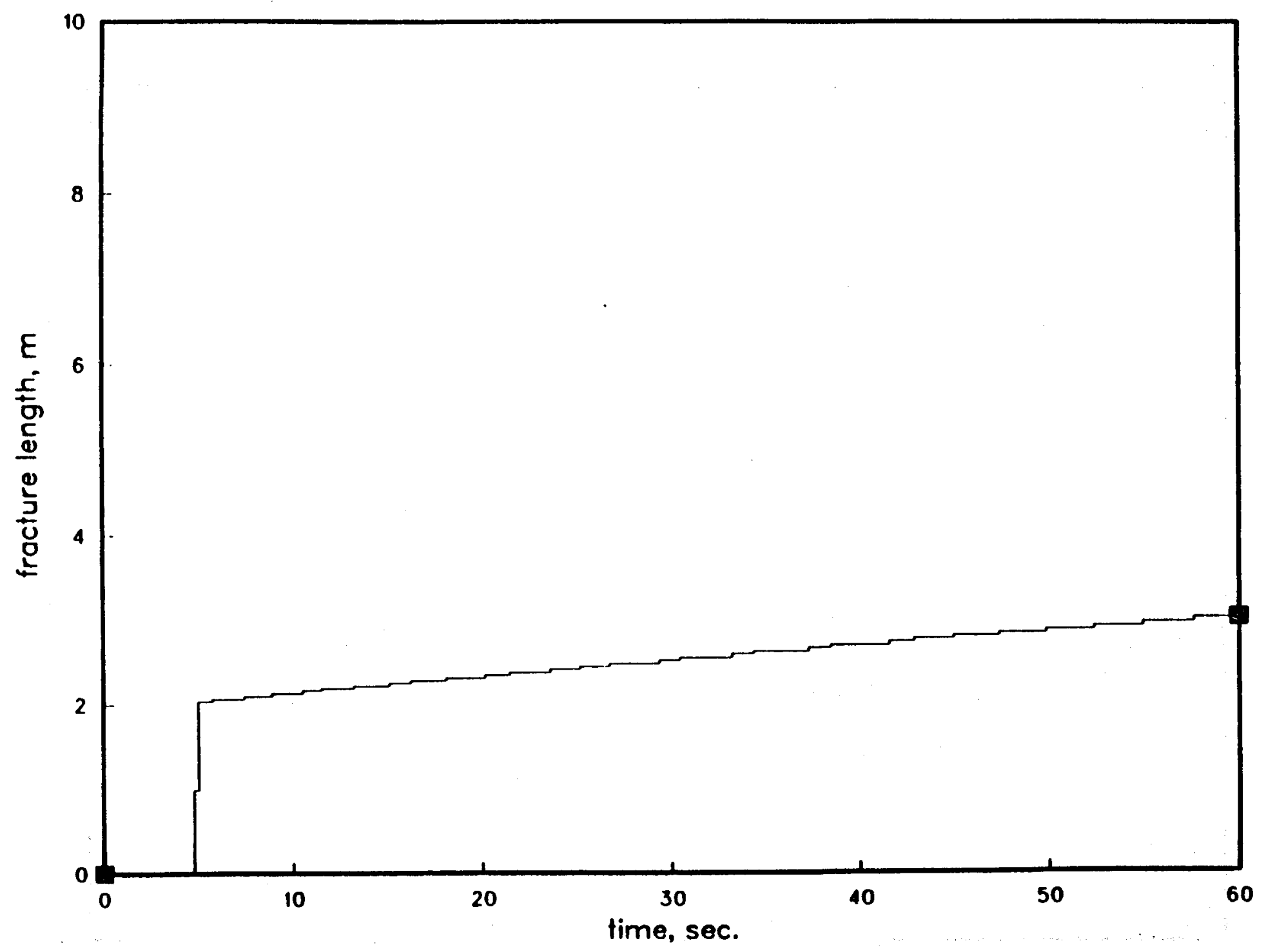

Figure 4C: Case I-1: Constant flow rate of 2 lps. Fracture length as a function of time. 


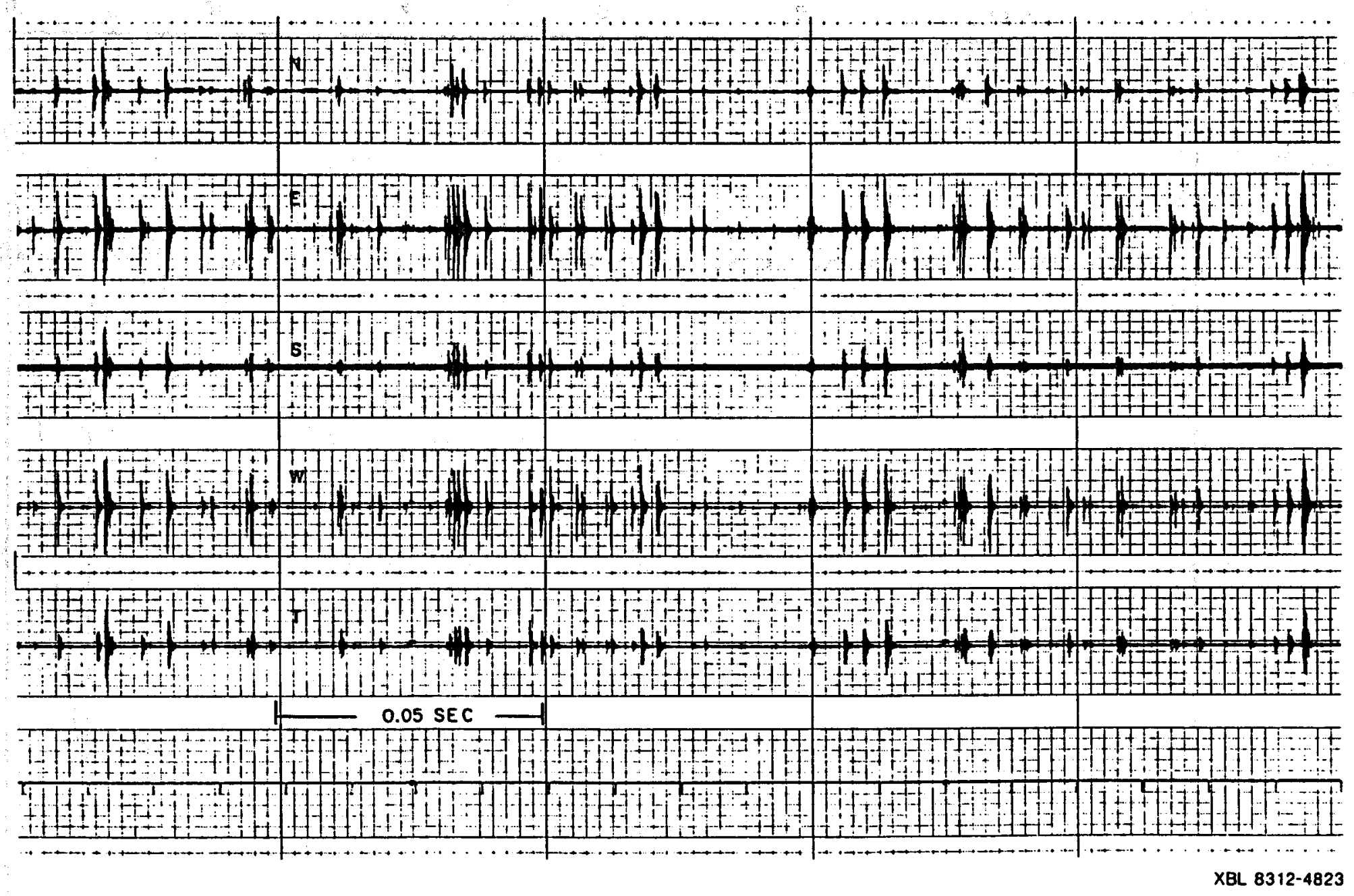

Figure 5: Typical occurrence rate of seismic activity during the salt block experiment. Notice the banded nature of the activity. 


\section{casel-2: constant flow rate \\ well bore pr. heads}

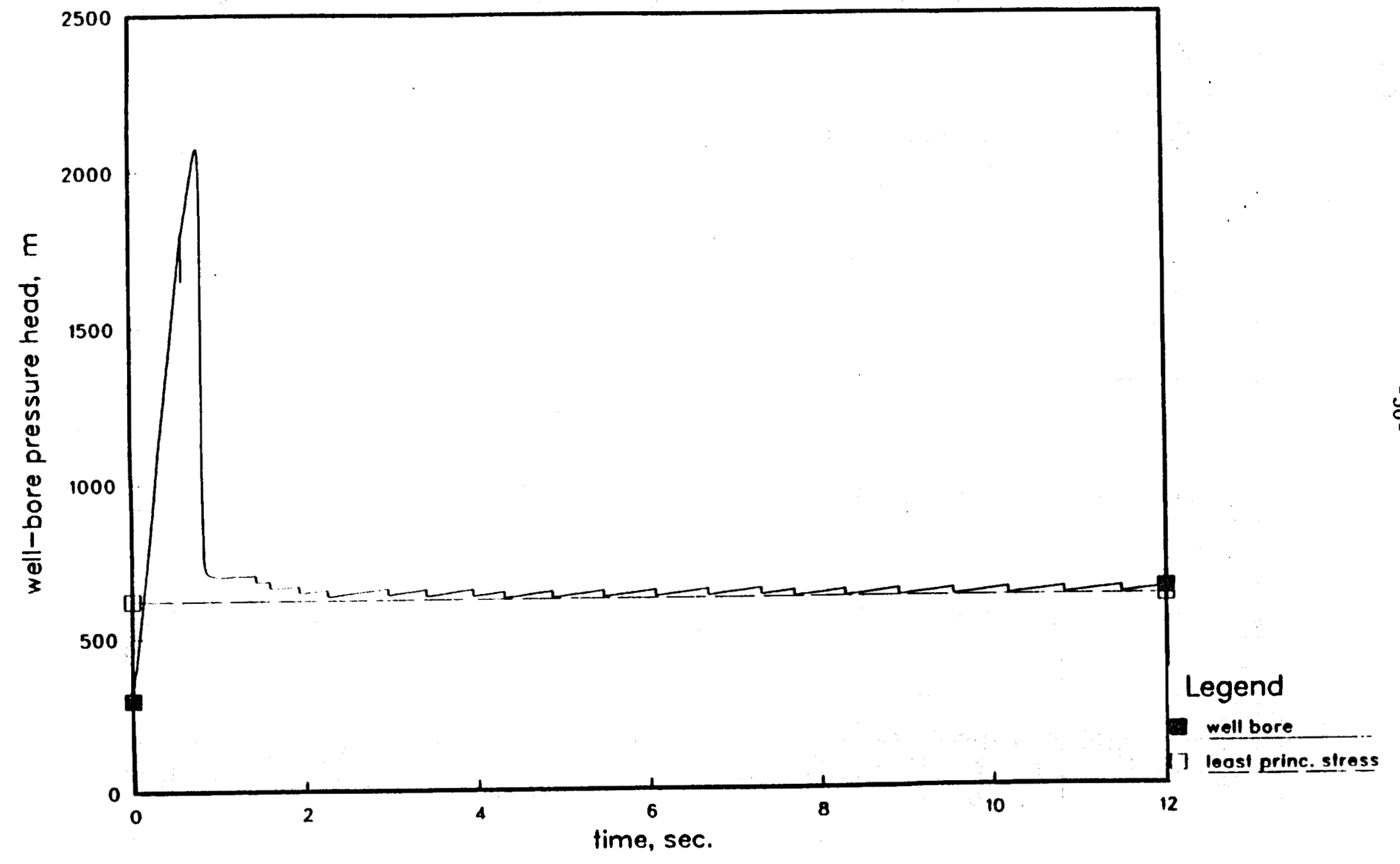

Figure 6: Case I-2: Constant now rate of 8lps. Well bore pressurc head as a function of time. 
Fac. length and Flow rate versus time

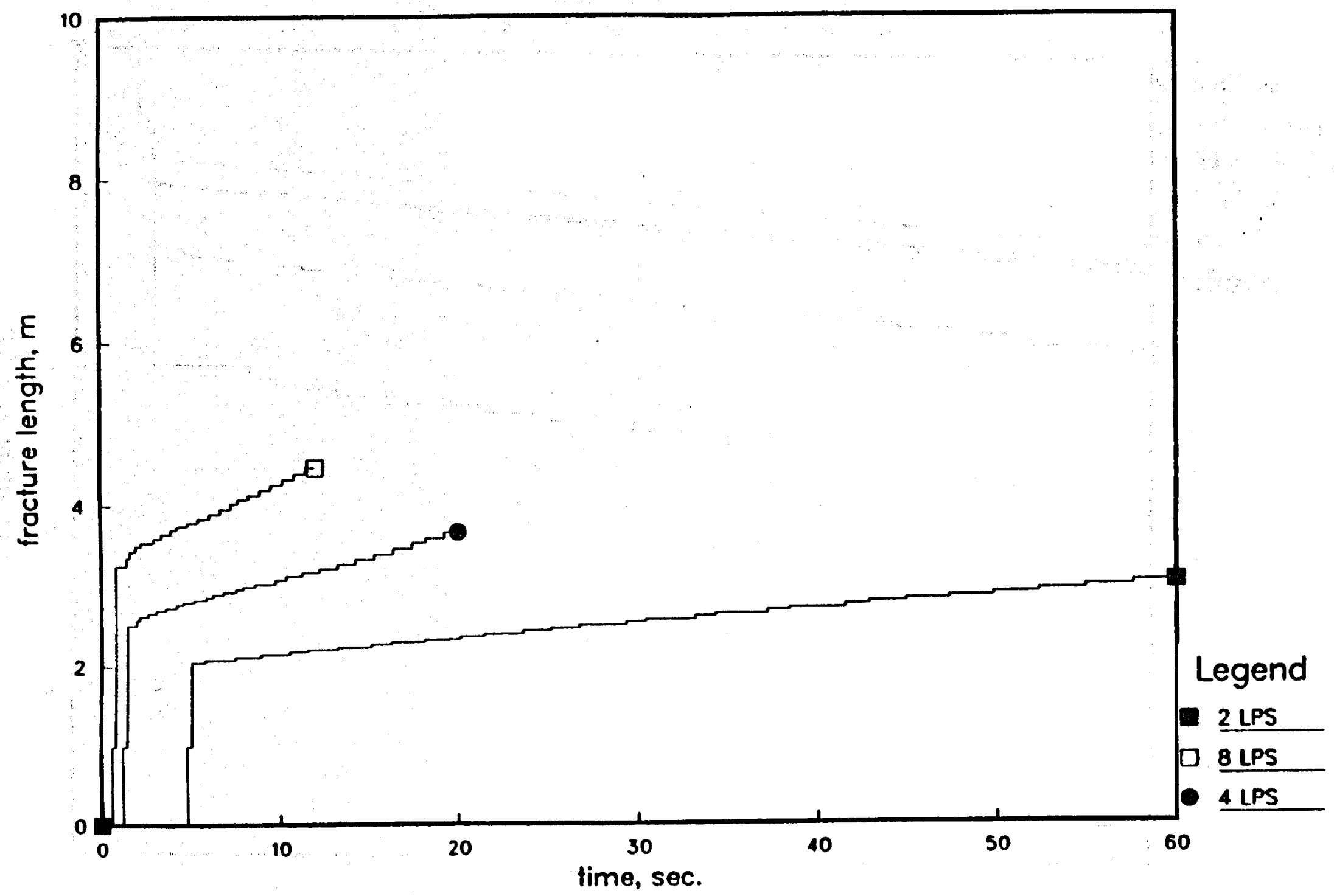

in

Figure 7: Constant flow rate. Effect of injection rate on fracture propagation. 
Frac. length senstivity

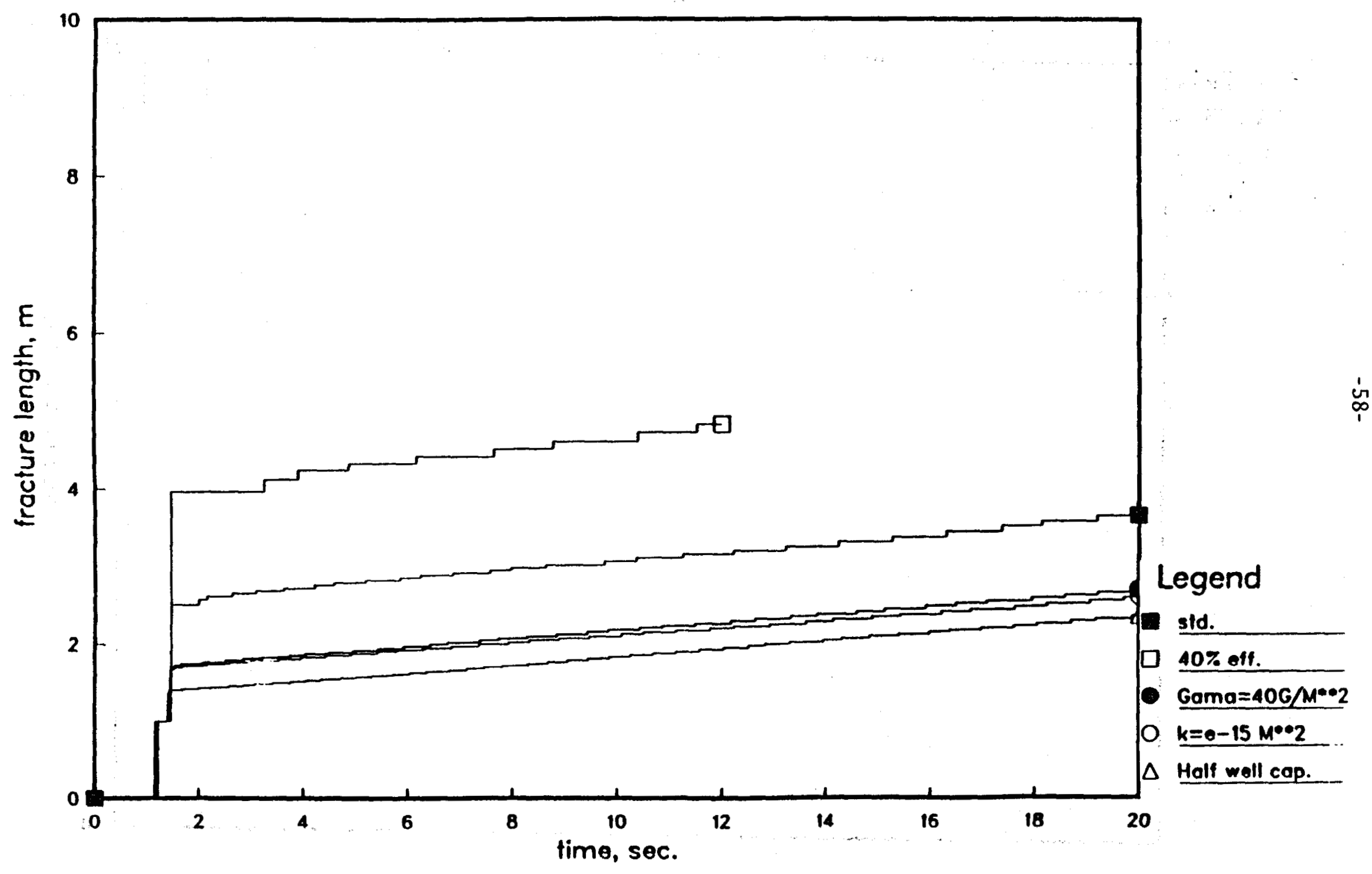

Figure 8: Sensitivity of fracture propagation to efficiency, $r_{c}, k_{r o c k}$ and well bore capacity. 
case $\|-1$ continuation flow rate versus time

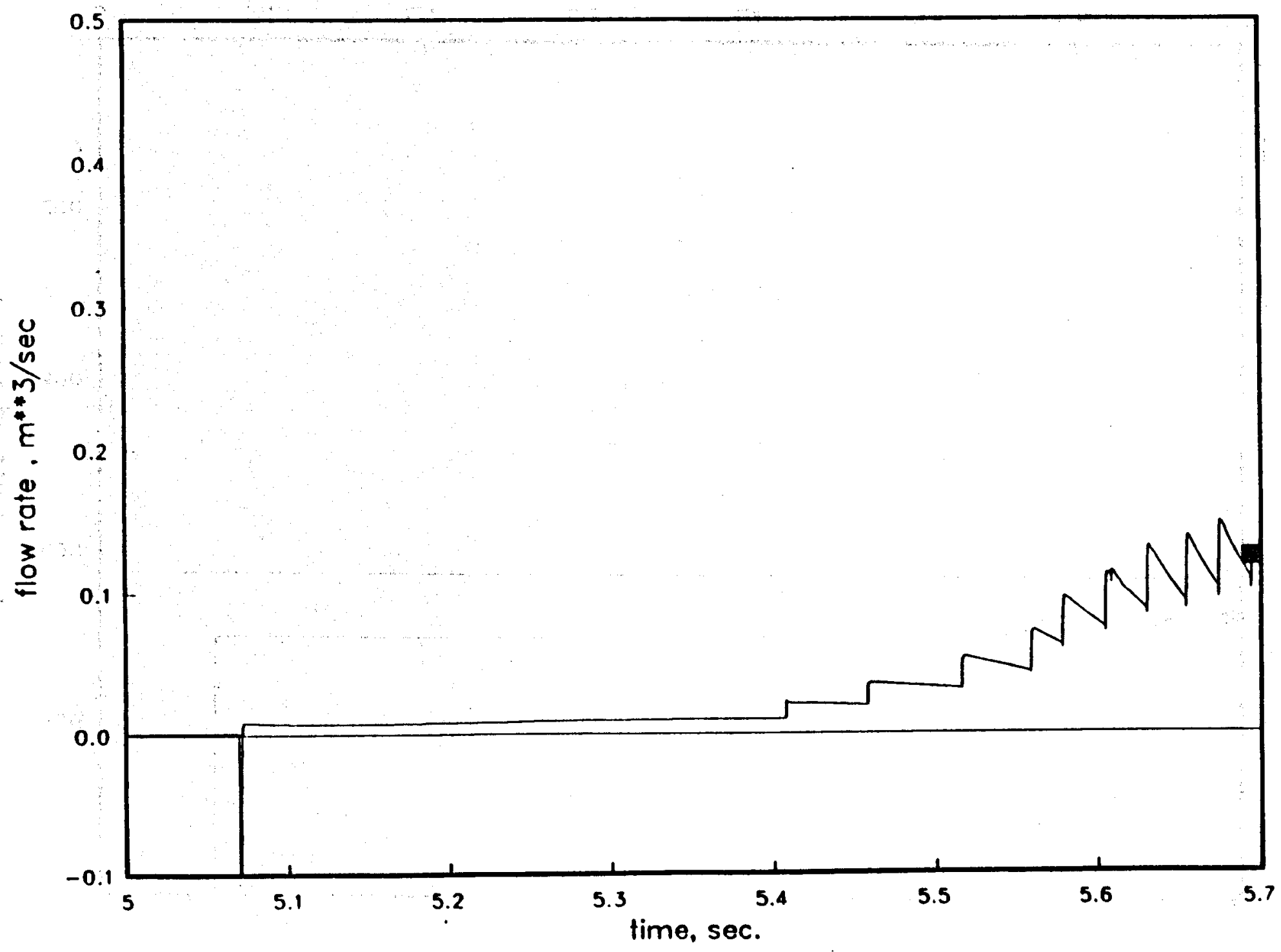

Figure 9A: Constant pressure head injection Case II-1. Injection rate versus time. 
case $\|-1$ continuation

well bore pressure head

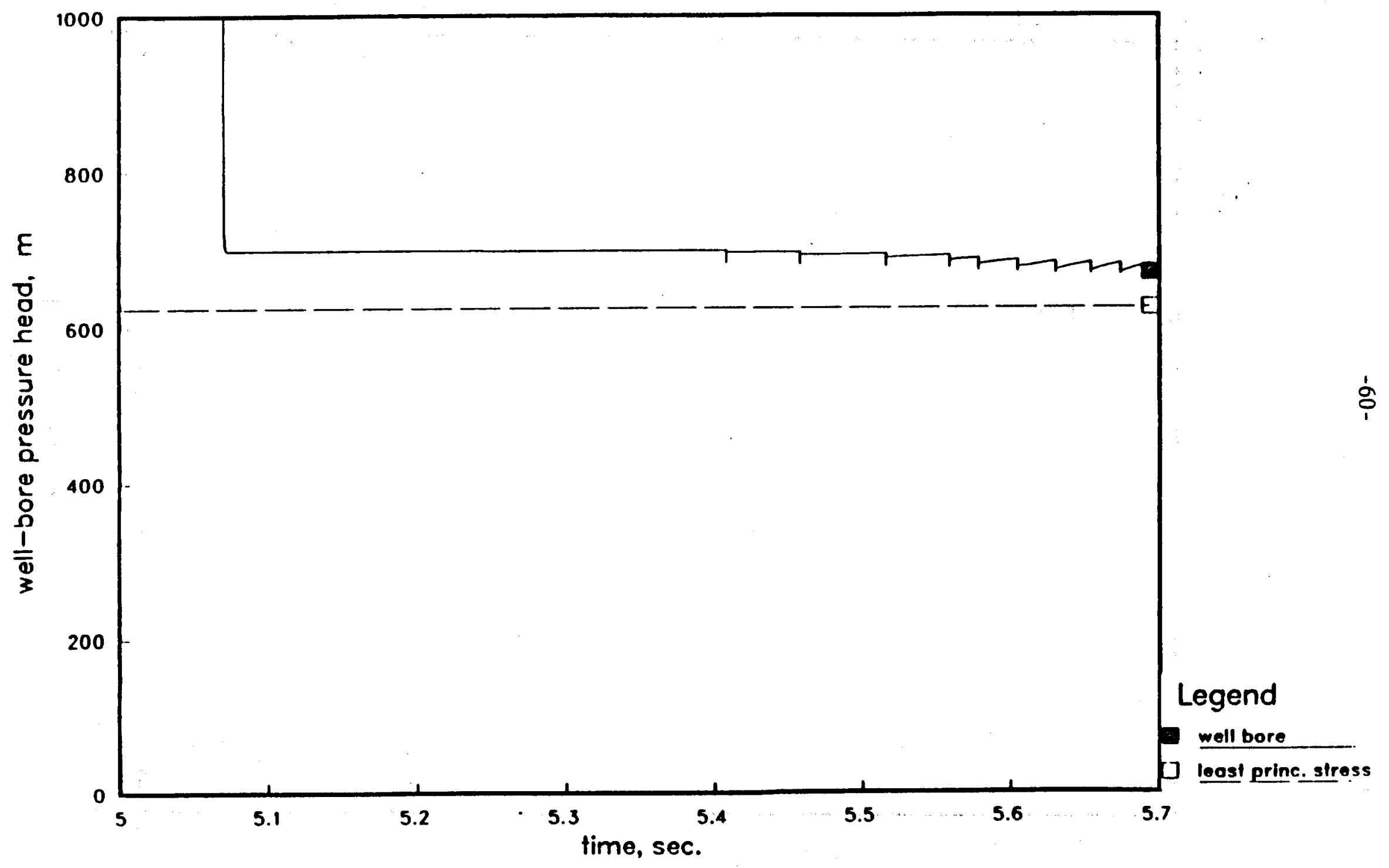

Figure 9B: Constant pressure head injection Case Il-1. Well bore pressure head versus time. 
case $11-1$ continuation

fr. node 100 pressure head

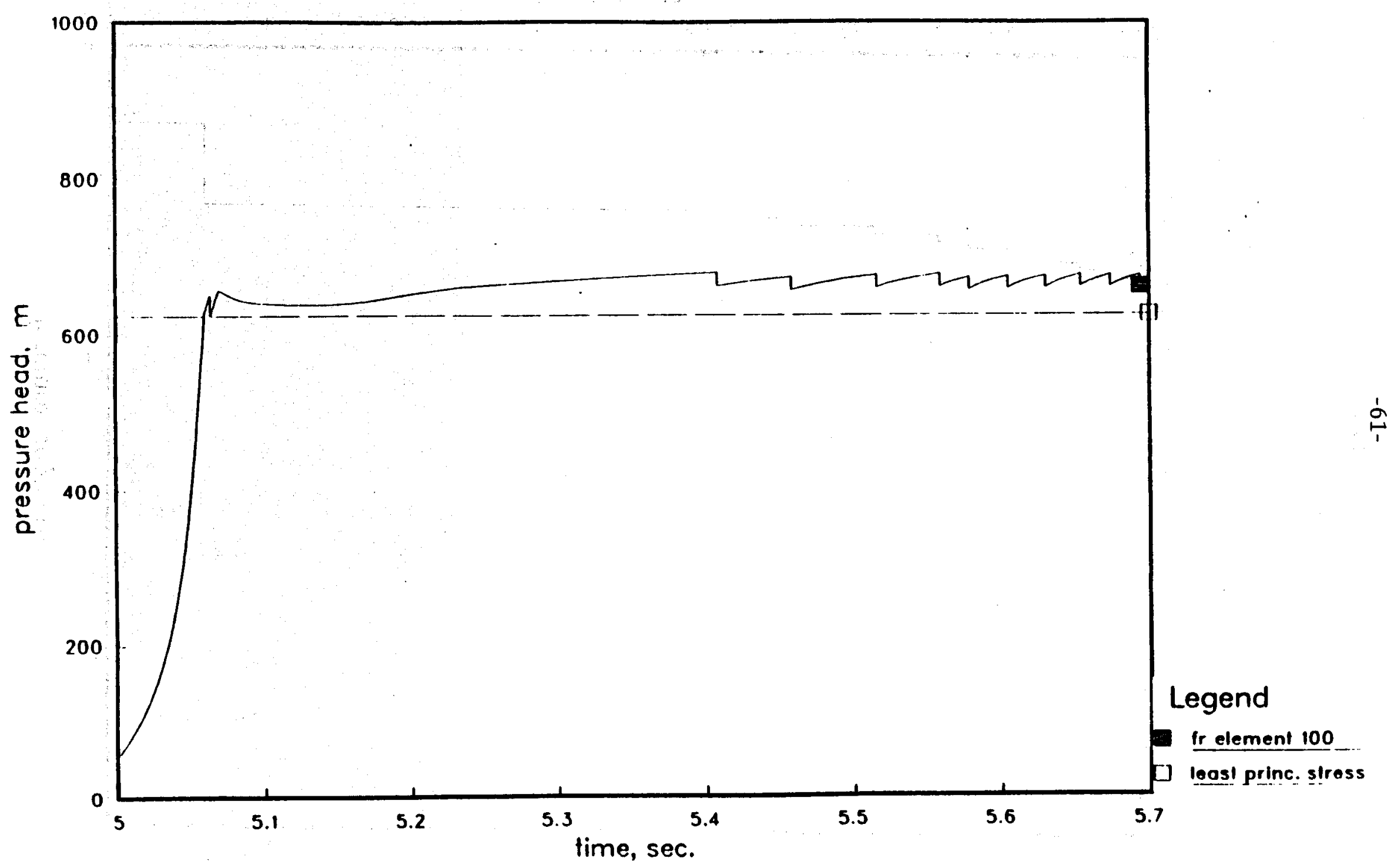

Figure 9C: Constant pressure head injection Case II-1. Pressure head in the fracture element 100 versus time. 
case $11-1$ continuation

frac length versus time

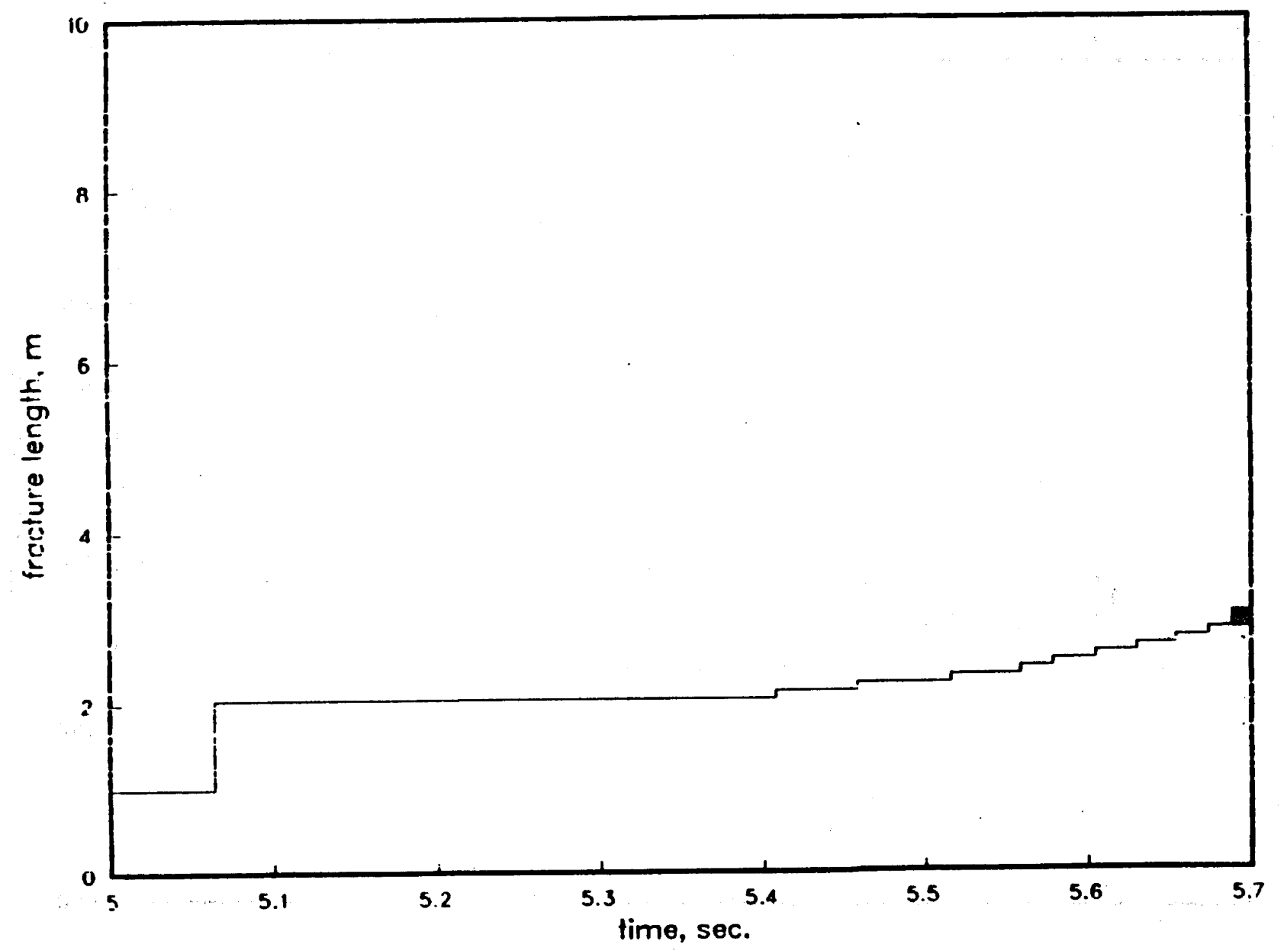

Figure 9D: Constant pressure head injection Case II-1. Fracture propagation versus time. 


\section{case $11-2$ continuation}

flow rate versus time

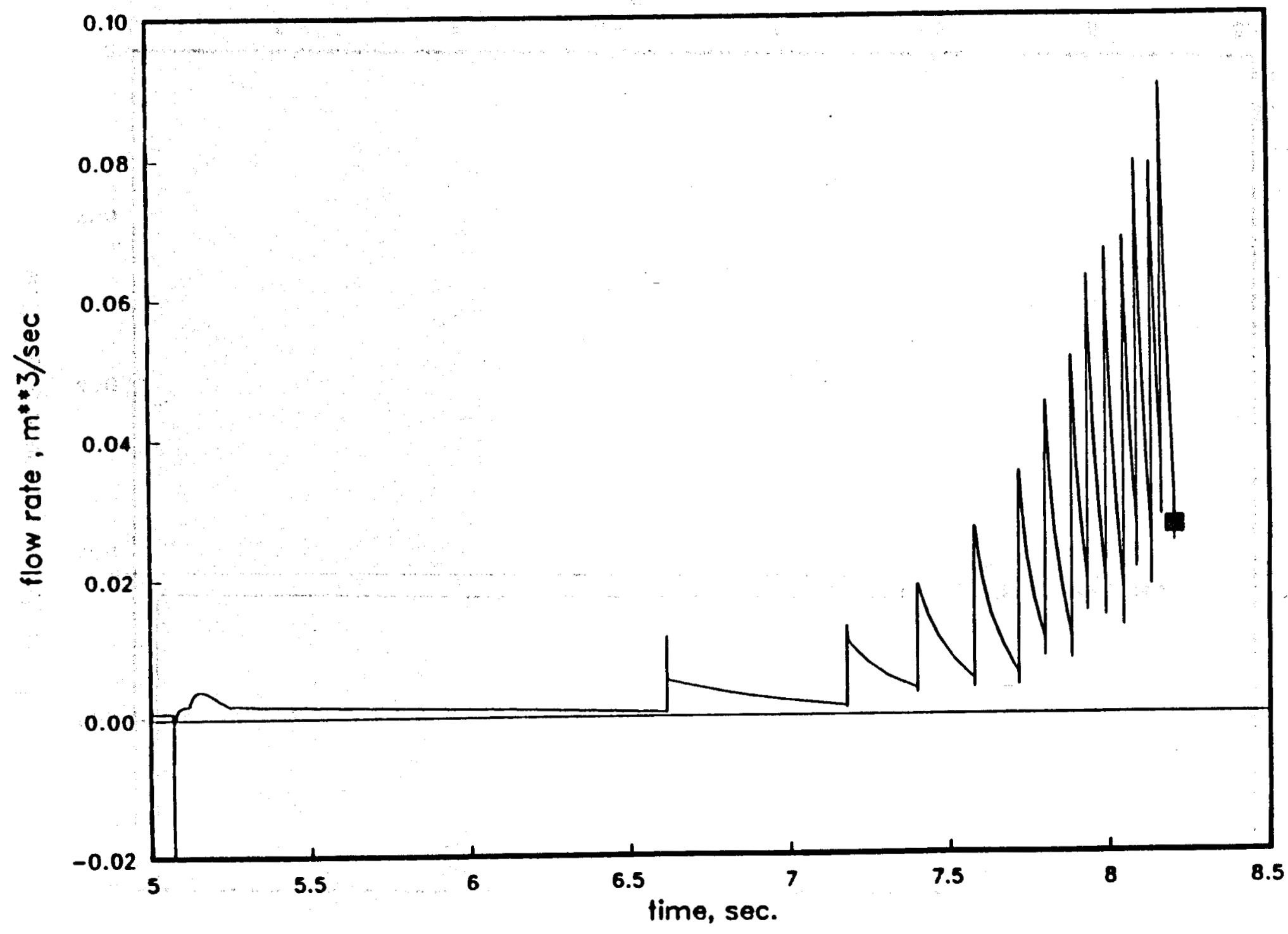

Figure 10A: Constant pressure head injection Case II-2. Injection rate vers'ss time. 
case $\|-2$ continuation

well bore pressure head

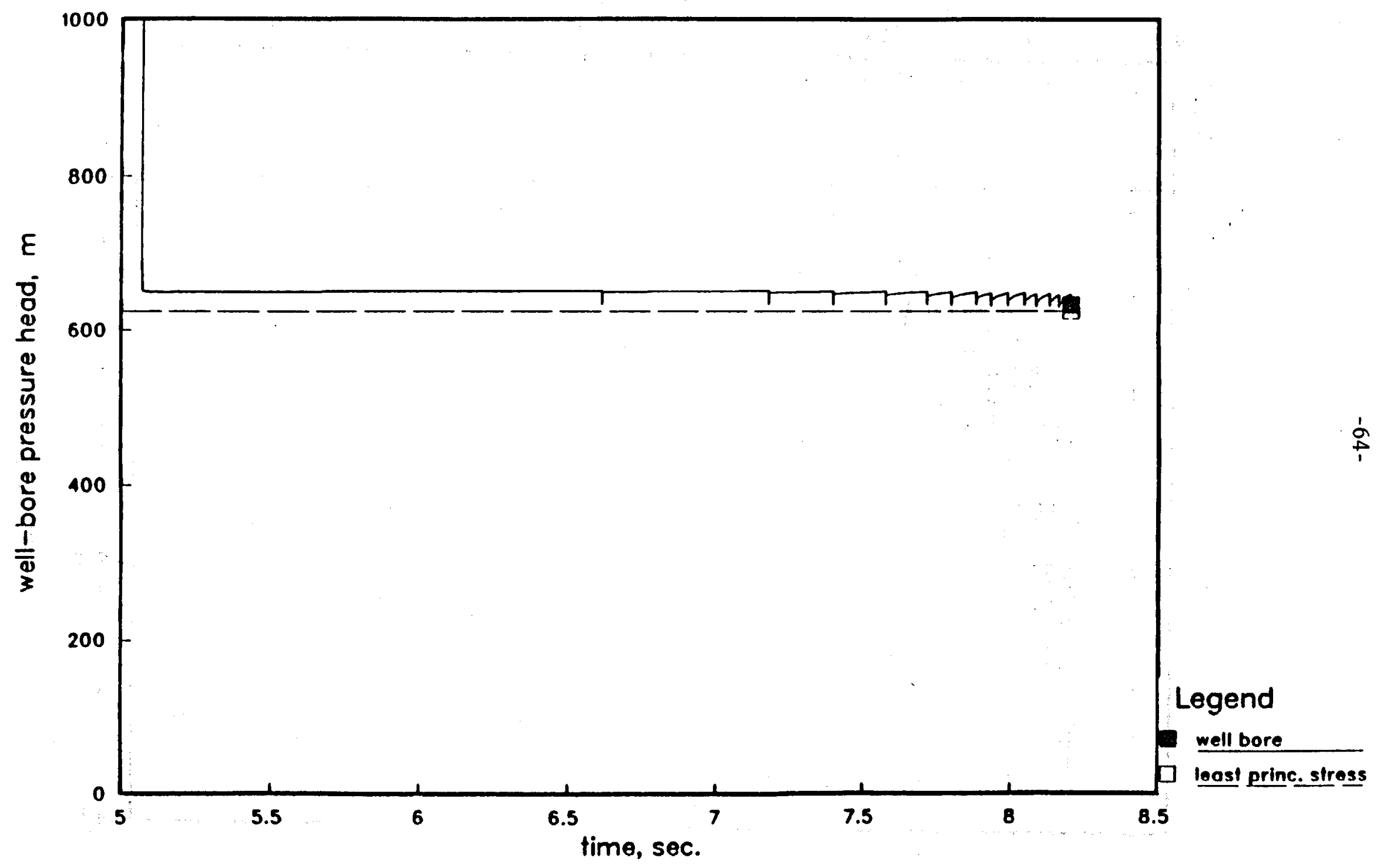

Figure 10B: Constant pressure head injection Case II-2. Well bore pressure head versus time. 


\section{case $\|-2$ continuation \\ fr. node 100 pressure head}

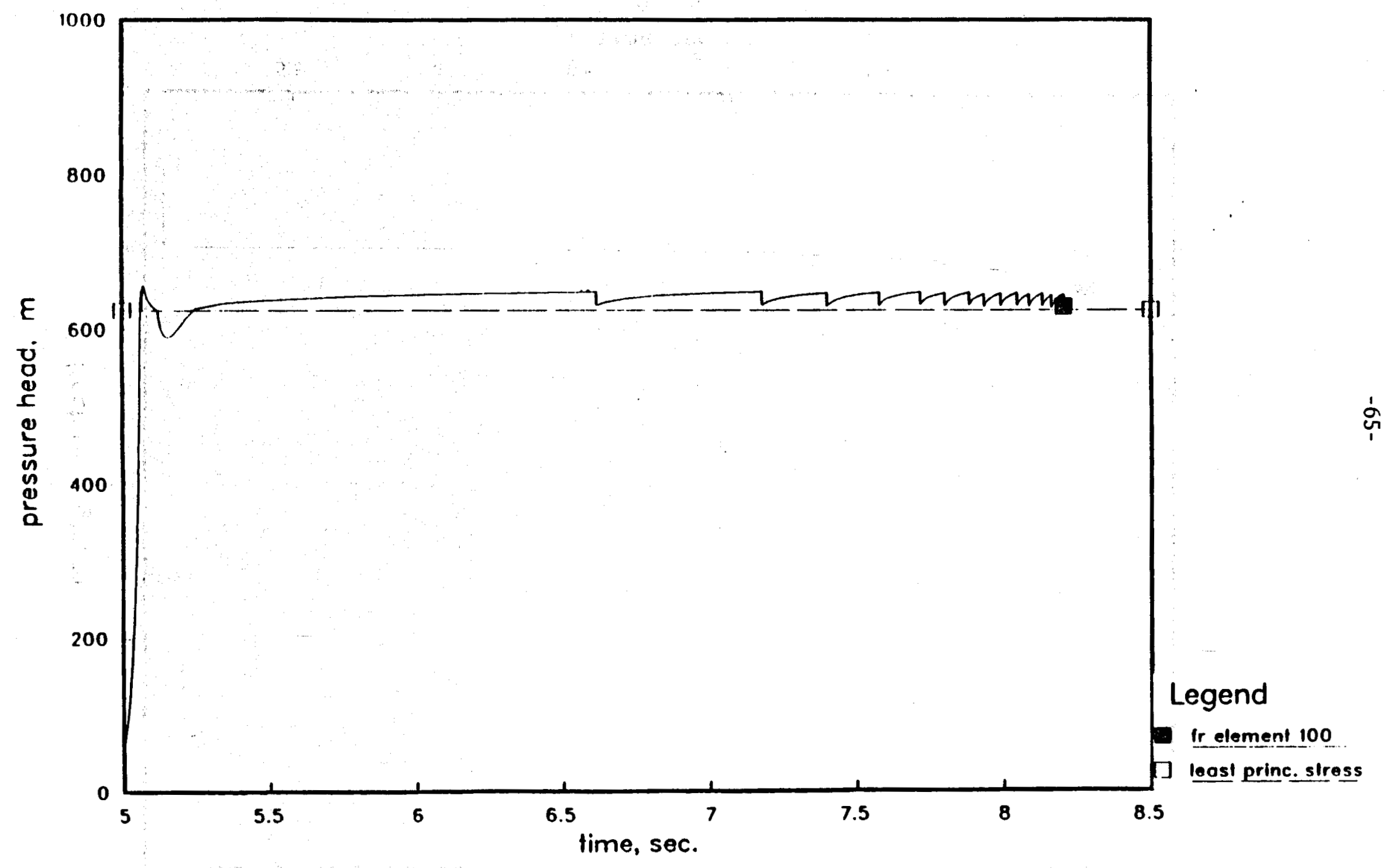

Figure 10C: Constant pressure head injection Case 11-2. Fracture pressure head $0.5 \mathrm{~m}$ from well. 
case II-2 continuation

frac length versus time

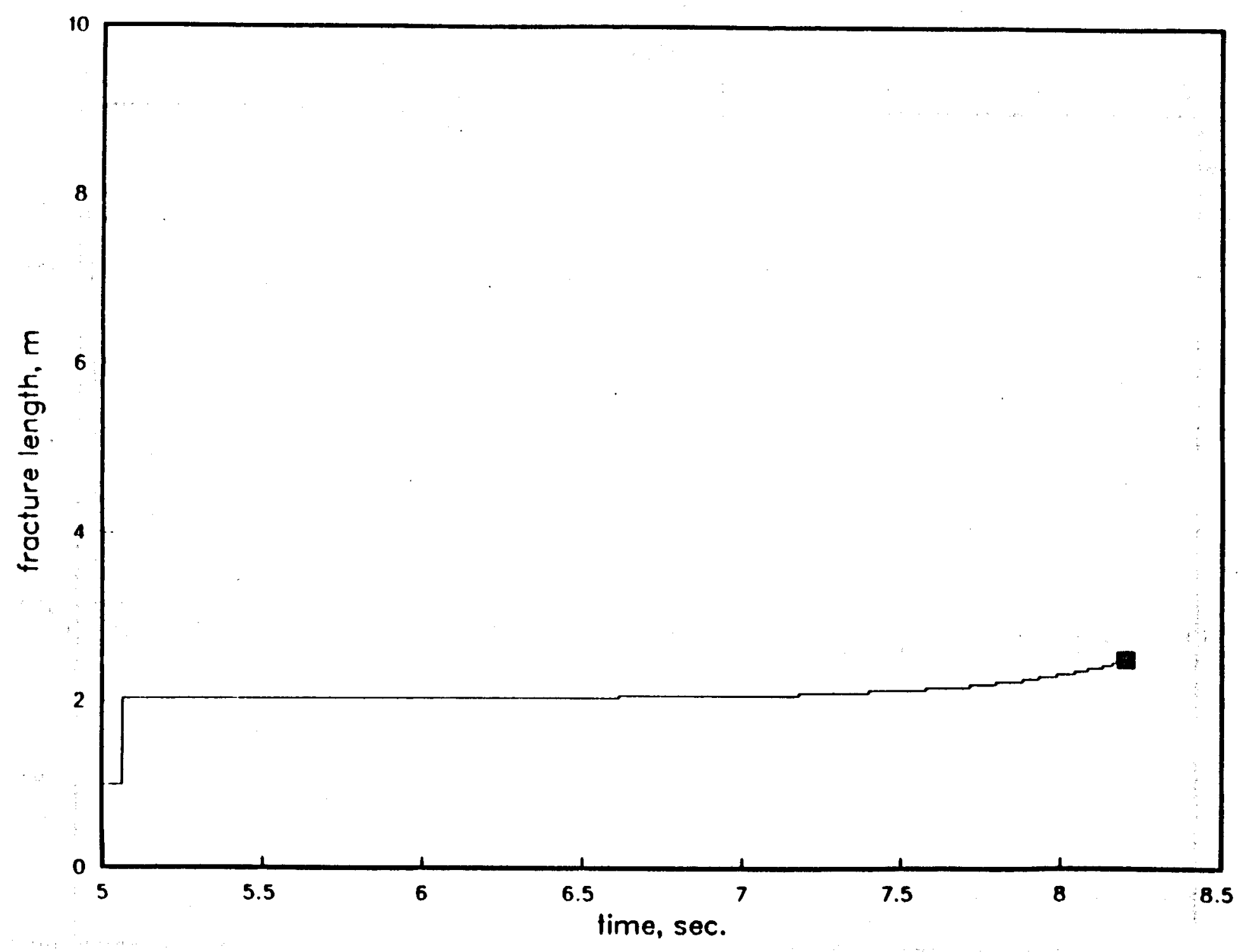

Figure 10D: Constant pressure head injection Case II-2. Fracture length versus time. 


\section{case III-2 0.2 lps. av =1.e-11}

flow rate versus time

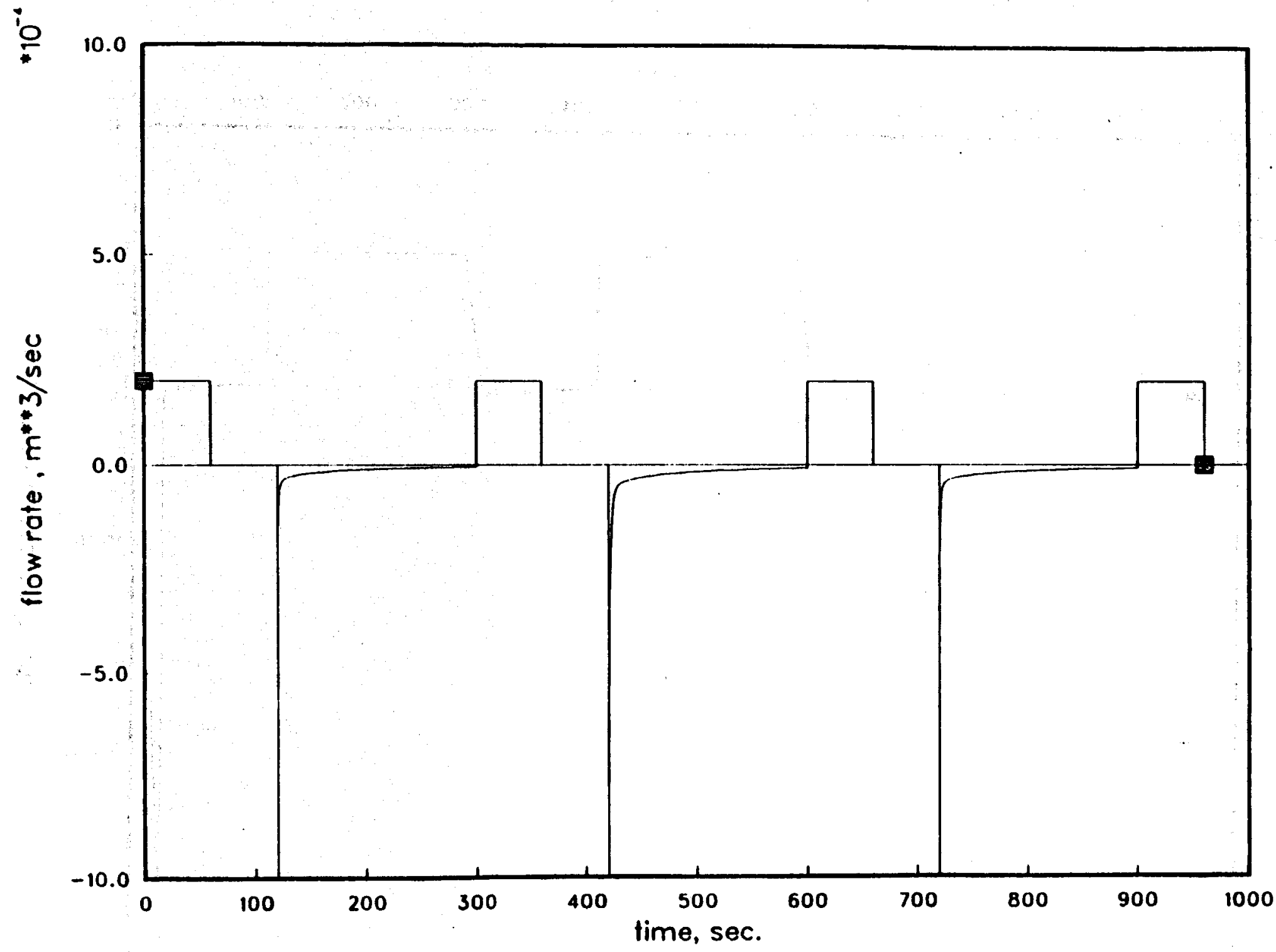

Figure 11: An example fluid injection history for an experiment involving 4 cycles of injection separated by 3 cycles of shut in and bleed off. 


\section{case III-1 continuation well bore pressure head}

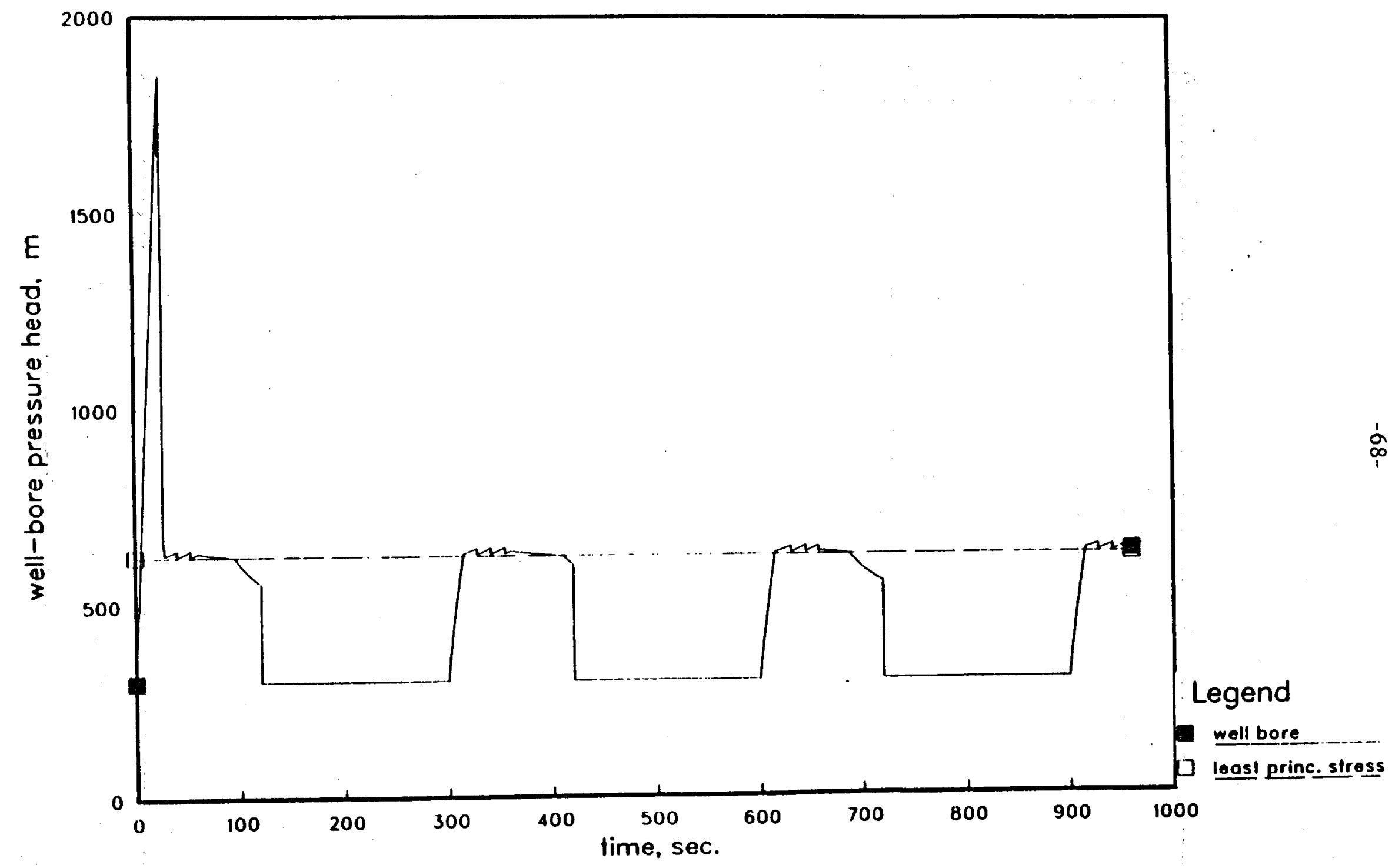

Figure 12A: Sensitivily to inilial fracture aperture and compressibility: Case III-1 $a_{v, f}=3 \times 10^{-11} \mathrm{~Pa}^{-1} ; w_{f, 0}=20$ microns. 
case III-2B continuation

well bore pressure head

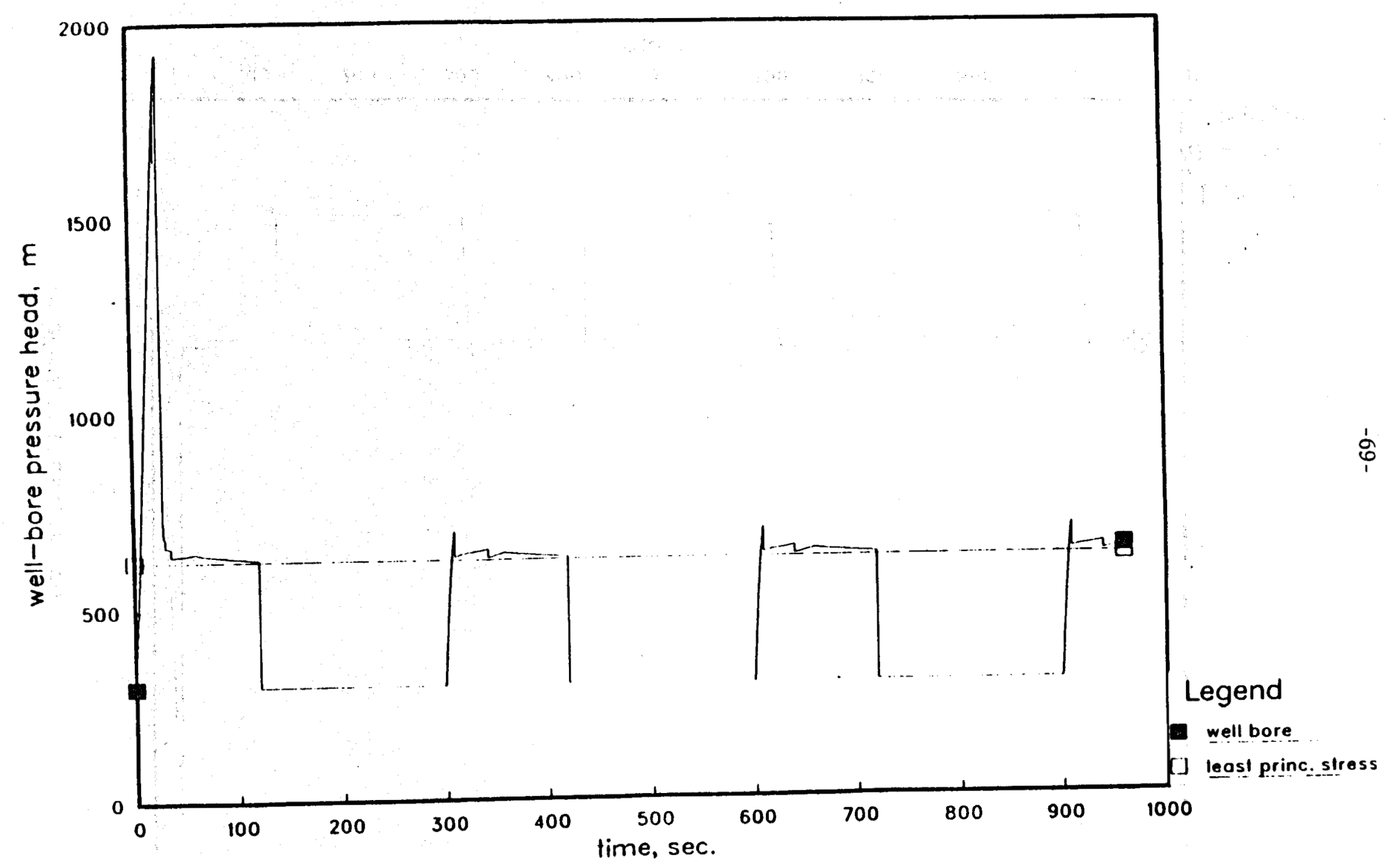

Figure 12B: Sensitivity to initial fracture aperture and compressibility: Case III-2B, $a_{v, i}=1 \times 10^{-11} \mathrm{~Pa}^{-1} ; w_{f, o}=10$ microns. 
case $\| 1-2 \quad 0.2$ lps. av $=1 . e-11$

well bore pressure head

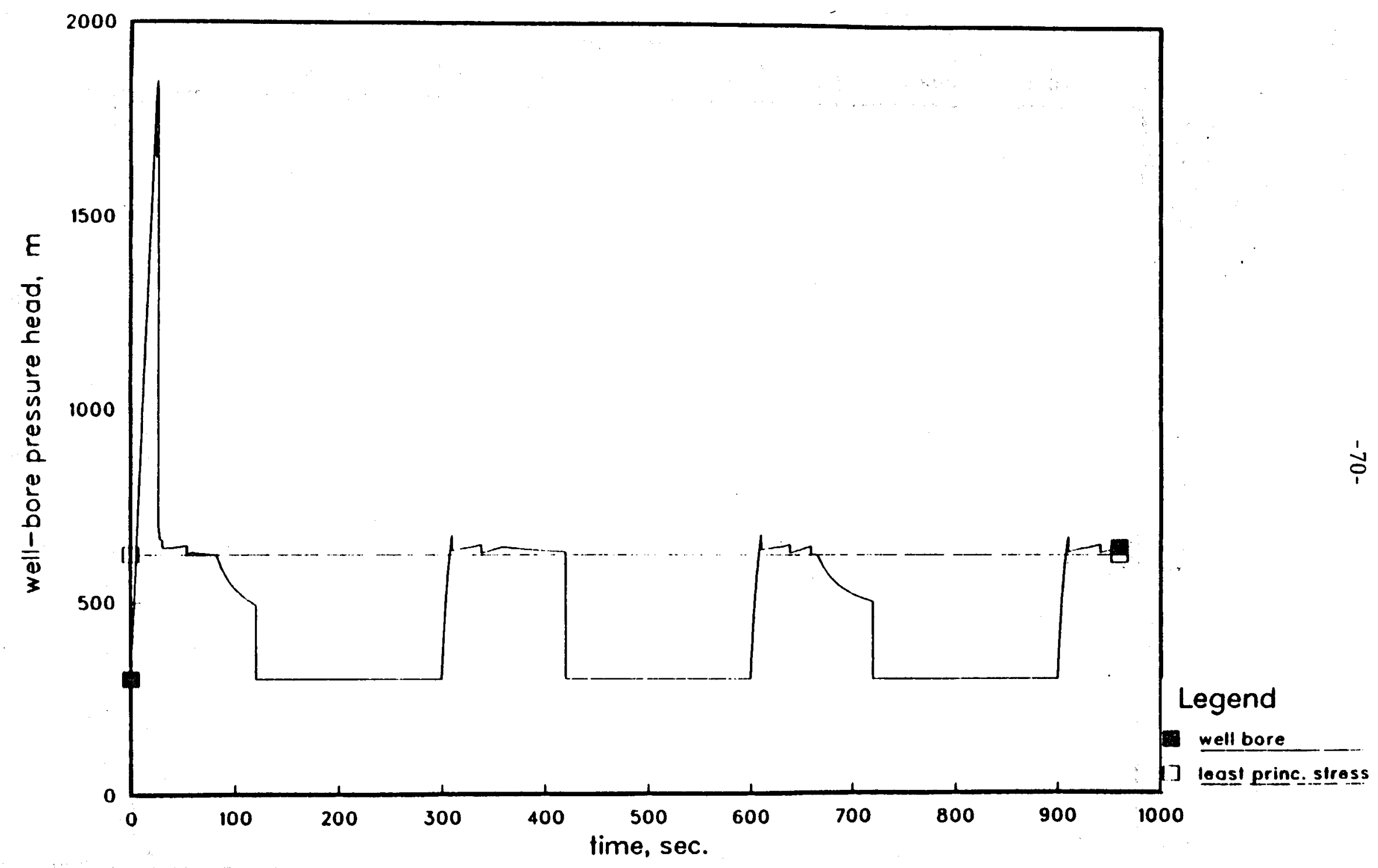

Figure 12C: Sensitivity to initial fracture aperture and compressibility: Case III-2 $a_{v, f}=1 \times 10^{-11} \mathrm{~Pa}^{-1} ; w_{f, o}=20$ microns. 


$$
\begin{aligned}
& \text { case III-1 } 0.2 \text { Ips. av }=3 . e-11 \\
& \text { fr. node } 100 \text { pressure head }
\end{aligned}
$$

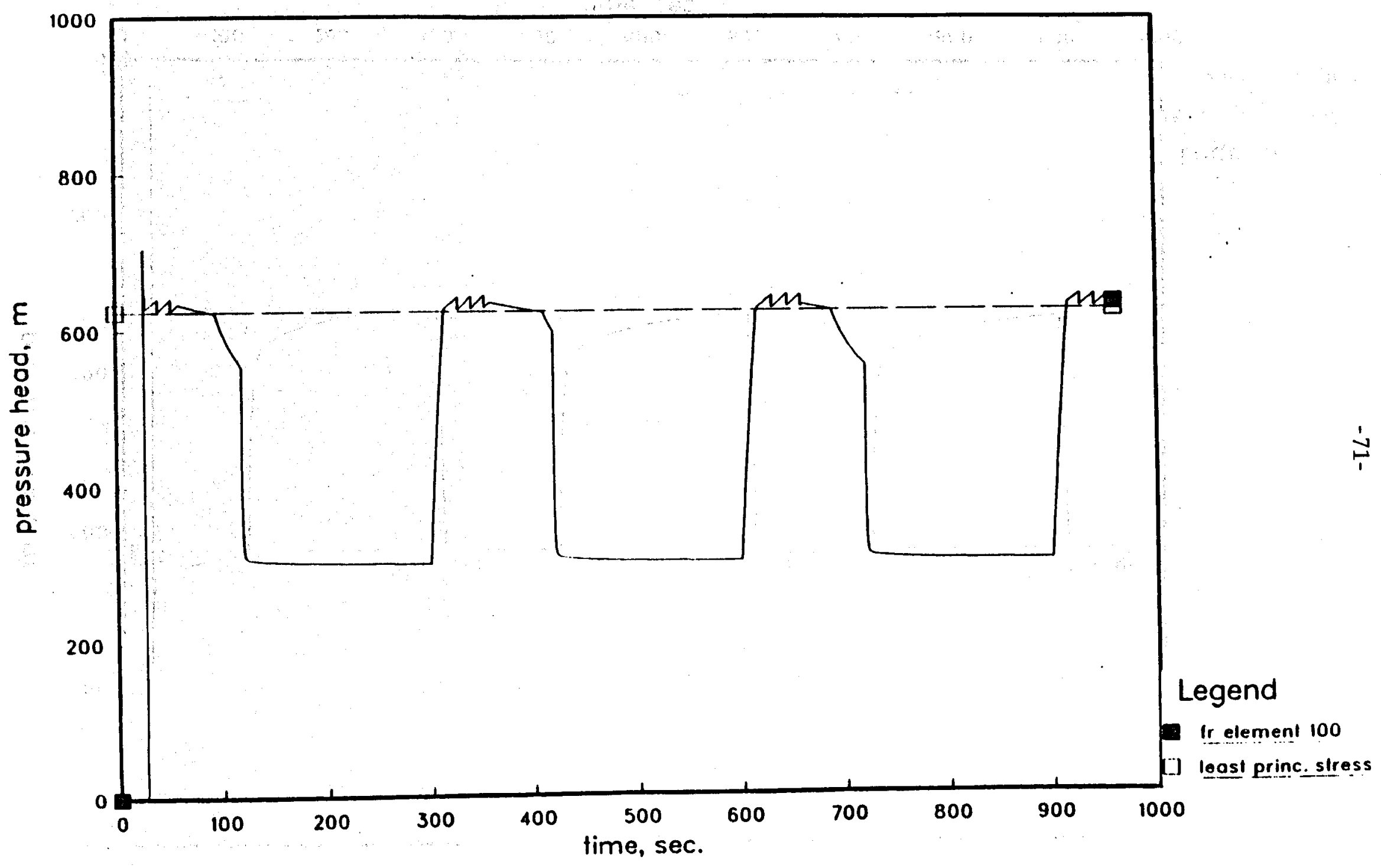

Figure 13A: Pressure within the fracture, $0.5 \mathrm{~m}$ from well bore; Case III-1. 


\section{case $|1|-2 \mathrm{~B}$ continuation \\ fr. node 100 pressure head}

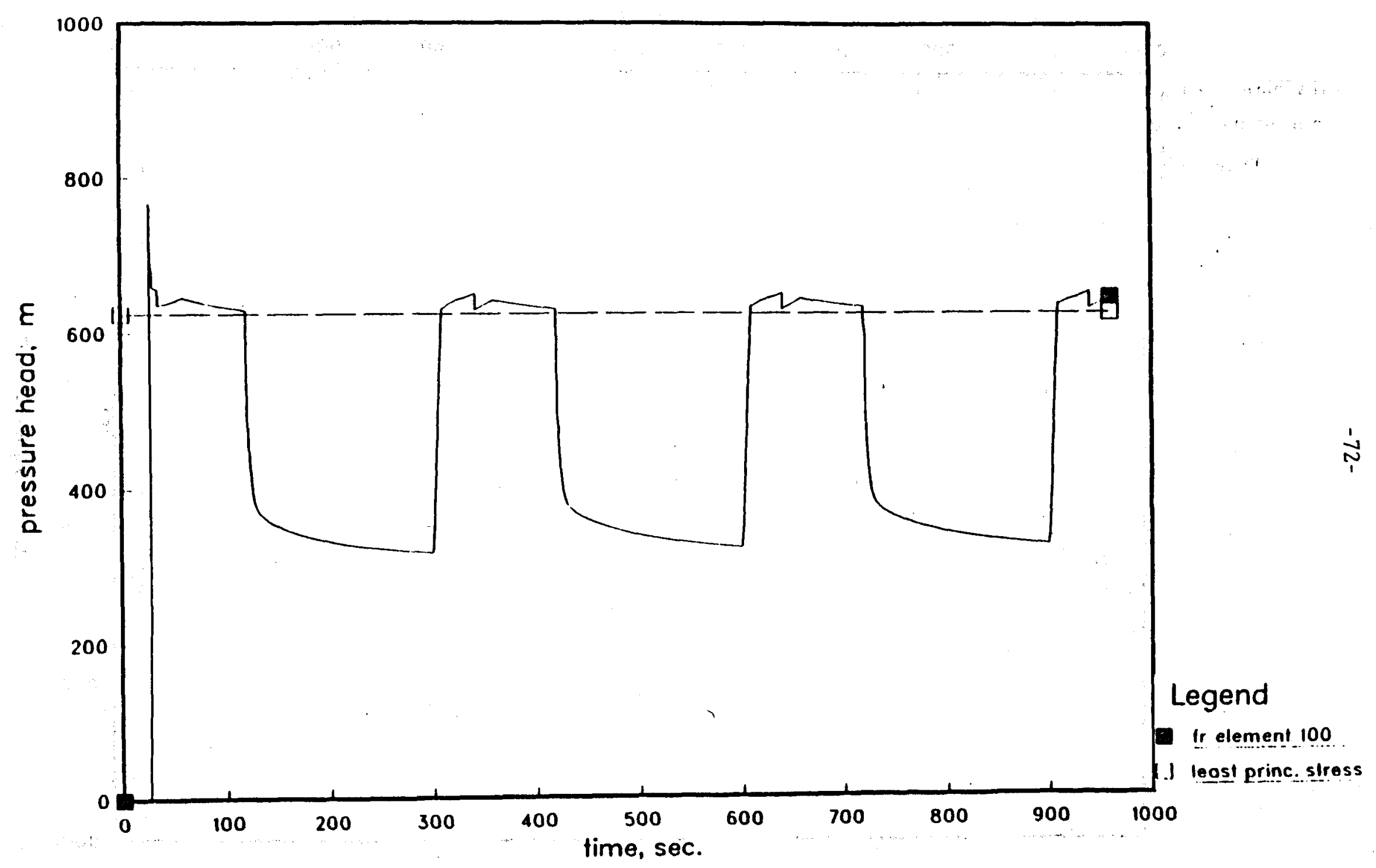

Figure 13B: Pressure within the fracture, $0.5 \mathrm{~m}$ from well bore; Case 111-2B. 
case $111-2 \quad 0.2$ lps. av $=1 . e-11$

fr. node 100 pressure head

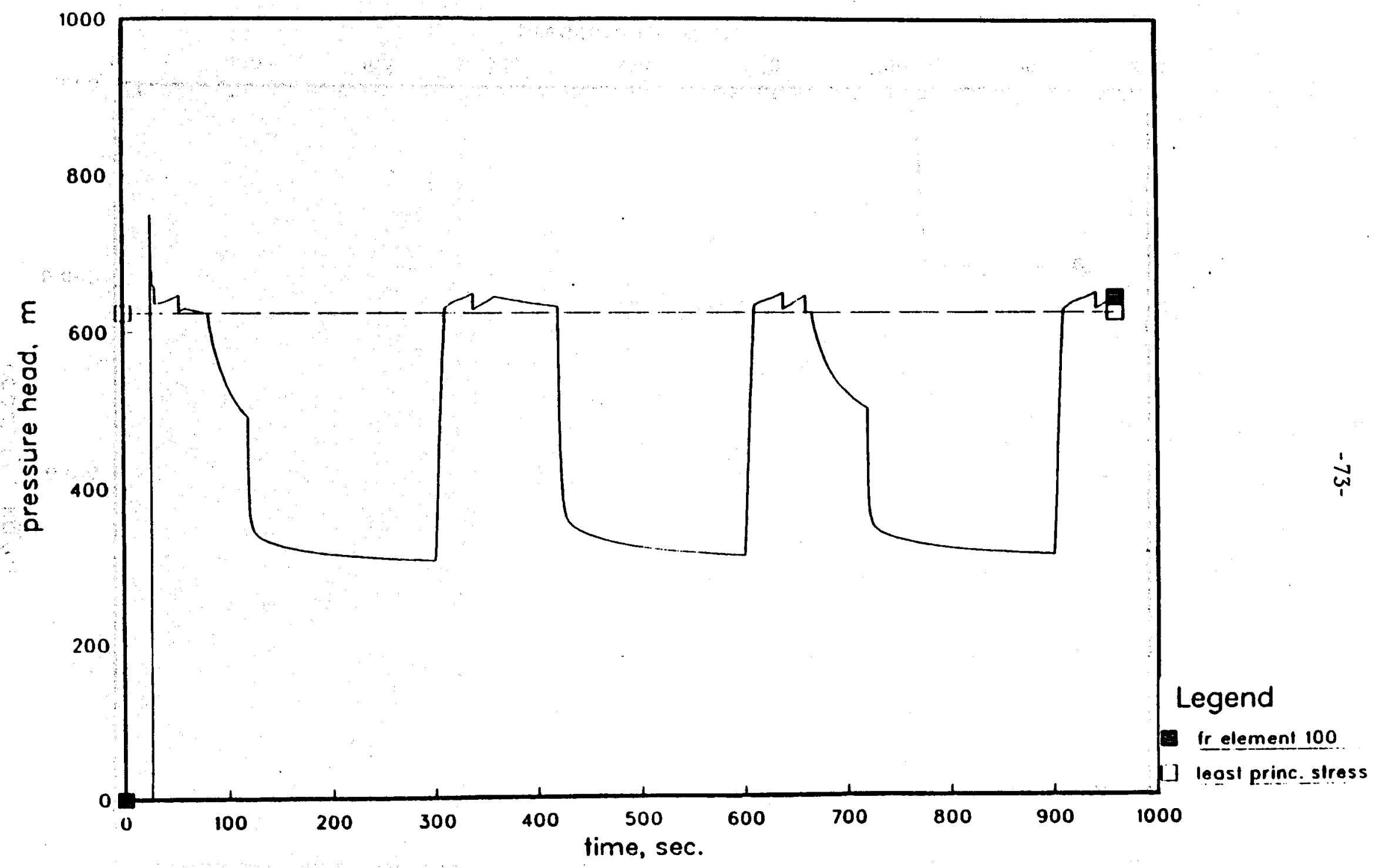

Figure 13C: Pressure within the fracture, $0.5 \mathrm{~m}$ from well bore; Case III-2. 
case III-2A.

capacity of node 100 versus pressure head

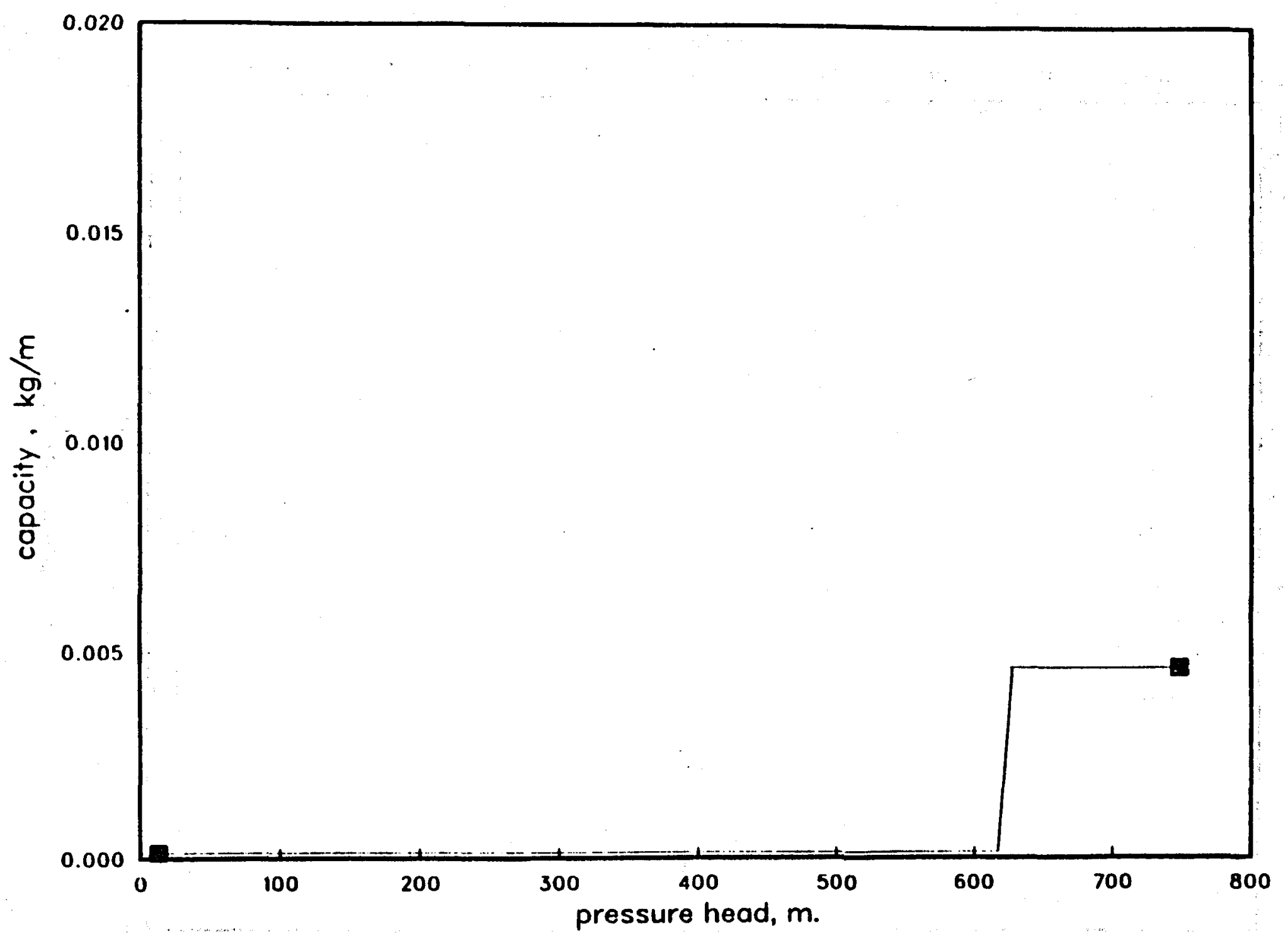

Figure 14: Capacity of the fracture element closest to the well bore as a function of time. 


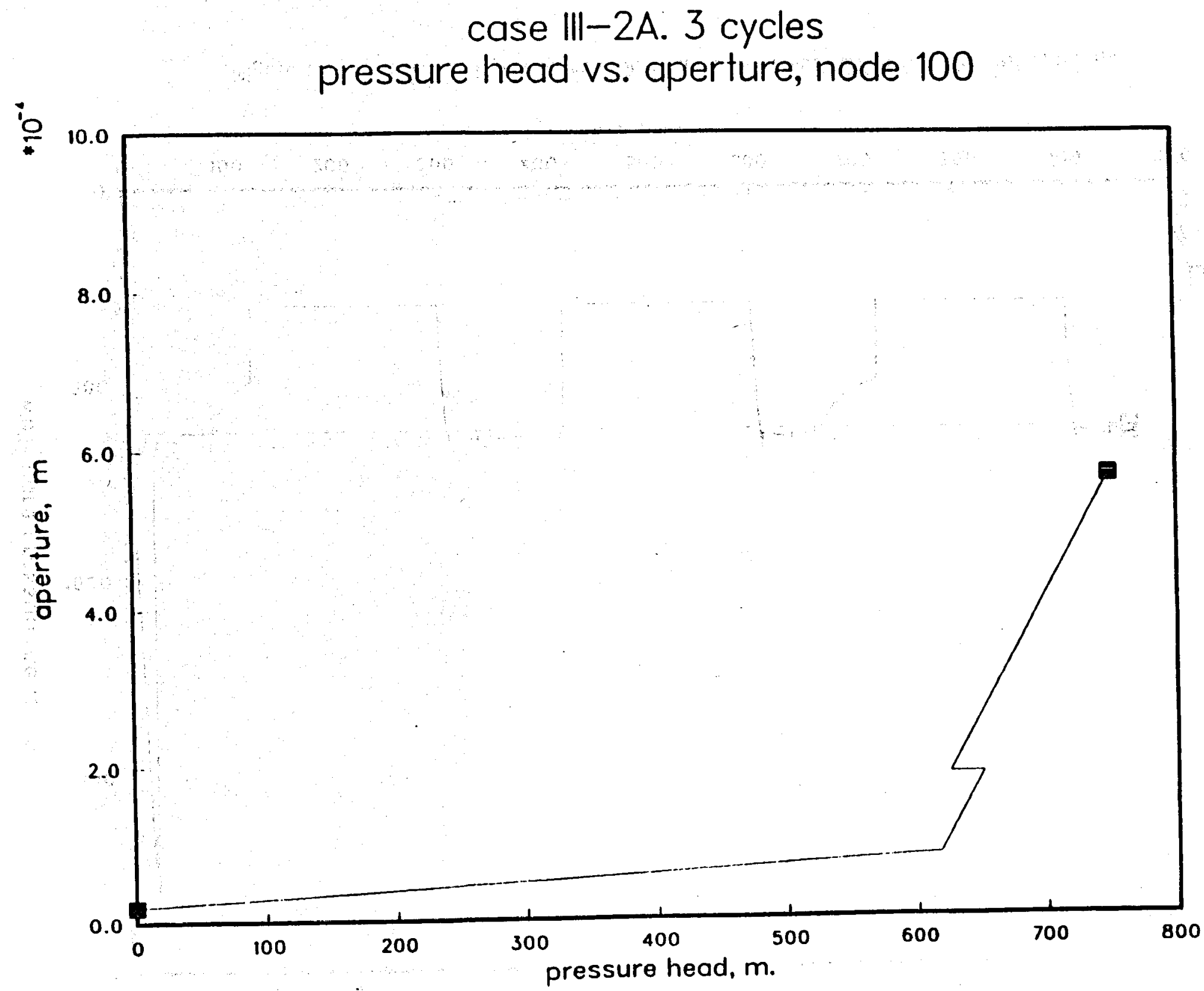

Figure 15: Aperture of the first fracture element as a function of time. 
case III-2 0.2 lps. av $=1 . e-11$

well bore pressure head

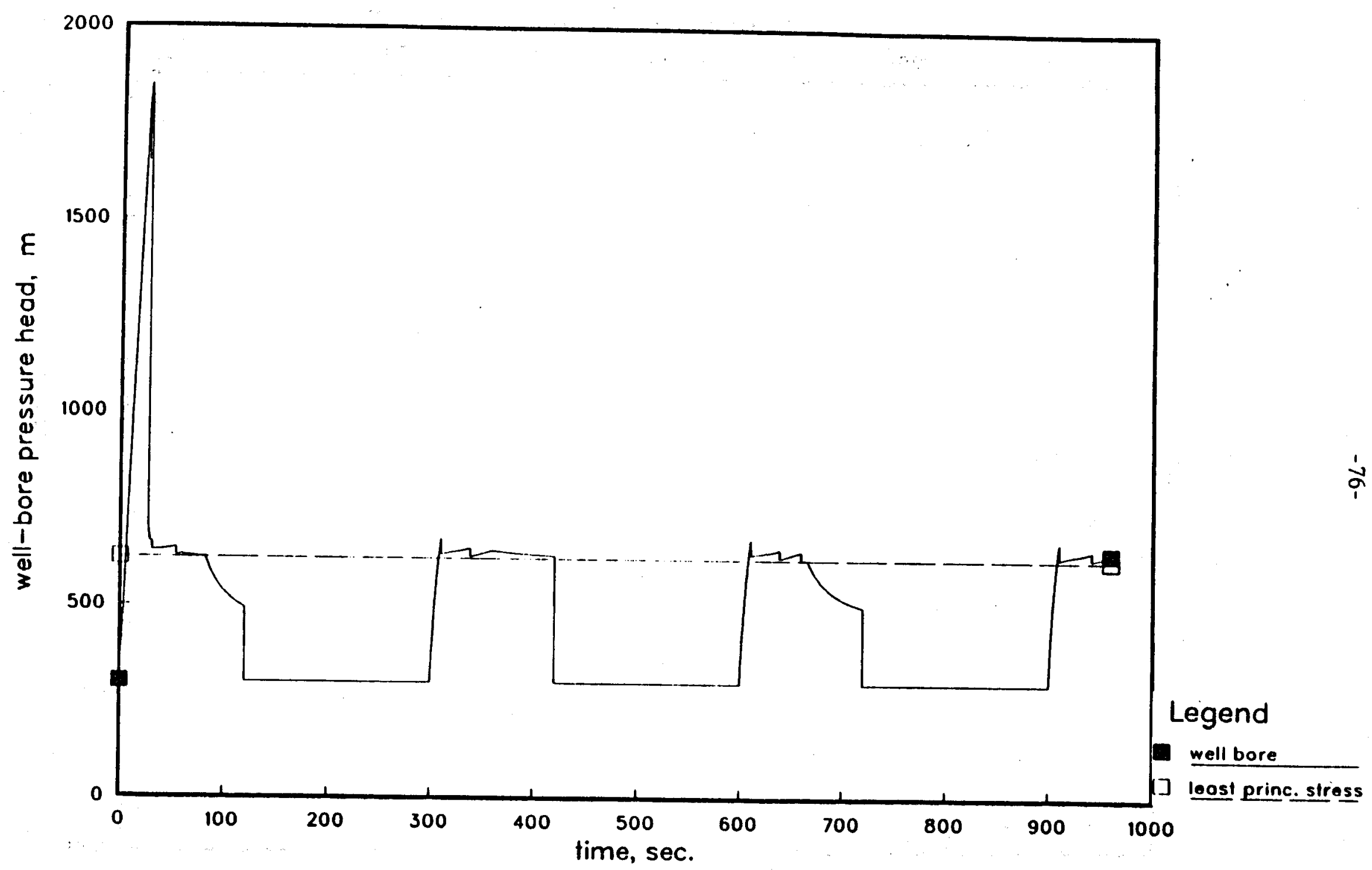

Figure 16A: Effect of injection rate on well bore pressure transient; Case III-2, 0.2 lps. 


\section{case III-3 continuation well bore pressure head}

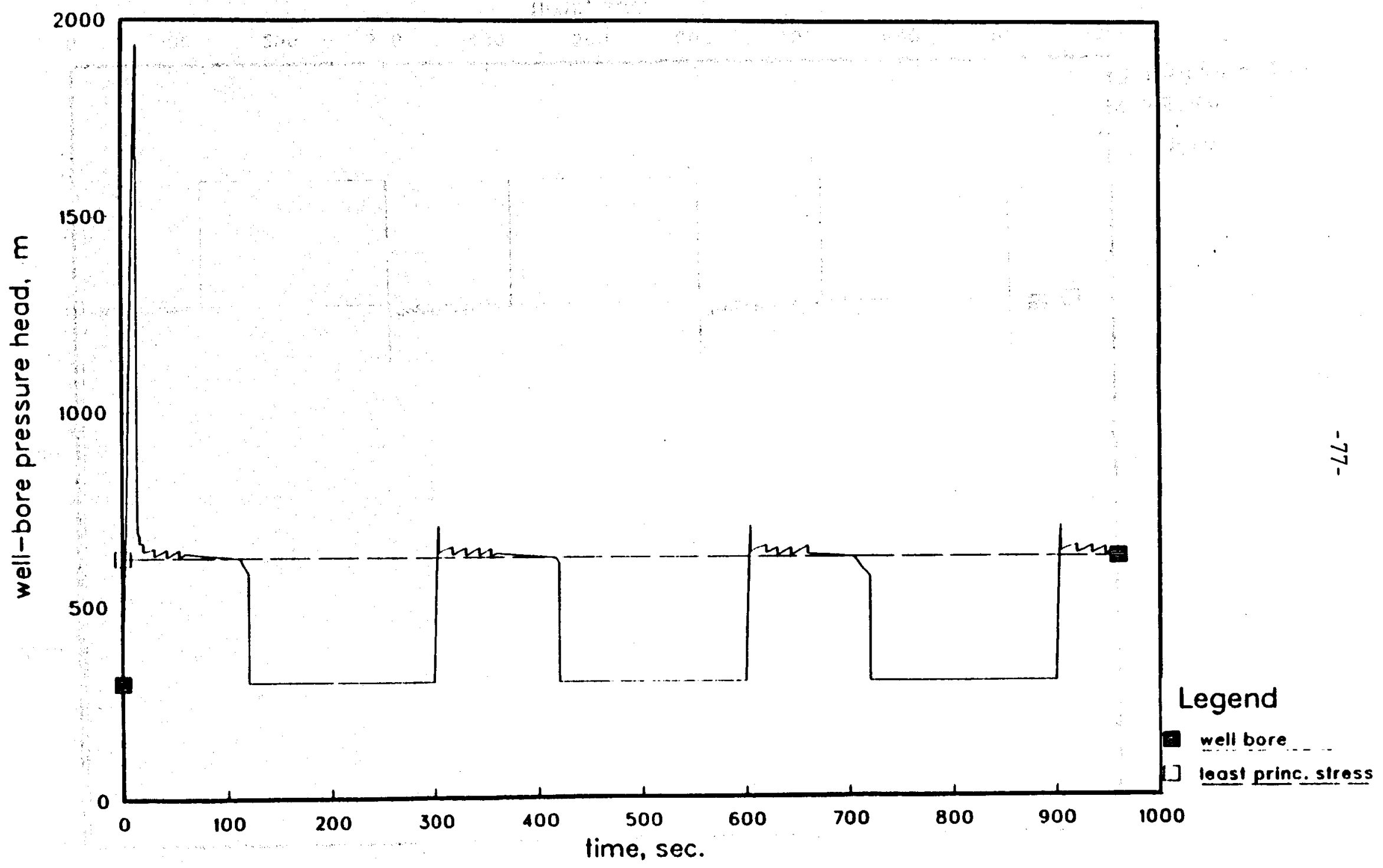

Figure 16B: Eilfect of injection rate on well bore pressure transient: Case $111-3,0.4 \mathrm{lps}$. 
case III-4 continuation

well bore pressure head

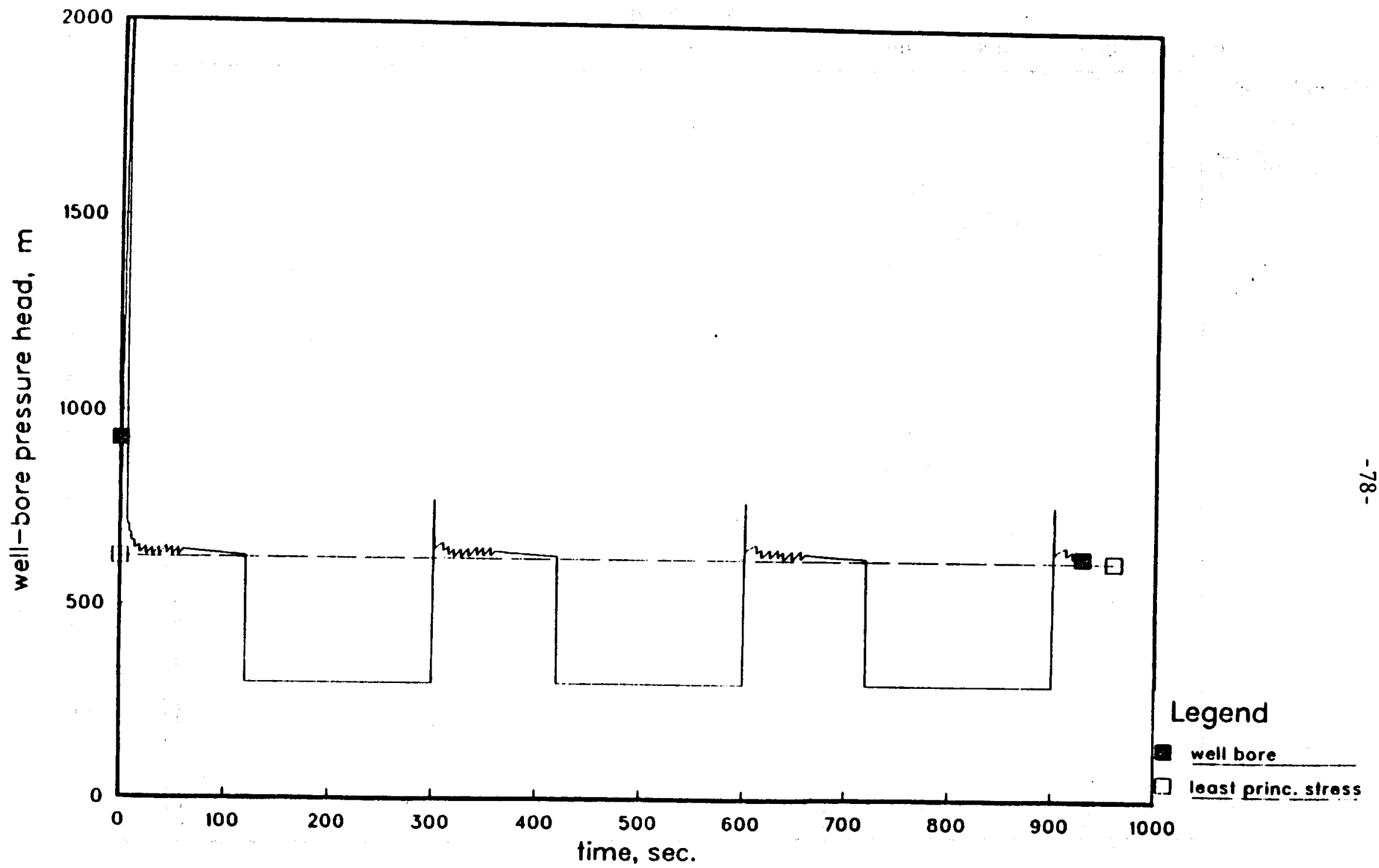

Figure 16C: Eifect of injection rate on well bore pressure transient: Case III-4, 1 lps. 


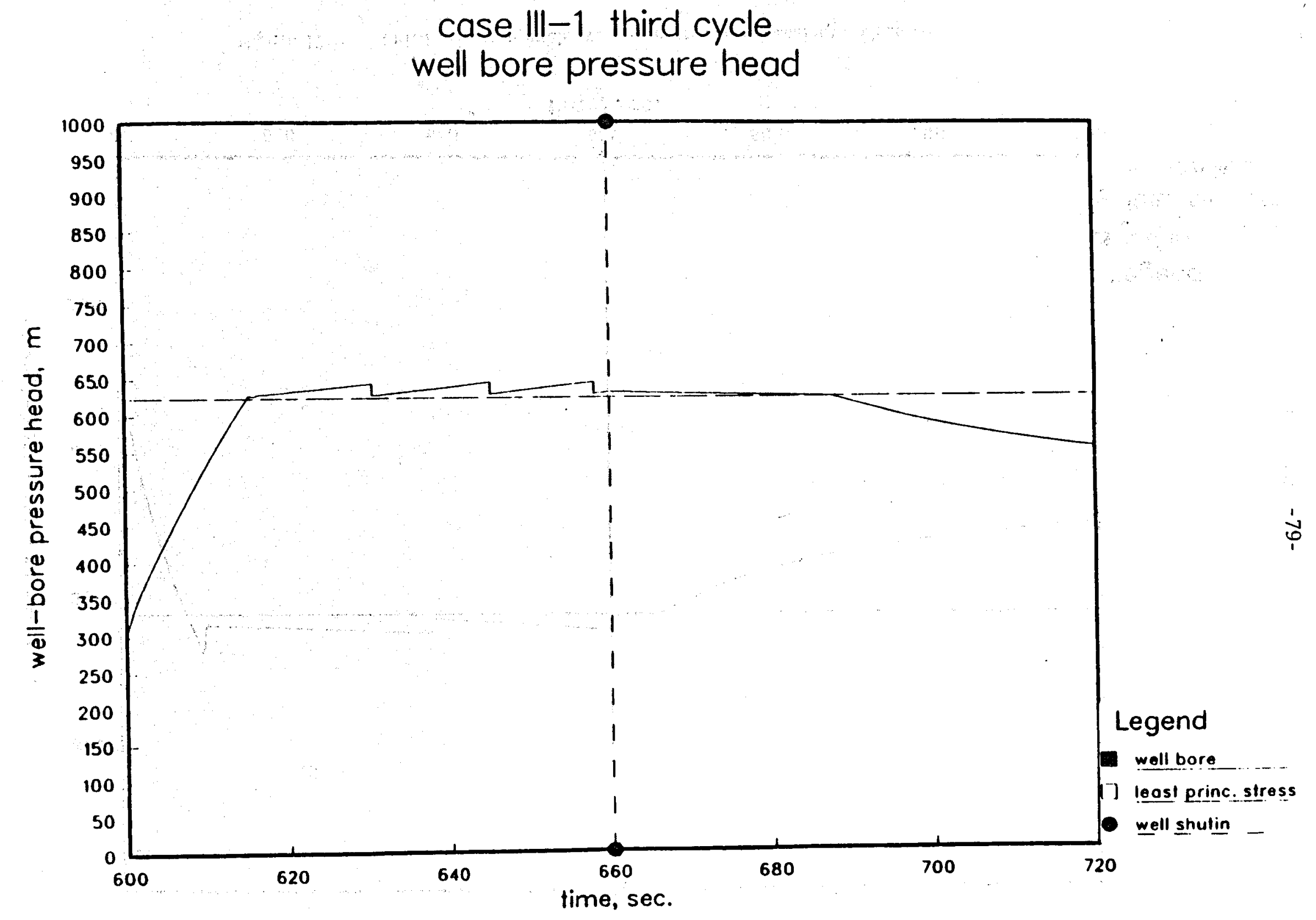

Figure 17A: Third injection cycle well bore pressure transients: Case III-1. 


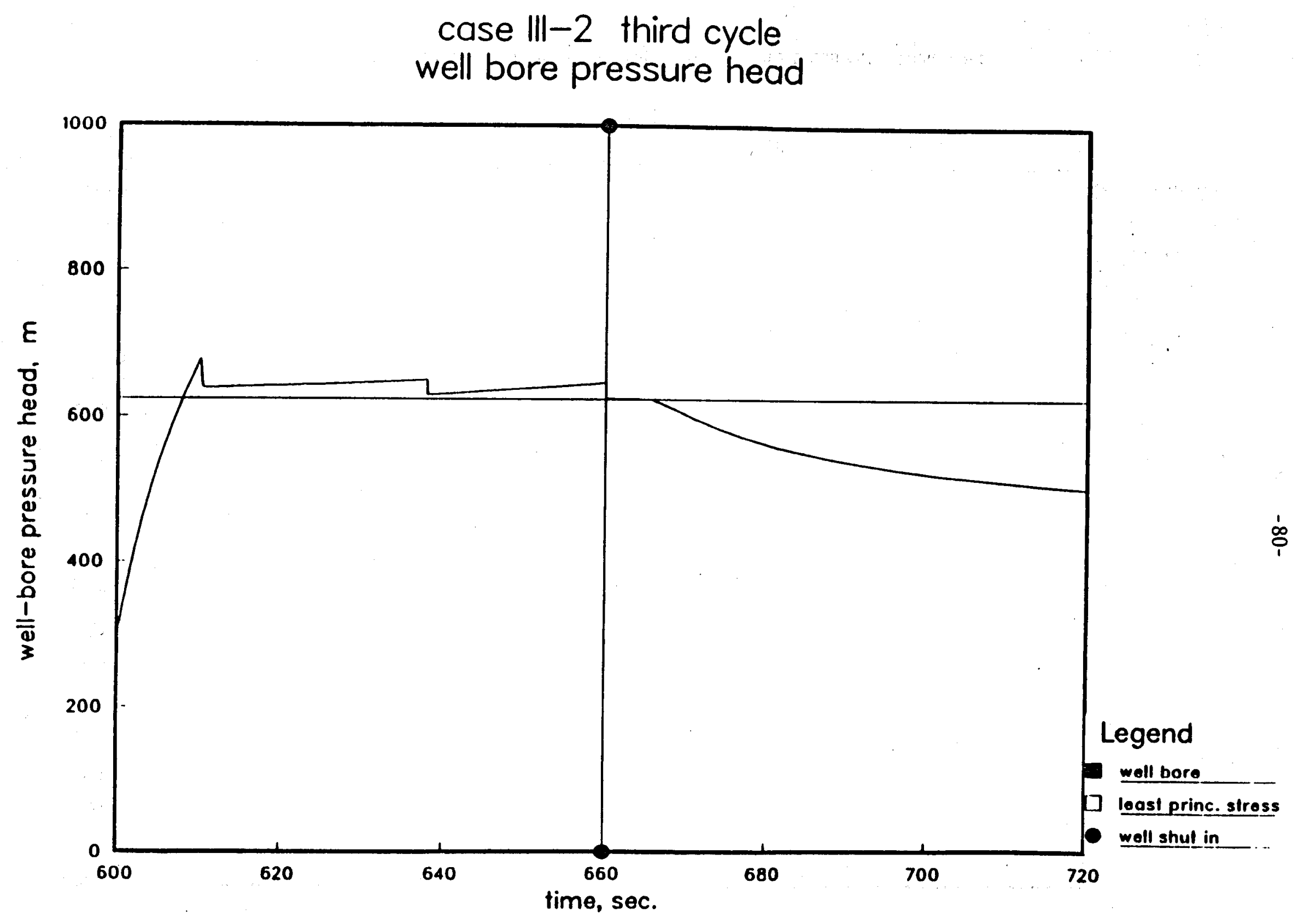

Figure 17B: Third injection cycle well bore pressure transients: Case III-2. 


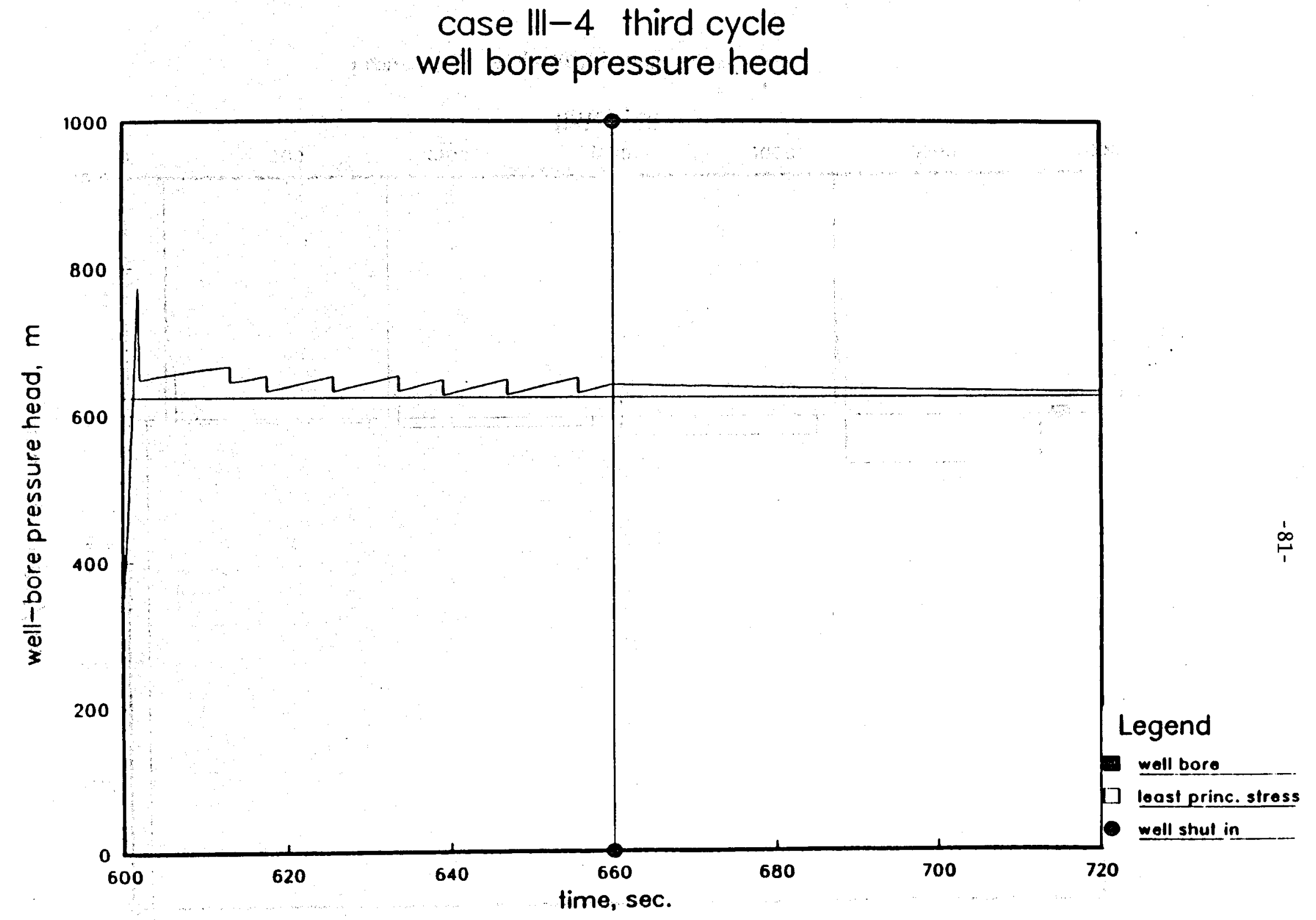

Figure 17C: Third injection cycle well bore pressure transients: Case III-4. 
case IV-2A continuation

flow rate versus time

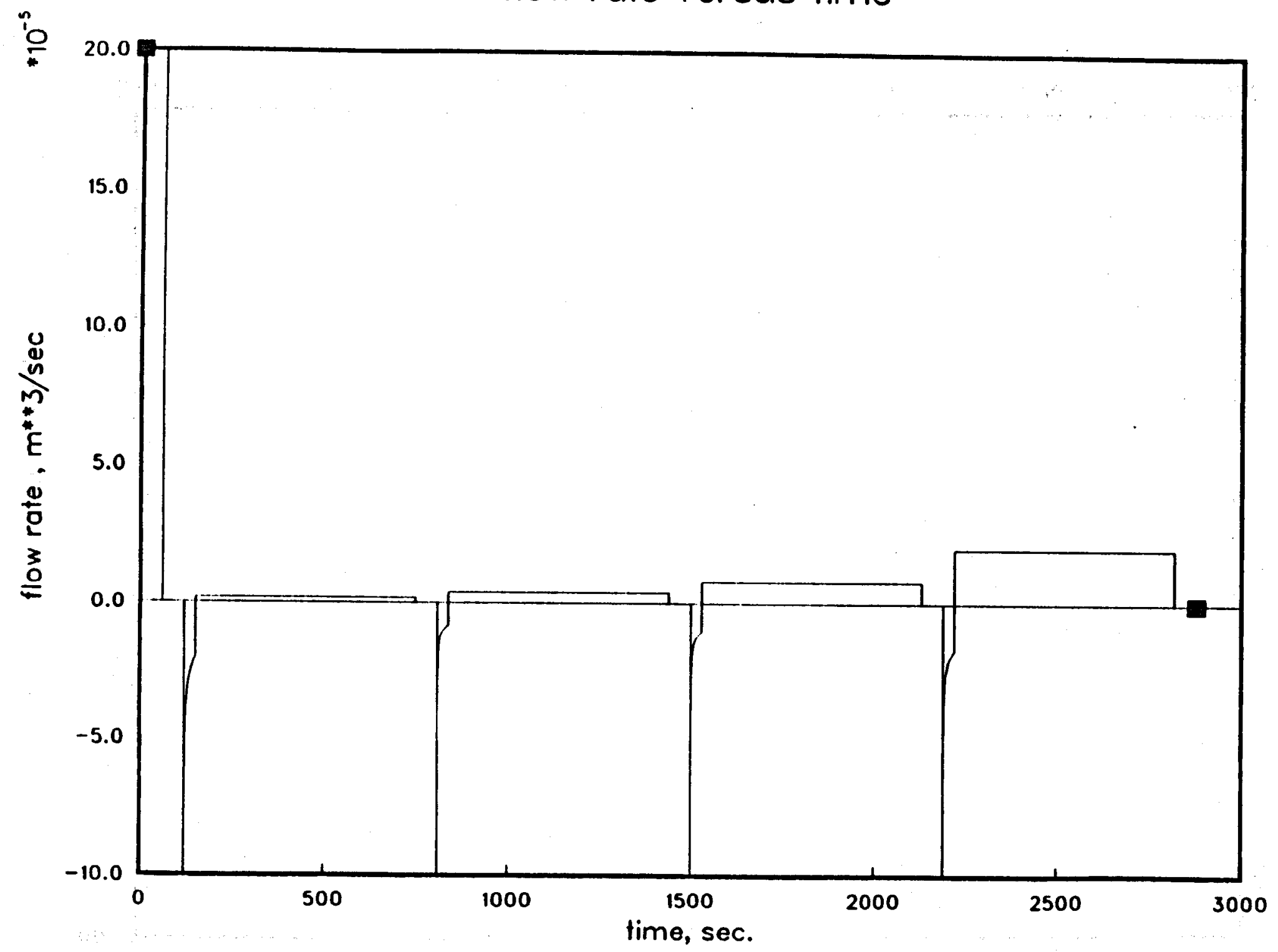

Figure 18A: Stepwise injection. Case IV-2A. 


\section{case IV -2 continuation}

flow rate versus time

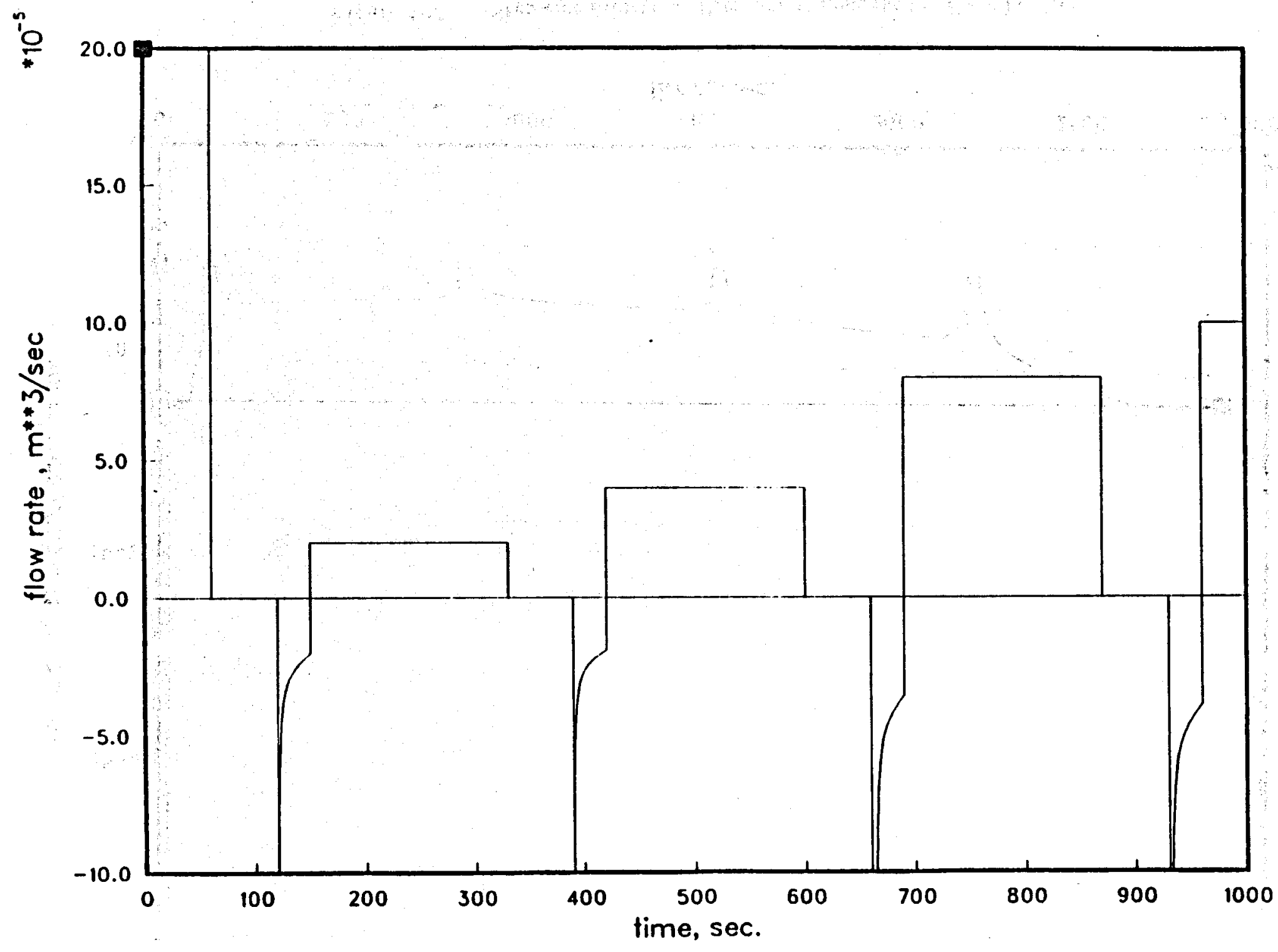

Figure 18B: Stepwise injection. Case IV-2. 
case IV-2A continuation

well bore pressure head

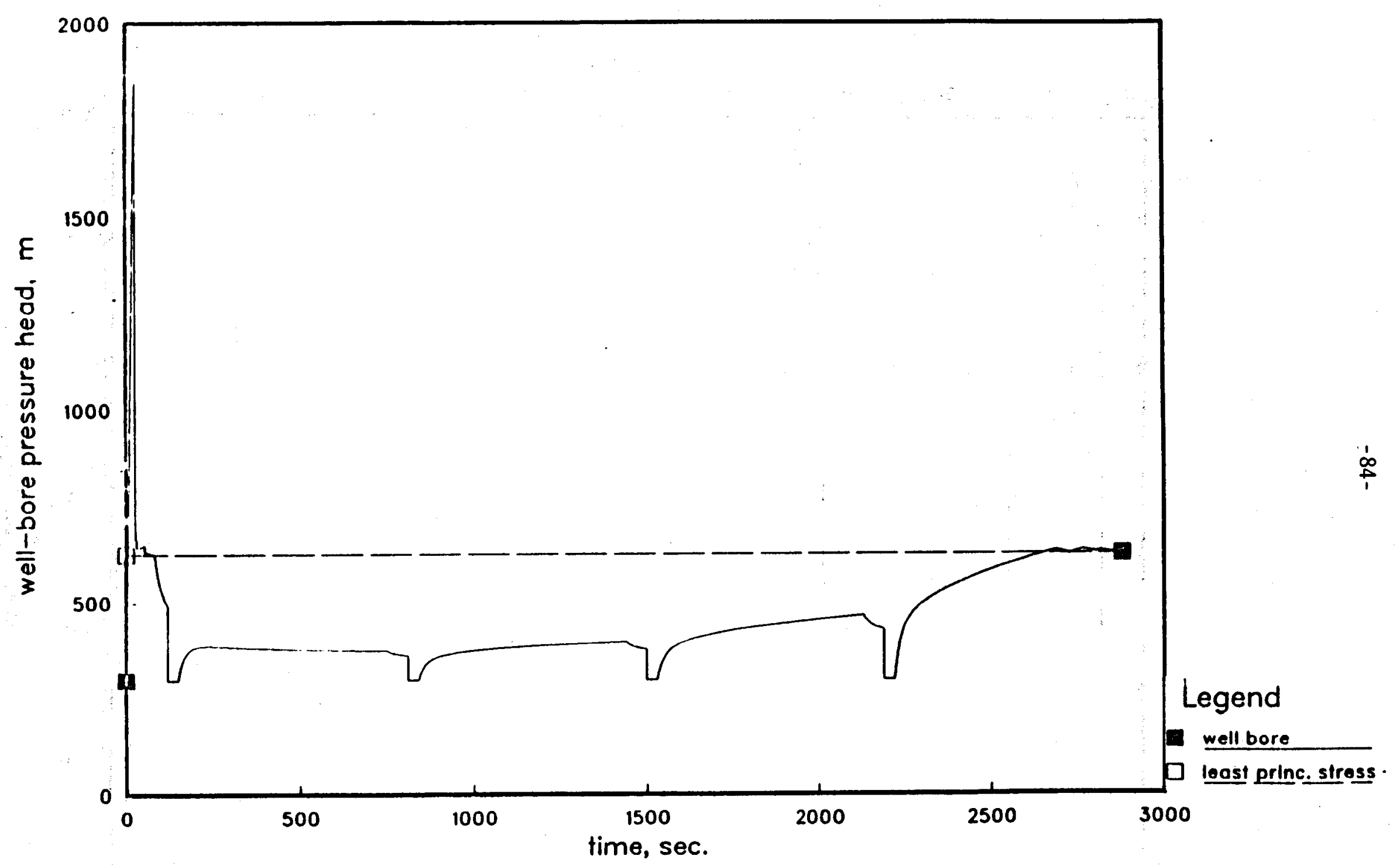

Figure 19A: Stepwise injection: Pressure transients for Case IV-2A. 
case IV-2 continuation

well bore pressure head

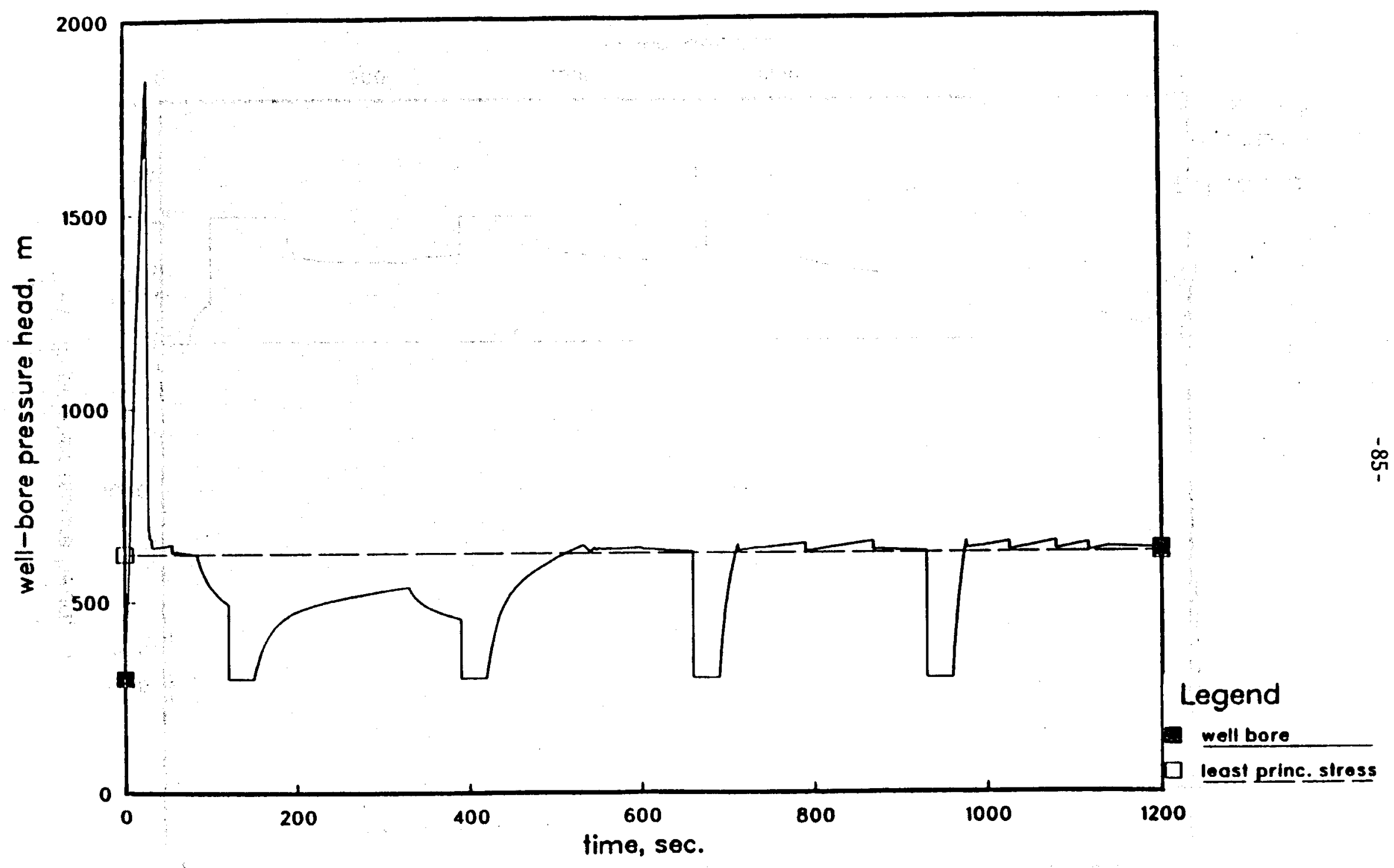

Figure 19B: Step wise injection: Pressure transients for Case IV-2. 
case IV-4A continuation

well bore pressure head

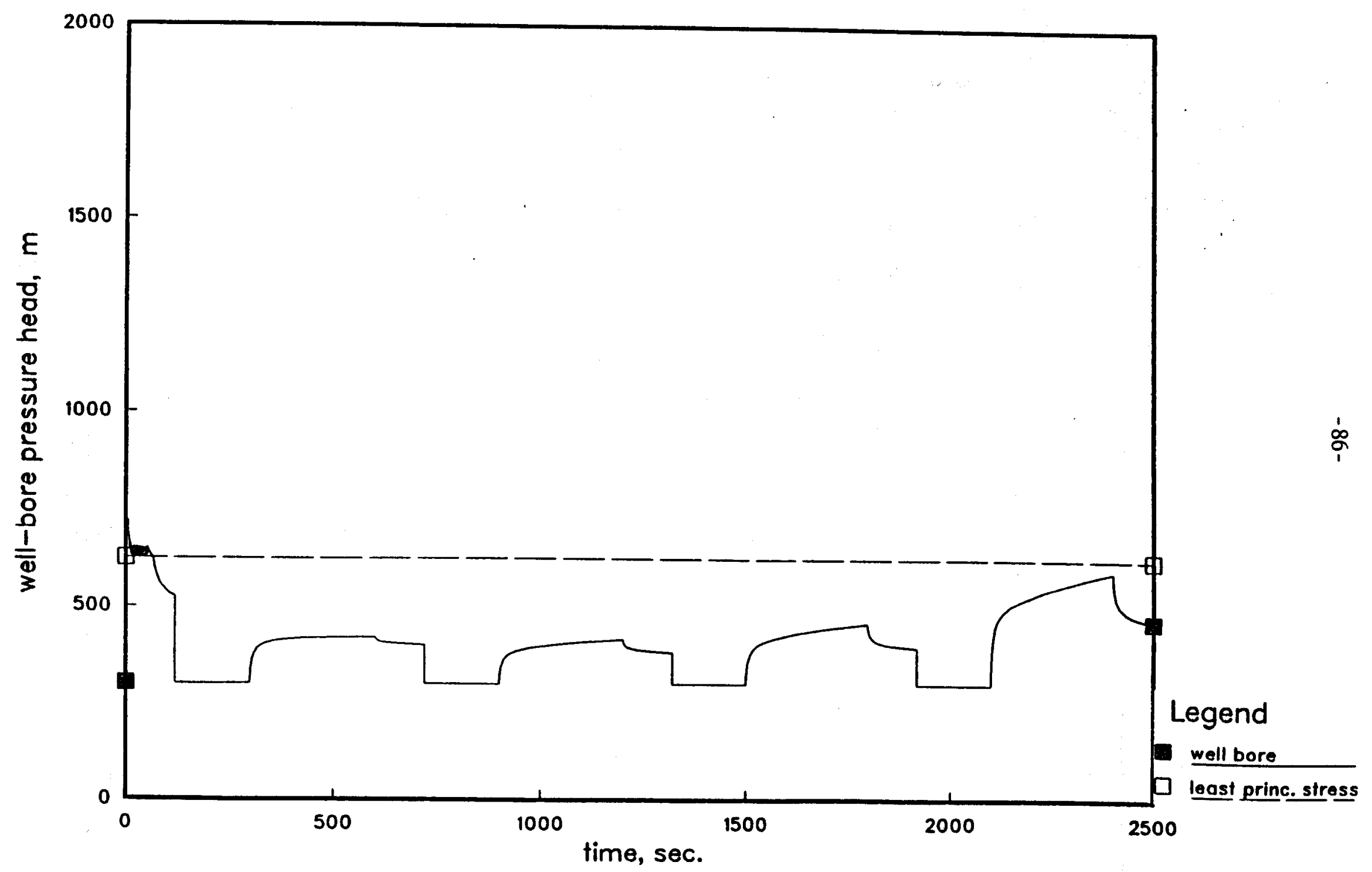

Figure 20A Threshold injection : Pressure transients for Case IV-4A 
case IV-5 continuation

well bore pressure head

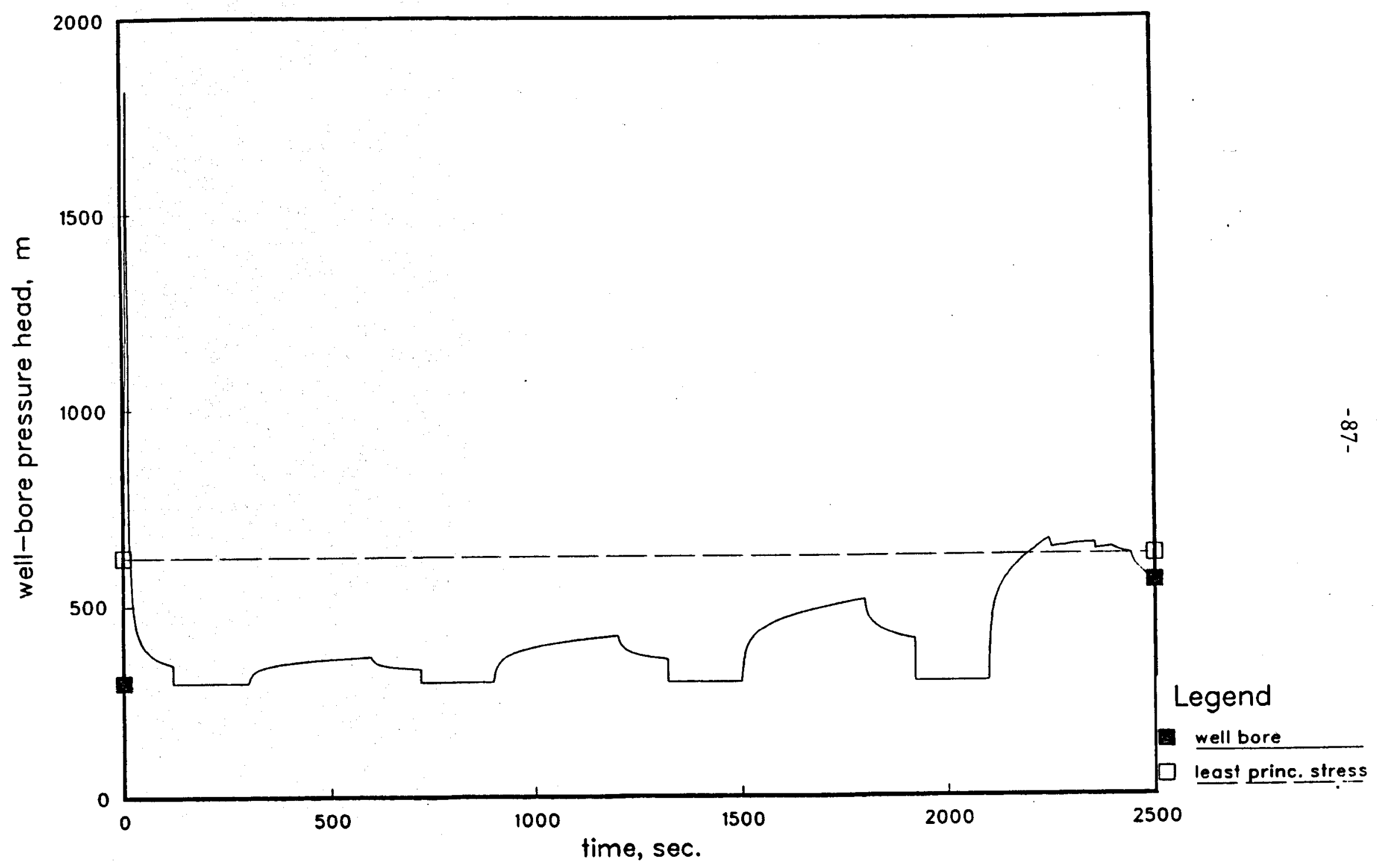

Figure 20B Threshold injection: Pressure Transients for Case IV-5 